\title{
THE DESIGN AND DEVELOPMENT OF A WEB-BASED GIS APPLICATION FOR MANAGING FISH SPECIES AT RISK IN ONTARIO
}

By

Haibin Liu

B.Sc., Nankai, Tianjin, China, 1987

A thesis presented to Ryerson University

in partial fulfillment of the requirements for the degree of

Master of Applied Science

in the Program of Civil Engineering

Ryerson University

Toronto, Ontario, Canada

Haibin Liu, 2005 


\title{
UMI Number: EC53044
}

\author{
All rights reserved \\ INFORMATION TO USERS
}

The quality of this reproduction is dependent upon the quality of the copy submitted. Broken or indistinct print, colored or poor quality illustrations and photographs, print bleed-through, substandard margins, and improper alignment can adversely affect reproduction.

In the unlikely event that the author did not send a complete manuscript and there are missing pages, these will be noted. Also, if unauthorized copyright material had to be removed, a note will indicate the deletion.

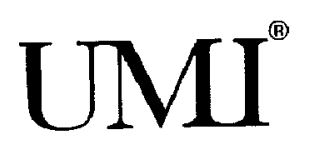

UMI Microform EC53044

Copyright 2008 by ProQuest LLC

All rights reserved. This microform edition is protected against unauthorized copying under Title 17, United States Code.

ProQuest LLC

789 East Eisenhower Parkway

P.O. Box 1346

Ann Arbor, Ml 48106-1346 



\section{Borrower's Page}

Ryerson University requires the signatures of all persons using or photocopying this thesis. Please sign below, and give address and date.

\begin{tabular}{|c|c|c|c|}
\hline Name of Borrowers & Date & Address & Signature \\
\hline & & & \\
\hline & & & \\
\hline & & & \\
\hline & & & \\
\hline & & & \\
\hline & & & \\
\hline & & & \\
\hline & & & \\
\hline & & & \\
\hline & & & \\
\hline & & & \\
\hline & & & \\
\hline & & & \\
\hline & & & \\
\hline
\end{tabular}




\title{
The Design and Development of A Web-based GIS Application for Managing Fish Species at Risk in Ontario
}

\author{
Haibin Liu \\ Master of Applied Science \\ Department of Civil Engineering \\ Ryerson University, 2005
}

\begin{abstract}
This thesis presents a study on the design and implementation of a Web-based Geographic Information Systems (GIS) application to support effective management of fish species at risk (FSAR) in Ontario, Canada. By using Internet and GIS technologies, a fish distribution management application was created and implemented for the Department of Fishery and Ocean Canada, Ontario Great Lake Area (DFO-OGLA). The goal of the study is to implement a web-based fish species viewing and querying system that would allow users to obtain information about the FSAR data.
\end{abstract}

The proposed WebGIS system not only includes common GIS mapping tools to navigate the map and geospatial data, but also provides specific geospatial search engine tools and fish species reporting tools. WebGIS provides an easy and inexpensive way for the biologists and environmental scientists to access FSAR information with web browsers. 


\section{Acknowledgements}

My greatest thanks go to my supervisor, Dr. Jonathan $\mathrm{Li}$, for his thoughtful and valuable input, time, ideas and suggestions. Without his patience, encouragement and understanding, this thesis would not have been possible.

I greatly appreciate the work of my committee members, Dr. Mike Chapman and Dr. Songnian $\mathrm{Li}$. These professors took their valuable time reviewing and providing feedback on my thesis.

I would also like to thank Fisheries and Oceans Canada (DFO) - Burlington, for providing me with the opportunity of studying in the area of Web-GIS and environmental protection. In particular, I would like to express my thanks to Peter Brunette, who enlightened me with his expertise and experience in WebGIS and geo-database.

My thanks equally go to Andrew Doolittle of DFO. As a geo-database analyst and mapping specialist, he offered me valuable suggestions and helped me with the building of the geo-database.

I also attribute my accomplishment to Dr. Mohamed Lachemi and other faculty and staff members in the Department of Civil Engineering, for their help and support. Many thanks for the help of Desmond Rogan, Leah Stanwyk, Kim Kritzer and Dianne Mendonca for their help and administrative support. 
I would like to thank my fellow graduate students in the Program of Civil Engineering at Ryerson University, Sean Gao, Haibin Dong, Mark Tulloch, Xu Sun, Yu Li, Ruiqiu Li, Hongmei Zhao, Eric Chang, Lijun Gu, Wenhao Gu, and Wensong Hu for their help. The time with them was always happy and enjoyable.

Thanks also go to Doug Mount for prove reading of the thesis.

I wish to express my gratitude to my parents for their unconditional love and support, and to my wife, Huiquan Zhang, and my son Henry for their endless love, patience, and encouragement. Without their help and understanding, I would never have completed this thesis. 


\section{Table of Contents}

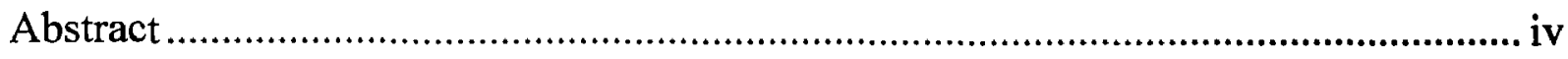

Acknowledgements....................................................................................

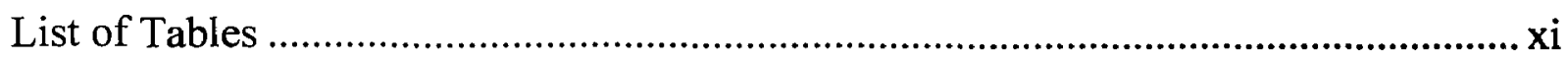

List of Figures ......................................................................................... xiii

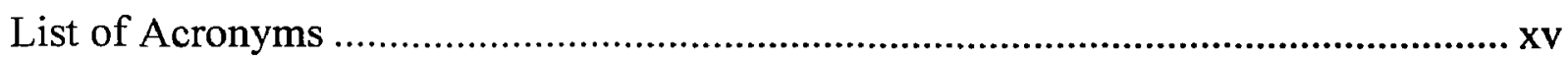

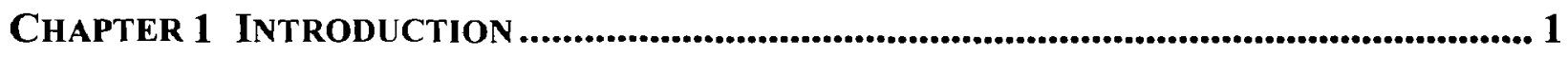

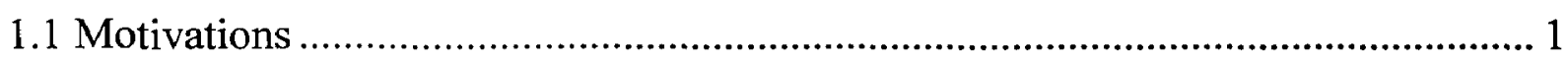

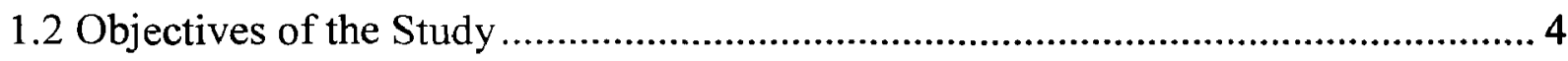

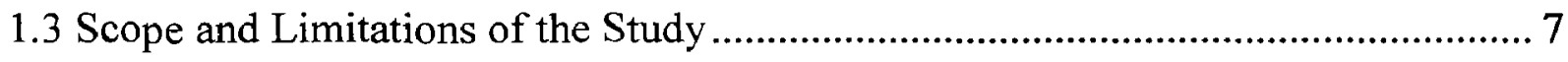

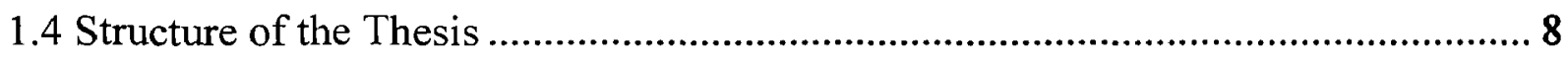

Chapter 2 Background ANd LITERATURE REVIEW .......................................... 10

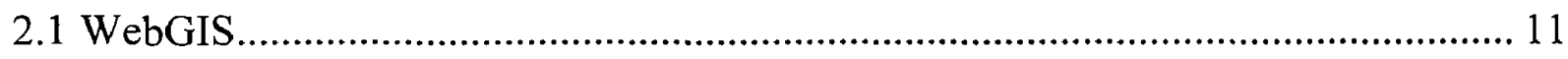

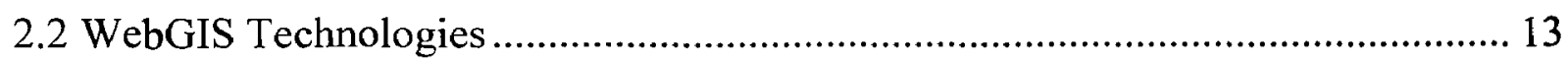

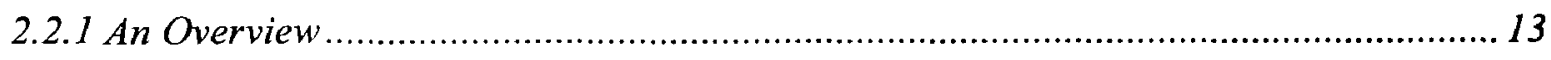

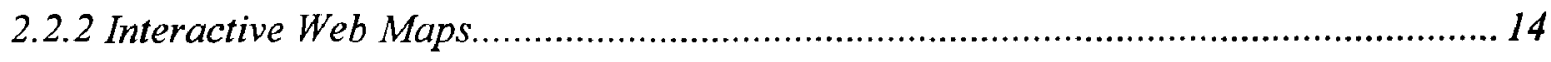

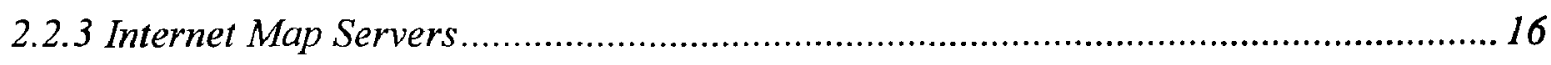

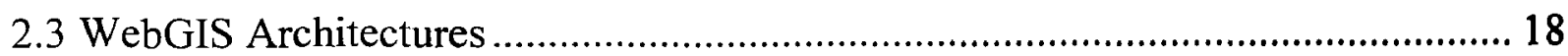

2.3.1 Thin Client Architecture (Server Side Applications) ............................................ 20

2.3.2 Thick Client Architecture (Client Side Applications) ........................................... 22

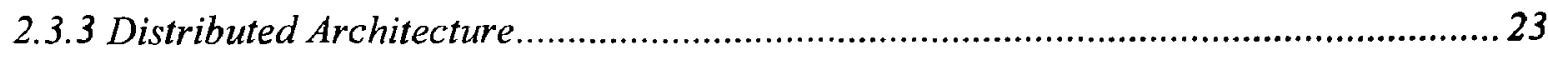

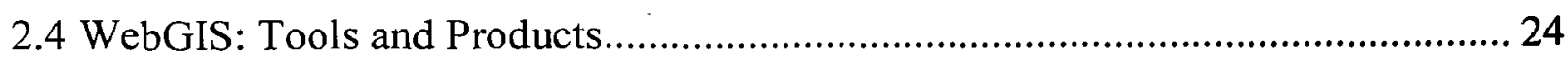

2.4.1 Non-commercial Open Source Tools ...............................................................24

vii 
2.4.2 Commercial Non-Open Source Products...............................................................25

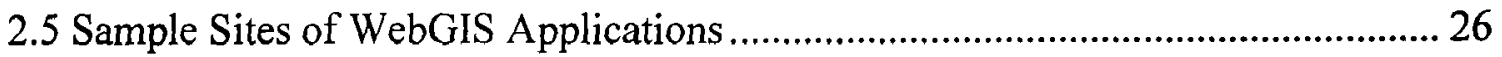

2.5.1 Conservation Allas of Wetlands in the St. Lawrence Valley, Canada.........................27

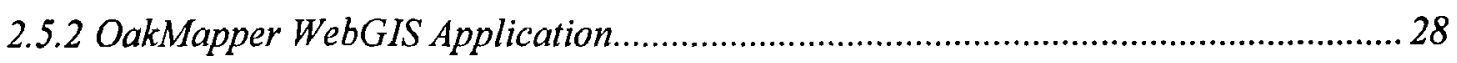

2.6 Rapid GIS Application Development Method.............................................. 29

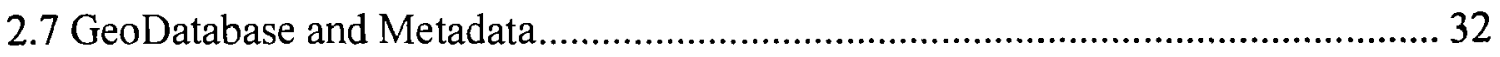

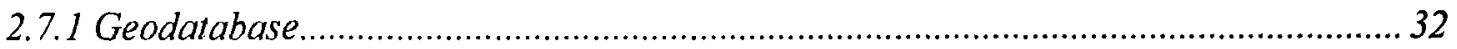

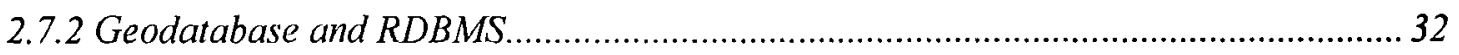

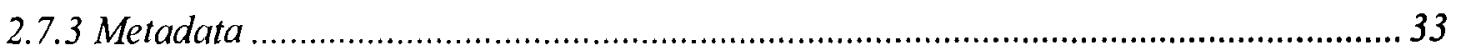

Chapter 3 USER RequIREMENTS AND INFORMATION NEEDS ANALYSIS .................. 35

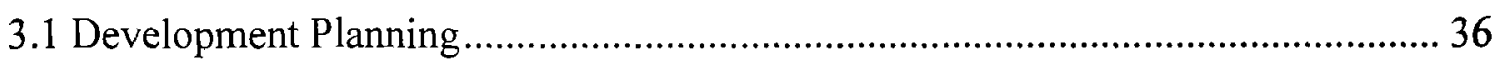

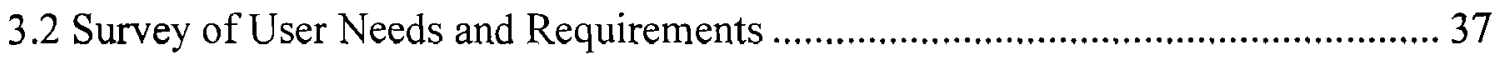

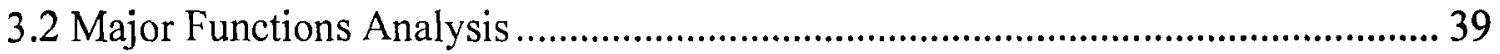

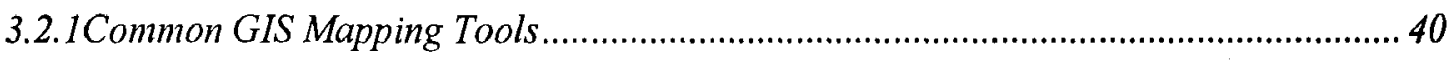

3.2.2 Ontario Search Engine ................................................................................. 4

3.2.3 Reporting Tools for Access to SAR Information ..................................................... 42

3.3 Data and Database Analysis...................................................................... 43

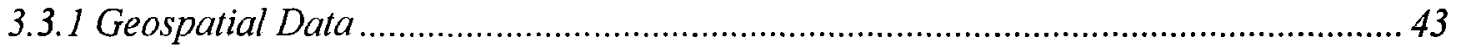

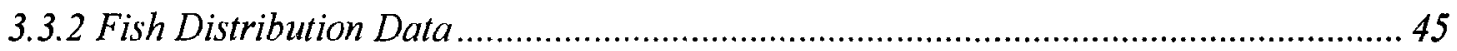

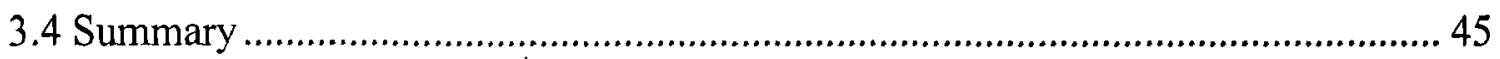

Chapter 4 DeSign Of THE FRAS SYSTEM ARChITECTURE ....................................... 47

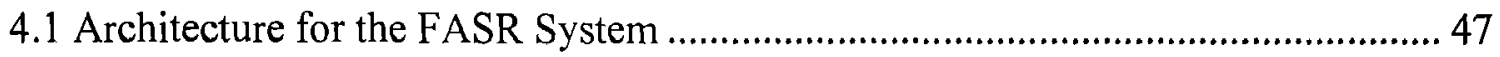

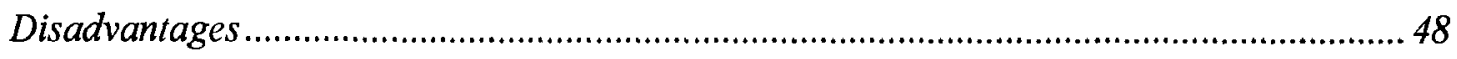

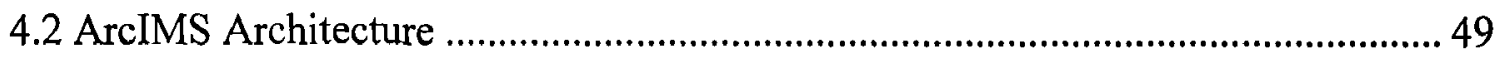

viii 


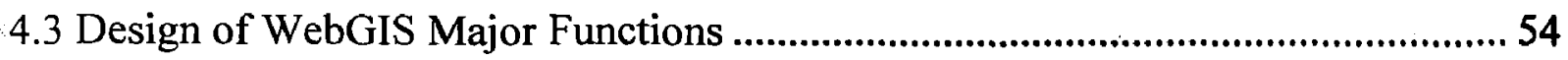

4.3.1 Common GIS Mapping Tools ........................................................................... 54

4.3.2 Ontario Search Engine Tools :................................................................................5

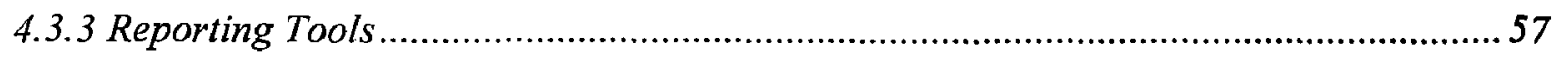

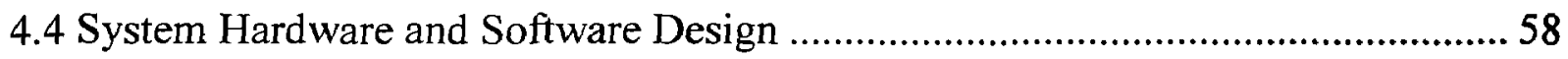

CHAPTER 5 DEVELOPMENT OF THE FASR SYSTEM.......................................................... 61

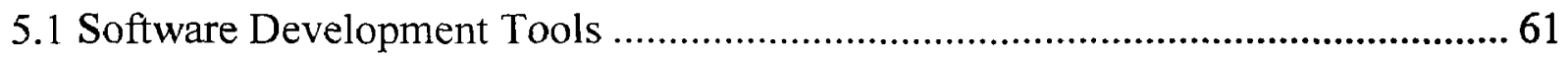

5.2 Customizing the HTML Viewer Parameters .......................................................... 62

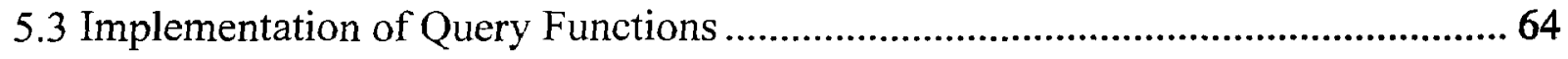

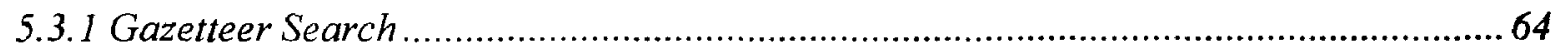

5.3.2 Topographic Search Tool..................................................................................... 66

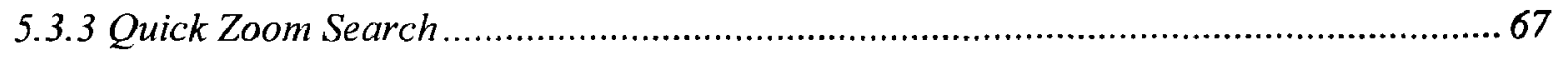

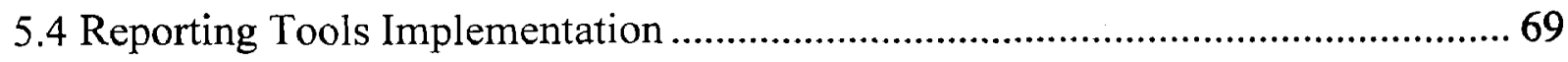

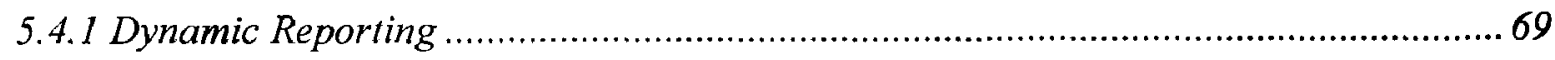

5.4.2 Static Reporting ........................................................................................... $7 \mathrm{I}$

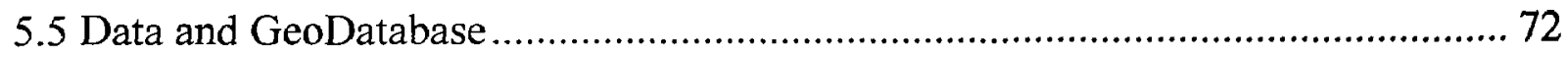

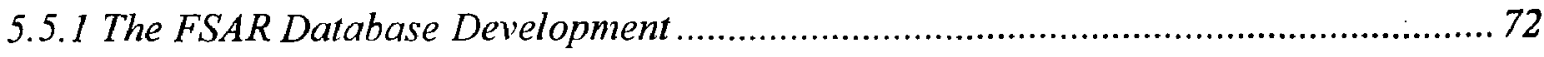

5.5.2 Global Rank (GRANK) and Provincial Rank (SRANK) ............................................. 74

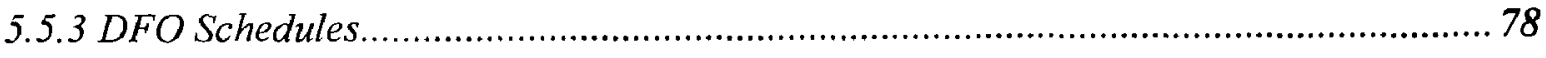

ChAPTER 6 CONClUSIONS AND RECOMMENDATIONS.......................................................... 79

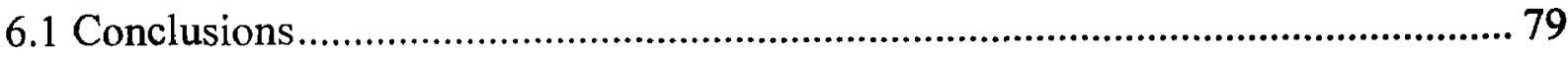

6.2 Future Enhancement ........................................................................................ 81

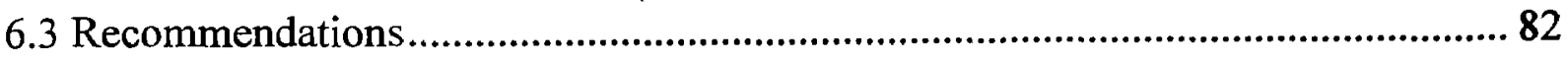


REFERENCES.................................................................................................................................. 85

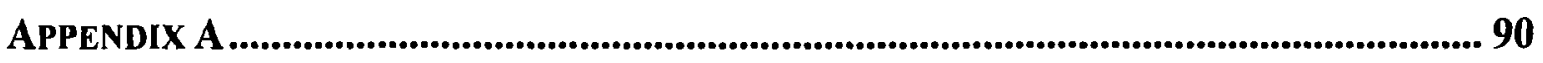

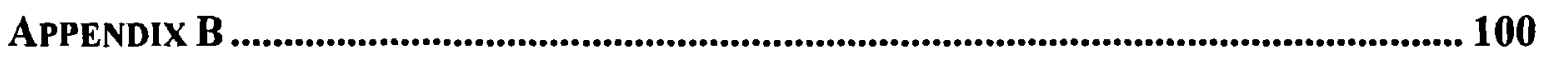

APPENDIX C 


\section{List of Tables}

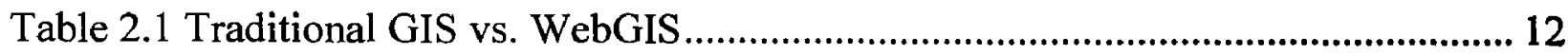

Table 2.2 Selected Internet Map Servers ....................................................................... 17

Table 3.1 Common GIS Mapping Tools........................................................................... 40

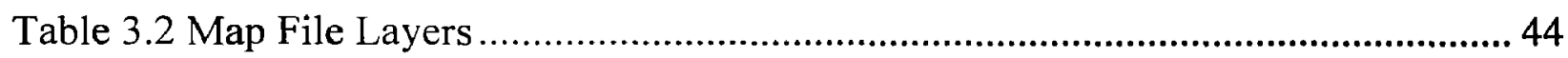

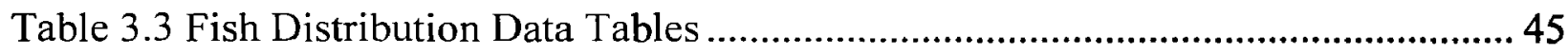

Table 4.1 Comparison of Server-Side and Client-Side WebGIS Architectures ................ 48

Table 4.2: A Comparision of ArcIMS Standard Viewers............................................... 52

Table 4.3 Common GIS Mapping Tools Description...................................................5

Table 4.4 Description of the Ontario Search Engine Tools .............................................5 57

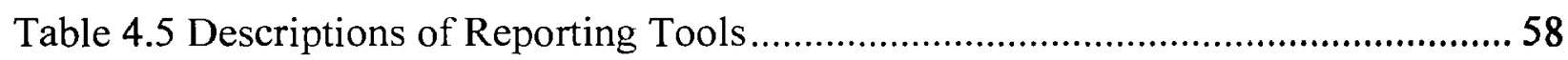

Table 4.6 Configuration of the FARS Server System..................................................59

Table 4.7 Configurations of Geodatabase (ArcSDE) Server ..............................................5 59

Table 5.1 Global Rank (MNR Ontario, 2005a) …….................................................... 74

Table 5.2 Provincial Rank (MNR Ontario, 2005b)_................................................ 76

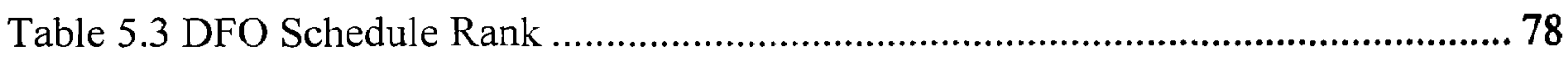

Table A.1 Gazetteer Category List Table ...................................................................... 90

Table A.2 The C\# Code for Gazetteer Page Load and Refresh Control of 'Name' ......... 94

Table A.3 The JavaScript Code for Button Zoom-To ....................................................... 99 
Table B.1 Topographic Category List Table:

Table C.1 Species Lookup Table (DFO.SAR_lookup) ................................................. 101

Table C.2 Species Summary Table by Watershed...................................................... 101

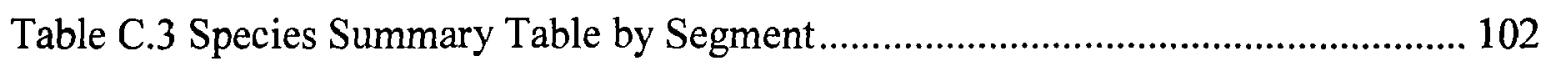

Table C.4 Tertiary Watershed Layer (NRVIS.WATSHD_TERT_SUMMARY_BT)... 102 


\section{List of Figures}

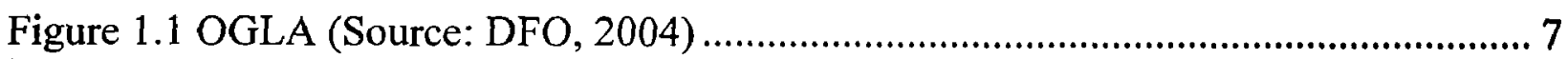

Figure 2.1 OpenGIS Model of Portrayal Workflow ....................................................... 15

Figure 2.2 How a Typical WebGIS Model Works ..................................................... 19

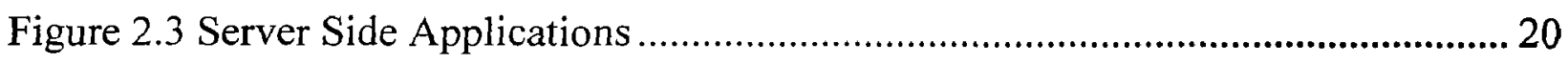

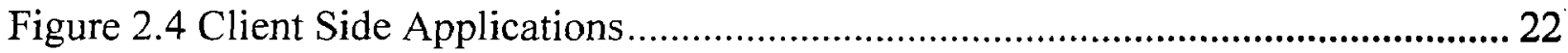

Figure 2.5 Conservation Atlas of Wetlands in the St. Lawrence Valley, Canada ............. 26

Figure 2.6 OakMapper WebGIS Application .......................................................... 28

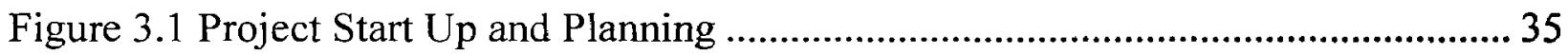

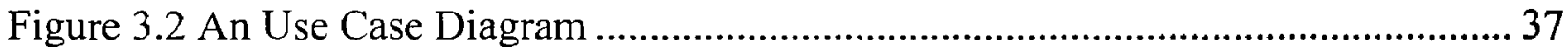

Figure 3.3 Major Functions of FSAR WebGIS Application .......................................... 39

Figure 3.4 Ontario Search Engine Tools...................................................................... 41

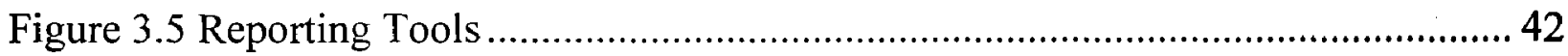

Figure 4.1 Client-Side vs. Server-Side Architecture …................................................ 47

Figure 4.2 ArcIMS Three-Tier Architecture (Source: ESRI, 2003) ............................... 50

Figure 5.1 Customized Viewer of the FSAR system .....................................................6 63

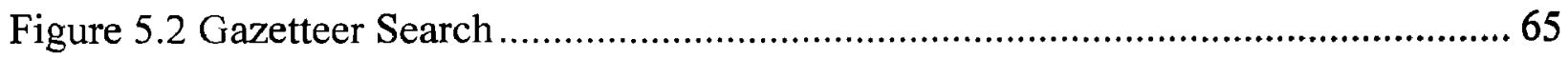

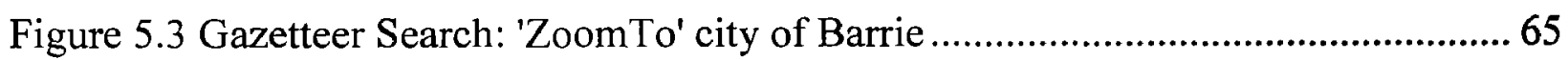

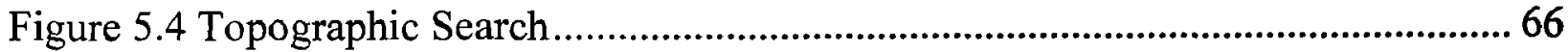


Figure 5.5 Topographic Search: 'ZoomTo' Dace Lake .................................................... 67

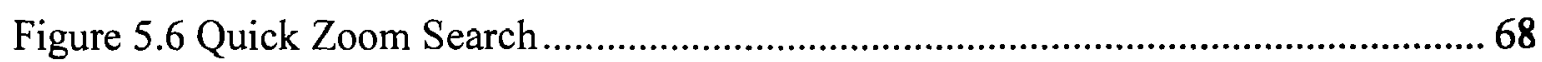

Figure 5.7 Quick ZoomTo the Map of "Sarnia "................................................................. 68

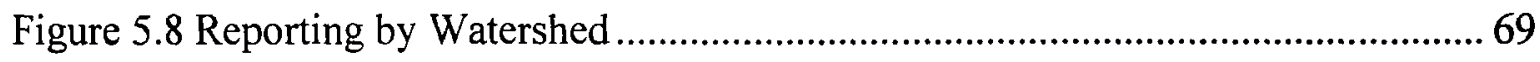

Figure 5.9 Report of fish distribution in watershed 2GG .......................................... 70

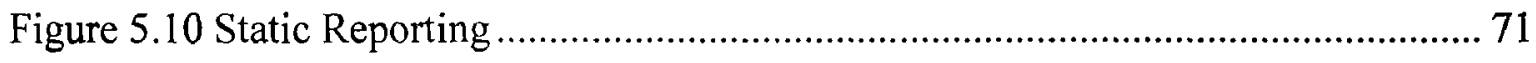

Figure 5.11 FSAR Geodatabase Implementation ……………….................................. 73

Figure A.1 Gazetteer Category Lookup: City ........................................................... 92

Figure A.2 Topographic Category Lookup: Hydrography ............................................... 93 


\section{List of Acronyms}

\begin{tabular}{ll} 
ADO & Active Data Object \\
ASP & Active Server Page \\
C\# & C Sharp \\
CGI & Common Gateway Interface \\
COSEWIC & the Committee on the Status of Endangered Wildlife in Canada \\
CPU & Central Processing Unit \\
DEG & Display Element Generator \\
DFO & Department of Fisheries and Oceans \\
ESRI & Environmental Systems Research Institute, Inc \\
FSAR & Fish Species at Risk \\
GIS & Geographic Information Systems \\
HTML & Hypertext Mark-up Language \\
HTTP & Hypertext Transfer Protocol \\
IMS & Internet Map Server \\
IT & Information Technology \\
LAN & Local Area Network \\
Mbps & Megabits Per Second \\
NRVIS & Natural Resources Values Information System \\
NTDB & National Topographic Database \\
OGLA & Ontario - Great Lakes Area \\
OMNR & Ontario Ministry of Natural Resources \\
\hline
\end{tabular}




$\begin{array}{ll}\text { PNG } & \text { Portable Network Graphics } \\ \text { PDF } & \text { Portable Document Format } \\ \text { RMI } & \text { Remote Method Invocation } \\ \text { RAD } & \text { Rapid Application Development } \\ \text { RDBMS } & \text { Relational Database Management Systems } \\ \text { SARA } & \text { The Species at Risk Act } \\ \text { SIG } & \text { Special Interest Group } \\ \text { SOD } & \text { Sudden Oak Death } \\ \text { URA } & \text { User Requirement Analysis } \\ \text { URL } & \text { Uniform Resource Locator } \\ \text { WAN } & \text { Wide-Area-Network } \\ \text { WWW } & \text { World Wide Web }\end{array}$





\section{Chapter 1}

\section{Introduction}

\subsection{Motivations}

Today, a growing number of wildlife species in Canada face a very real, and in many cases, immediate threat of extinction. Some of these species are important to industries such as Canada's fisheries. Some of them are the last of their kind in the world. All of these species have an essential role to play in the environments where they live (DFO, 2005). In Ontario alone, there are many fish species that are considered at risk, due mainly to human factors such as habitat loss, pollution, overexploitation, and disease. Humans are the major cause of the loss of species and their habitats. In Southern Ontario, as more and more people move into the area and industries continue to grow, phosphorus pollution and human activities are severely threatening fish habitats and local water quality.

For all of these reasons, the federal government is actively committed to protecting species at risk. The Species at Risk Act is one of the most important tools in this effort. The Species at Risk Act (SARA) was created to protect wildlife species from becoming extinct in two ways:

- By providing for the recovery of species at risk due to human activity; and

- By ensuring, through sound management, that species of special concern do not become endangered or threatened. 
The Act became law in June 2003. It includes prohibitions against killing, harming, harassing, capturing or taking species at risk, and against destroying their critical habitats (DFO, 2005).

Three government departments are directly involved in protecting species at risk: Environment Canada, Parks Canada, and Fisheries and Oceans Canada or the Department of Fisheries and Oceans (DFO), among which DFO is responsible for all aquatic species, freshwater and saltwater alike.

Under SARA, DFO must produce recovery strategies and action plans for aquatic species listed as endangered or threatened. Once a species is added to the list and protected officially under SARA, a recovery strategy must be developed. For endangered species, this strategy must be developed within a year of the listing; for threatened or extirpated (extinct in Canada) species, it must be developed within two years.

These recovery strategies and action plans will detail the specific steps that need to be taken to protect identified species. To make sure that DFO's strategies and plans are practical, effective, and in keeping with a sound fisheries management approach, accurate, reliable, and updating spatial information about the fish species at risk and the effective information technologies are to be used to manage, analyze, and utilize such information as well as communicate such information with stakeholders - the people being affected. From the DFO's perspective, there can be no success without the 
collaboration of everyone involved; the scope, scale and importance of this process demand a truly collective effort.

This study is motivated by the DFO's requirement for spatial information technologies to support the effective management of fish species at risk.

Geographic information systems (GIS) have been used in watershed-related studies and decision-support systems for fish species management in the last decade (Pickus and Hewitt 1992, James and Hewitt 1992, Angermeier and Bailey 1992, Frye and Denning 1995). GIS have been proved to be a successful tool in a wide variety of natural resource management practices (Schreier and Brown 1992), environmental monitoring and pollution contamination assessment (Runyon et al. 1994). However, most existing GIS applications have been based on the use of the commercial desktop GIS software packages such as ArcGIS (ESRI Inc., Redlands, CA), which are costly and require extensive training and high-end hardware to get reasonable performance. In contrast, WebGIS provides end-users a cost-saving solution to access up-to-date spatial datasets and information (Horanont 2002; Painho, 2001). A WebGIS is designed with tools and features that are common on Web pages and it is therefore easy to understand for users familiar with the Internet (Nelson, 2002). Other advantages of WebGIS include independence of platforms and operating systems. Usually only a simple Web browser is used to establish a client/server connection. Furthermore, WebGIS can be customized to provide specific data and information and/or services to end-users. In this study a WebGIS application will be customized for Ontario's fish species at risks management. 
The DFO in Ontario - Great Lake Area (DFO OGLA) is part of the DFO Central and Artic Regions with headquarters in Burlington, Ontario. The district offices of the DFO OGLA are located in Burlington, Parry Sound, Peterborough, Prescott, Sarnia, Sault Ste. Marie, Sudbury, and Thunder Bay. Their mandate is to implement a fish habitat program in Ontario and throughout Canada, focusing on habitat provisions of the Fisheries Act in cooperation with regulatory partners. However, the centre of the geospatial data and fish species data is located and managed at the Burlington office. This study attempts to develop a Web-based application, in which WebGIS will hold the potential to make distributed geographic information available to multiple users in different locations. Also, those Internet users will be able to access GIS applications from their browsers without purchasing proprietary GIS software.

\subsection{Objectives of the Study}

This study aims at designing and developing a Web-based GIS system for effective management of fish species at risk in Ontario. The system, named FSAR in this thesis, is a Web-based application using GIS tools to provide spatial definition and visual presentation of inland water biological and fisheries data. The development of such an application was initially sponsored by the DFO to meet the geospatial data management needs of the department and its partners. 
The objectives of FSAR are closely aligned with the SARA. The vision for the FSAR system is to provide biologists and environmental scientists an improved access to the information of Ontario inland water fish species in order to make plans and decision making that relate to and impact on Ontario inland-water fish species environment.

Specific objectives of the system are to:

- Support decision-making processes that affect Ontario inland water fish species biological diversity.

- Implement the WebGIS mapping applications for the distributed users of the DFO's nine district offices and the DFO's partners across Ontario. The WebGIS mapping tools provide search, query and reporting tools for all fish species, aquatic habitats, watersheds and ecosystems in Ontario.

- Improve the management of Ontario inland water aquatic information through the implementation and maintenance of a common geospatial database and metadata standards.

A key benefit of the proposed FSAR system over other options is its user-friendly web browser interface. The web browser interface makes it possible to create a dynamic system that makes access to inland-water aquatic information easier for both fisheries management personnel and the DFO's partners of external organizations. This system should meet the following requirements:

- Web browser interface that makes access easy, 
- Central data and WebGIS system management role in DFO in Ontario - Great Lake Area (OGLA),

- No GIS experience required for users, and

- Wide range of potential uses.

The Web-based FSAR system should be able to provide web-mapping tools of fish distribution and reporting tools for the access to fish species at risk information, such as fish species listings and designations, distribution maps, the COSEWIC (Committee on the Status of Endangered Wildlife in Canada) reports, and the SAR fact sheets. The environmental scientists and geoscientists use the system as a tool to protect fish species at risk from becoming extinct or lost from the wild in Ontario. The ultimate objective is, therefore, to help their numbers to recover. To protect fish species at risk and to protect their habitats, it is necessary to have a database that houses the information of their distribution, abundance and life history, including species at risk (SAR). Currently, there is a significant amount of data, such as ground truth data, laboratory data as well as research analytical data. These data have been developed by the fishery resource related research organizations. These data can often serve many applications. However, to date, there has been no single database designed to house the SAR data. The database to be built contains extensive geospatial and non-geospatial data information on fish species at risk and their habitat characteristics in Ontario, Canada. 


\subsection{Scope and Limitations of the Study}

The study area covers all watershed lands within Ontario. Although water levels fluctuate, the boundaries of fish habitat do not change. Fisheries and Oceans Canada, Ontario - Great Lakes Area (OGLA) determines the boundary of fish habitat (see Figure 1.1) using historical long-term water levels, linking the habitat to the requirements of fish populations throughout their life cycles (Fisheries and Ocean Canada, 2005). This means that the extent of fish habitat is not determined by short-period water level fluctuations. For example, in low gradient shoreline areas (e.g. sand beaches and wetlands) small decreases in water level sustained over a long period of time may result in large distances created between the current water level and the levels that are more indicative of an average year.

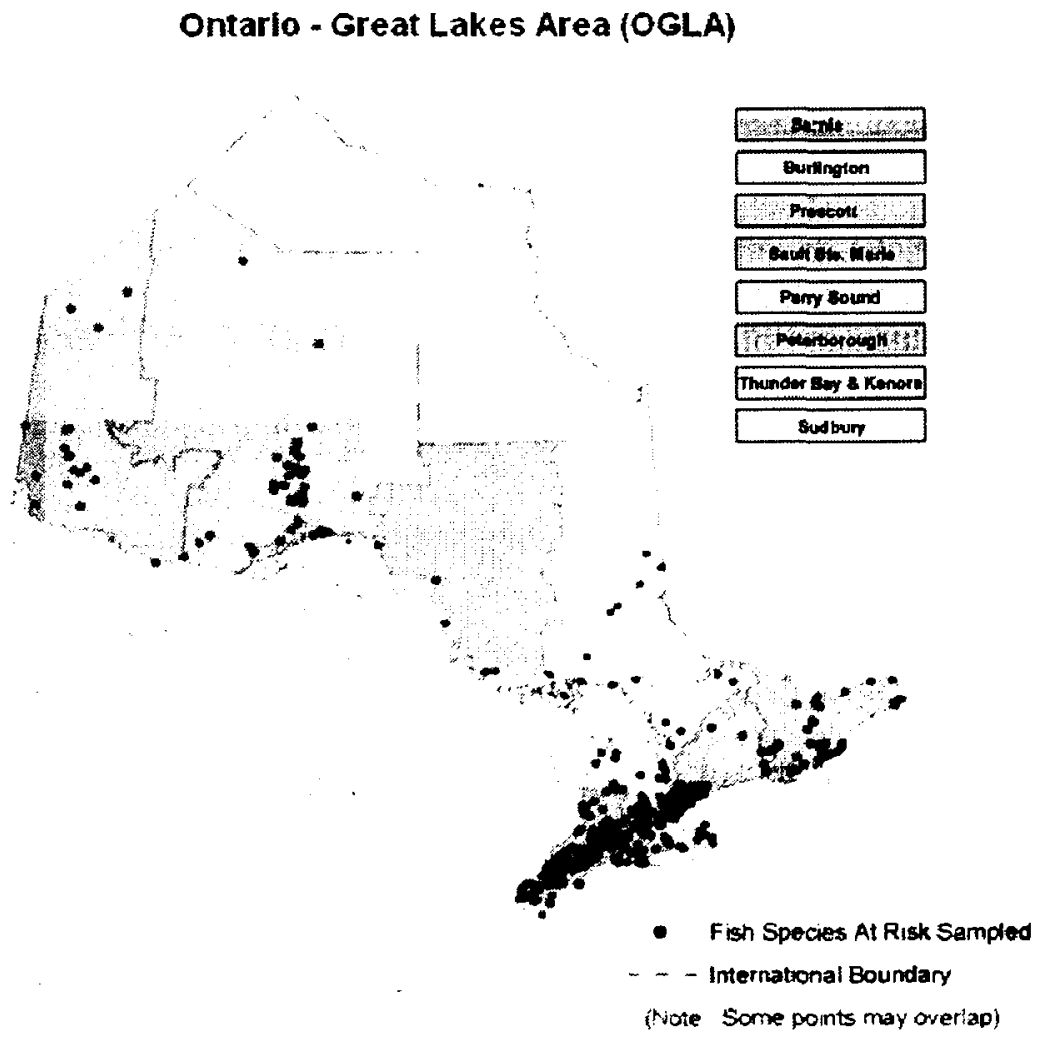

Figure 1.1 OGLA (Source: DFO, 2004) 
Currently, there are nine district offices across OGLA:

- Sarnia

- Bulington

- Prescott

- Sault Ste. Marie

- Parry Sound

- Peterborough

- Thunder Bay/Kenora

- Sudbury

Since the sensitive nature of the SAR database information, public is not allowed to access the website outside the DFO Intranet. The SAR database is only shared within the DFO's nine offices and their partners in Ontario. The firewalls block all Internet requests, which attempt to access the WebGIS site and retrieve information from outside of the DFO network. To protect sensitive database information, the onsite service is provided in this study in all development phases within the DFO Burlington office.

\subsection{Structure of the Thesis}

Following Chapter 1, the remainder of the thesis is organized into five more chapters.

Chapter 2 reviews literature on current WebGIS technologies and architecture, and presents a comparison of traditional GIS with WebGIS. Sample sites of WebGIS applications are introduced in detail together with ESRI's ArcIMS. Following a 
background of software engineering theory, this chapter introduces a rapid GIS application development approach, which is used for the WebGIS application development procedure.

Chapter 3 presents the first phase of an application development, and user requirement analysis. Following the user requirement analysis, the major components are described in the second part of the Chapter 3.

Chapter 4 gives a description of building hardware and software for a WebGIS system. The chapter then gives a rationale of why FSAR selected an HTML Viewer.

Chapter 5 presents the details of website implementation. Since the application uses a rapid application development method, the chapter presents a description of implementation of primary components and database design for fish species at risk.

Chapter 6 draws conclusions derived from the results of the thesis. Future enhancements of this project are discussed and recommendations are made on extending the use of WebGIS solutions. 


\section{Chapter 2}

\section{Background and Literature Review}

Geographic information systems (GIS) are "computer programs for acquiring, storing, interpreting, and displaying spatially organized information" (Green \& Bossomaier, 2002). GIS had its origins in many different disciplines and is characterized by widespread applications in many areas including cartography, geological surveys, environmental management, and urban planning. Three major aspects of GIS include cartographic ability, database management, and analysis and modeling. These aspects illustrate the diversity of applications of GIS' (Maguire, 1991).

In early times, generic GIS products experienced the changes from command-line interfaces to graphical user interfaces, and from mainframe GIS to desktop GIS. This evolution has been heavily influenced by the progress of computer technology and Information Technology (IT). The rise and boom of the Internet during the 1990s revolutionized the dissemination of information. GIS has inevitably been influenced in three major areas: data access, spatial information dissemination, and modeling/processing. Distributed GIS and Open GIS conceptions have begun to reshape the development of GIS and exploit new possibilities for the GIS industry (Maguire, 1999; Longley et al. 2001; Peng and Tsou, 2003). 


\subsection{WebGIS}

Traditional GIS systems consist of a single software package, with data on a single machine. This stand-alone desktop model lacks networking capability. Traditional GIS can no longer meet the requirements of complicated situations, which are often multidisciplinary, multi-platform, multi-software and multi-user. WebGIS separates the user interface, data storage and processing, all of which are normally on a single machine in traditional GIS. WebGIS can provide GIS users with scalability, reusability, and flexibility. However, the stand-alone GIS software is specialized at geospatial data processing and geospatial data analysis. Some advantages of web or distributed GIS over traditional mainframe and desktop GIS include (Plewe, 1997; Green and Bossomaier, 2002; Peng and Tsou, 2003):

- World-wide access;

- Much more accessibility: easier and faster access expands potential GIS users

- Data, information or service can be distributed anywhere, anytime to the online desktop computers, laptops, or PDAs;

- No proprietary GIS products are necessary; people who could not afford expensive GIS software can access free data and services or pay a minimum price;

- Eliminate duplication of data collection and simplify the updating of data and information;

- Version control of the WebGIS application. When a WebGIS application is upgraded, only one copy on the web server need to be upgraded; 
- Able to combine data and information from many different sources including local data;

- Improve the efficiency of GIS database management and reduce the cost of GIS database maintenance;

Some major differences between traditional and WebGIS are listed in Table 2.1. Although WebGIS has many advantages over the traditional model, it still can not provide the same functionality as traditional GIS since analysis functions are still very limited compared with desktop GIS at present.

Table 2.1 Traditional GIS vs. WebGIS

\begin{tabular}{|c|c|}
\hline nal GIS & WebGIS \\
\hline $\begin{array}{l}\text { - Data needs to be gathered separately in } \\
\text { - } \text { large volume and at high cost } \\
\text { communication of effort due to lack of } \\
\text { - Proprietary GIS software is required for } \\
\text { all users } \\
\text { - GIS operations can only be available } \\
\text { locally } \\
\text { - Maintaining and updating the } \\
\text { information separately costs money and } \\
\text { effort. } \\
\text { The cost and availability of GIS data } \\
\text { and software limit the potential pool of } \\
\text { GIS users }\end{array}$ & 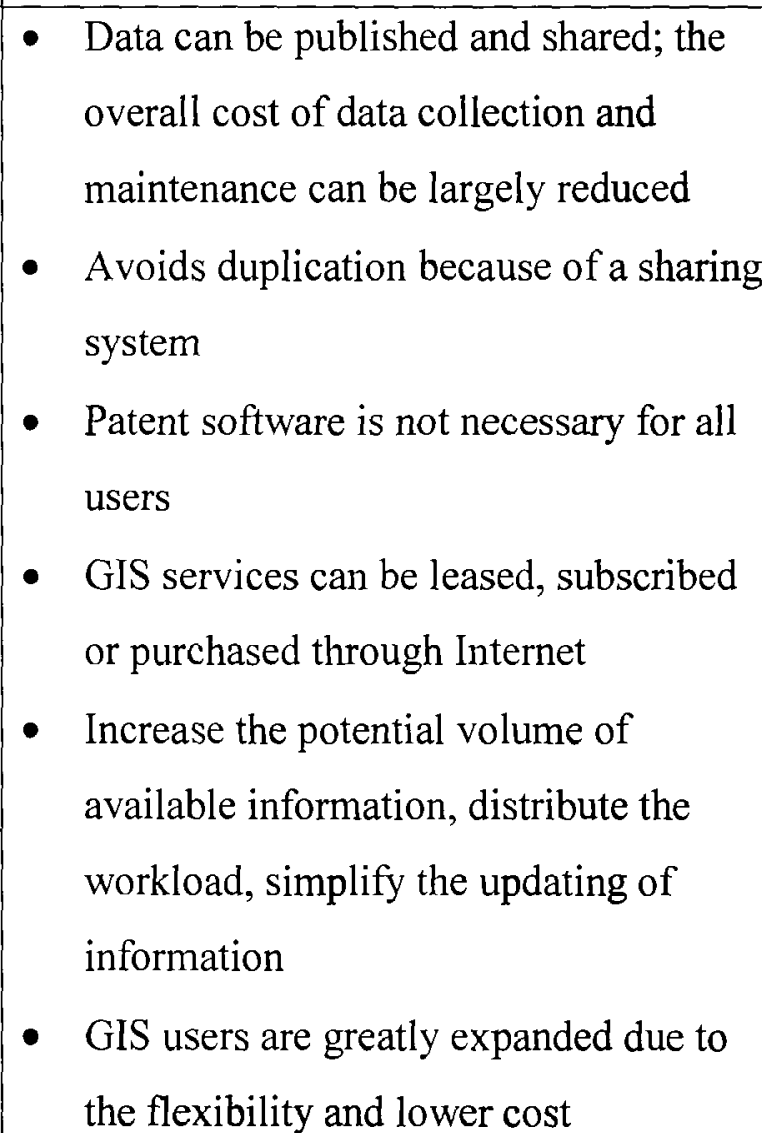 \\
\hline
\end{tabular}

(Source: Green and Bossomaier, 2002; Peng and Tsou, 2003) 


\subsection{WebGIS Technologies}

In this section, an overview of the current WebGIS technologies is presented. GIS software has enabled users to view spatial data in its specific format. As a result, the interpretation of spatial data has become easy and increasingly simple to understand. Unfortunately, not everyone has access to GIS. WebGIS becomes an inexpensive and easy way of disseminating geospatial data. A number of organizations are interested in distributing maps and geo-searching tools to their users without time and location restrictions. Internet technology has made this possible for many organizations as well as numerous individuals. To provide a successful WebGIS solution the implementation needs to be considered as a process rather than one simple step. The design and implementation should also respect the available IT and GIS technology and the end user requirements.

\subsubsection{An Overview}

Development of the Web and expansion of the Internet provide two key capabilities that can greatly help environmental scientists and geoscientists. First, the Web allows visual interaction with geospatial data. By setting up a Web Server, web users can browse the maps with web browsers. Since the maps and geospatial data are published on the Internet/Intranet, other users can view these updates, helping to speed up the fish species evaluation process. Second, because of the near ubiquitous nature of the Internet, the 
geospatial data can be widely accessible. Users can work on it from almost any location at any time. Both features will alter the way environmental scientists and geoscientists do their work in the very near future. At the same time, WebGIS does not require the same resources as the desktop programs. Powerful computers, extensive training, and expensive site licenses are not required for a site-wide GIS solution (Strand, 1998).

However, WebGIS is not without its drawbacks. The primary issue is connection speed, since GIS relies on extensive use of graphics, which makes the traffic over the Internet/Intranet quite heavy. WebGIS will not match the complexity of dedicated desktop GIS applications, such as ArcView or ArcMap.

\subsubsection{Interactive Web Maps}

There are several technology levels available to publish map data on the Web, ranging from sites that simply publish static Web maps to more sophisticated sites which support dynamic maps, interactively customized maps, as well as multiple computer platforms and operating systems. In terms of WebGIS, the most challenging map is the interactive one. Within the Open GIS Consortium, a Special Interest Group (SIG) for WWW Mapping is working on issues of Web-based GIS publishing. This group has recently developed an essential model of interactive portrayal (Figure 2. 1). 


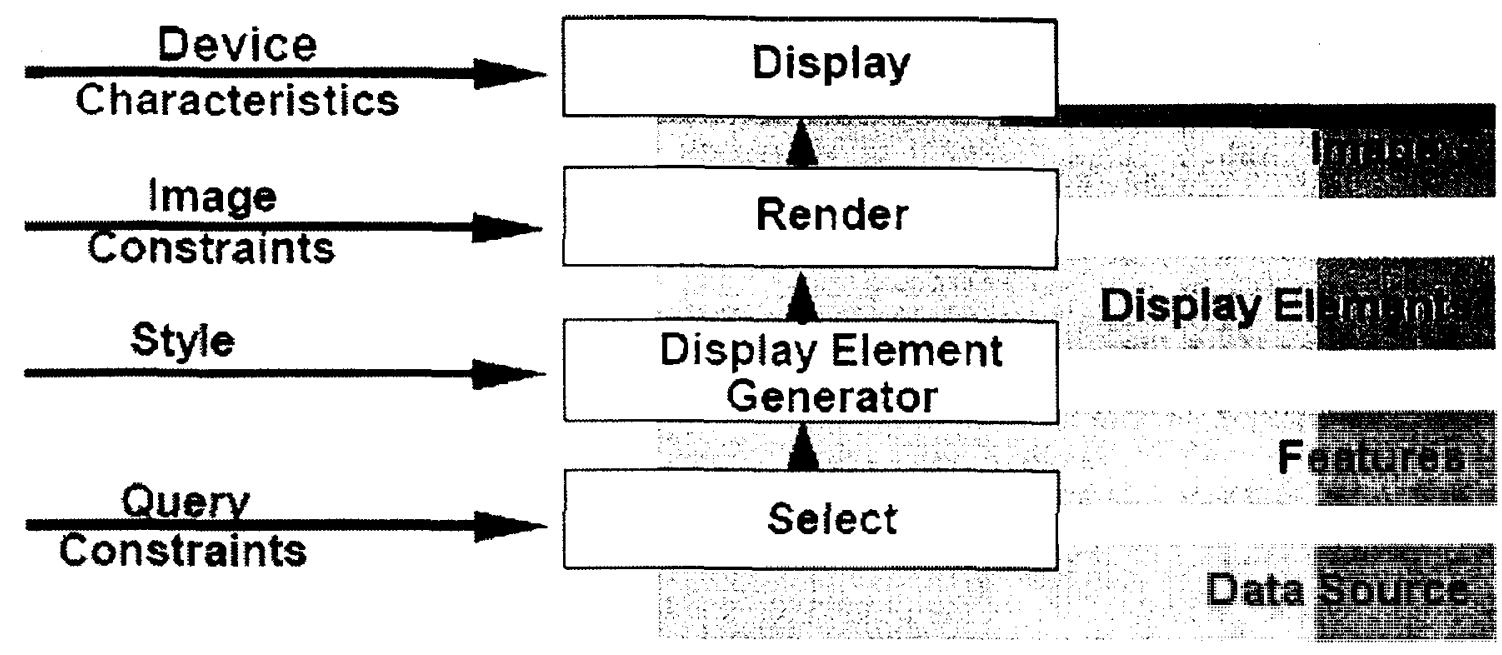

Figure 2.1 OpenGIS Model of Portrayal Workflow

This model is a very useful tool to analyze and compare different architectures for Internet Map Server (IMS) and other Internet based GIS applications. Moreover, it is more precise than the common expression, which often leads to misunderstandings. The interactive portrayal model has four tiers:

- The Selection process retrieves data from a geospatial data source according to query constraints such as a river stream id.

- The Display Element Generator process turns the selected geospatial data into a sequence of display elements. It attaches styles such as symbols, line styles, fill styles to spatial features, generates annotation from alphanumeric attributes; sorts the display elements in a certain order and does other graphical processing.

- The Render process takes the display elements and generates a rendered map. Examples of rendered maps are In-memory display lists, GIF -files or postscript files. 
- The Display process makes the rendered map visible to the user on a suitable display device.

Between these four tiers, there are three different types of data:

1. Features and coverages data (e.g. vector data) retrieved from the Selection process;

2. Display elements generated from the Display Element Generator;

3. Images produced by the Render process;

The next capability for interactive Web maps is to allow users to add new themes to the map from a catalog of available data sources. This can be accomplished by specifying the entire theme, or by querying the spatial or attribute data and returning all those features that satisfy the query criteria (Strand, 1998). When maps are comprised of multiple themes, each theme being displayed as a graphical layer in the map image, the displayed map can become too complex to be of value, unless users are allowed to select which themes are displayed.

\subsubsection{Internet Map Servers}

Internet Map Server (IMS) applications allow GIS database custodians to easily make their spatial data accessible through a web browser interface to end-users. The high-speed DFO Intranet makes an ideal network for distributing data in this manner, given the fact that bandwidth requirements can be high. Making data available to the entire world is 
certainly feasible and any organization that has a public website can certainly add an IMS without opening up too many additional security holes.

For a working IMS, the associated software requires two components to function. The first component is a geospatial data processing engine that runs on the server side as a service, such as Servlet or Common Gateway Interface (CGI) application. The second component processes the raw spatial data into a map and a standard web server that manages the incoming requests and replies with the proper map data back to the client side browser or application window. The end product is either a JPEG or GIF image or vector, which is transmitted back to the client web browser or a stream of data that is interpreted by a plug-in to the client browser. Generally, IMS that transmit back an image have a limited capability that does not extend much beyond pan, zoom, and basic vector attribute query. The feature streaming IMS requires a downloadable plug-in, which is a computer program that can interact with web browser to provide a certain GIS function. The plug-in allows for advanced query, labeling, and operations of uploading geo data files to be performed. Some IMS sites offer both a plug-in and a simple HTML version, which is nice for surfers who are weary of plug-ins. An overview of the six most commonly used Internet Map Servers is provided in Table 2.2.

Table 2.2 Selected Internet Map Servers

\begin{tabular}{|l|l|l|l|l|}
\hline $\begin{array}{c}\text { Internet Map } \\
\text { Server }\end{array}$ & $\begin{array}{l}\text { Transferre } \\
\text { d Geo data }\end{array}$ & $\begin{array}{c}\text { Platform of } \\
\text { IMS }\end{array}$ & $\begin{array}{c}\text { Browser } \\
\text { extension }\end{array}$ & Data interface \\
\hline $\begin{array}{l}\text { ArcIMS } 9.0 \\
\text { (ESRI) }\end{array}$ & $\begin{array}{l}\text { Raster, } \\
\text { vector } \\
\text { (Internal }\end{array}$ & $\begin{array}{l}\text { Win NT/2k, } \\
\text { Windows } \\
\text { 2003 Server }\end{array}$ & Html, Applet & $\begin{array}{l}\text { Shapefiles, } \\
\text { coverage, SDE } \\
\text { Layer, ... }\end{array}$ \\
& $\begin{array}{l}\text { ESRI } \\
\text { formats) }\end{array}$ & & & \\
\hline
\end{tabular}




\begin{tabular}{|c|c|c|c|c|}
\hline $\begin{array}{l}\text { MapXtreme NT } \\
\text { Ver } 2.0 \\
\text { (MapInfo) }\end{array}$ & Raster & Win NT & Html, Applet & \multirow{3}{*}{$\begin{array}{l}\text { MapInfo forma } \\
\text { map, } \\
\text { Shapefiles, } \\
\text { coverage, SDE } \\
\text { Layer, raster }\end{array}$} \\
\hline $\begin{array}{l}\text { MapXtreme Java } \\
\text { Ver } 2.0 \\
\text { (MapInfo) }\end{array}$ & $\begin{array}{l}\text { Raster, } \\
\text { vector }\end{array}$ & $\begin{array}{l}\text { Win NT, } \\
\text { UNIX }\end{array}$ & Applet & \\
\hline $\begin{array}{l}\text { MapXtreme } \\
2004\end{array}$ & $\begin{array}{l}\text { Raster, } \\
\text { vector }\end{array}$ & WinNT/2k & Html, Applet & \\
\hline $\begin{array}{l}\text { MapGuide } 4.0 \\
\text { (AutoDesk) }\end{array}$ & $\begin{array}{l}\text { Raster, } \\
\text { vector }\end{array}$ & Win NT & $\begin{array}{l}\text { Plug-in, ActiveX, } \\
\text { Applet }\end{array}$ & $\begin{array}{l}\text { DWG, DXF, } \\
\text { DGN, MapInfo, } \\
\text { Shapefiles, } \\
\text { coverage, }\end{array}$ \\
\hline $\begin{array}{l}\text { GeoMedia Web } \\
\text { Map / Interprise } \\
5.0 \text { (Intergraph) }\end{array}$ & $\begin{array}{l}\text { Raster, } \\
\text { vector }\end{array}$ & Win NT/2k & Plug-in, ActiveX & $\begin{array}{l}\text { MGE, MapInfo } \\
\text { format map, } \\
\text { Shapefiles, } \\
\text { coverage, } \\
\text { Oracle, Access }\end{array}$ \\
\hline $\begin{array}{l}\text { Map server } 3.5 \\
\text { (Minnesota } \\
\text { DNR) }\end{array}$ & $\begin{array}{l}\text { Raster, } \\
\text { vector }\end{array}$ & $\begin{array}{l}\text { Win9x, NT, } \\
\text { Win2k/XP }\end{array}$ & Html, Applet & $\begin{array}{l}\text { Shapefiles, } \\
\text { SDE layer, } \\
\text { raster }\end{array}$ \\
\hline
\end{tabular}

In the Internet Map Servers product suite, IMS acts either as out-of-the-box but customizable and expandable tool, or as development environment. When deciding on an IMS, one should pay attention to the offered data interface in order to use existing geospatial data without problems.

\subsection{WebGIS Architectures}

In performing the GIS analysis tasks, WebGIS is similar to the typical client/server threetier architecture. The geo-processing breaks down into server-side and client-side tasks. A client typically is a Web browser. The server-side consists of a Web Server, WebGIS software and Database (Figure 2.2) (Helali, 2001). 


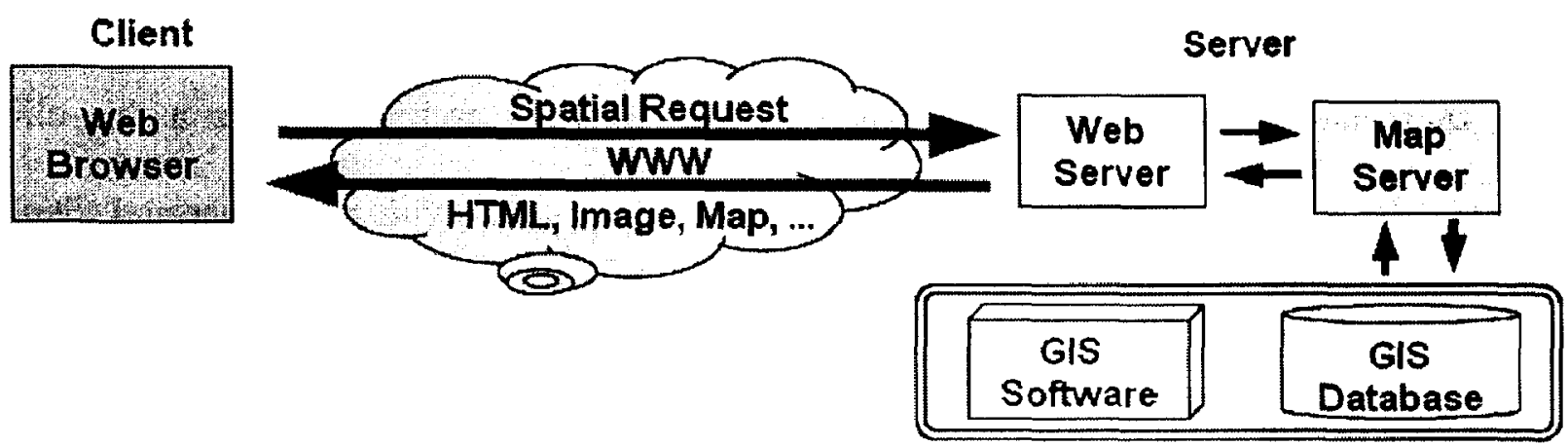

Figure 2.2 How a Typical WebGIS Model Works

This model of network widely exists within enterprises, in which some computers act as servers and others act as clients. A sever simply has the proprietary GIS running, and adds a client interface at the client side and a middleware at the server side to communicate between the client and the proprietary GIS software.

Recent development in object oriented programming makes it possible to produce software components, and sends them to the client before running it in the client machine, such as Java classes, ActiveX components and plug-ins. This development brings users the thick client GIS. The thick-client architecture lets the client machine do the most processing work locally. Both thin and thick-client systems have some advantages and drawbacks, but they are not the best solution in terms of taking advantage of network resources. 


\subsubsection{Thin Client Architecture (Server Side Applications)}

The thin client architecture is used in a typical WebGIS architecture. In a thin-client system, the clients only have user interfaces to communicate with the server and display the results. All the processing is done on the server as shown in Figure 2.2. The server computers usually have more power than the client computers, and manage the centralized resources. Besides, the main functionality is on the Server side in thin architecture, and there is also the possibility for utility programs at the server side to be linked to the server software. Figure 2.3 shows schematic communication between Web browser, Web Server and GIS server. On the Web Server side, there are some possibilities to realize the GIS connection to the World Wide Web; CGI, Web Server Application Programming Interface (API), Active Server Pages (ASP), Java Server Pages (JSP) and Java-Servlet. The descriptions of the five possibilities mentioned above are given in Helali (2001).

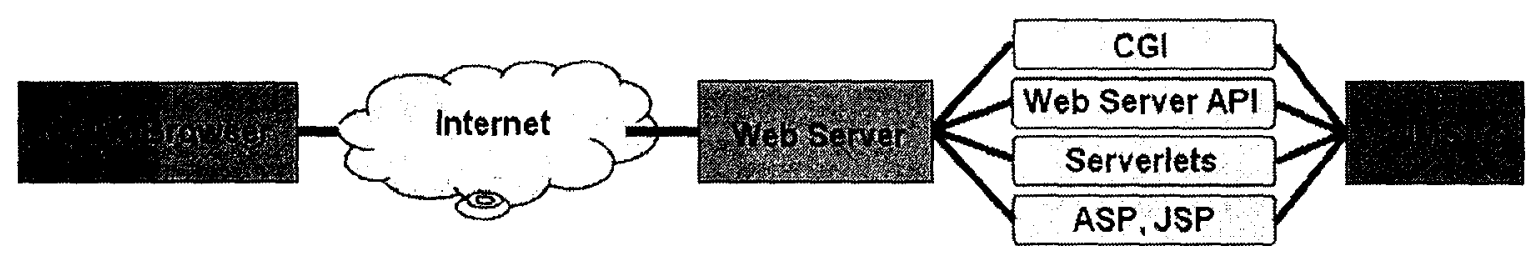

Figure 2.3 Server Side Applications

The user on the client side does not need any knowledge about the linkage of the IMS at the server side, but the system administrator or application developers should be familiar 
with these techniques. This architecture is used in ESRI ArcIMS, MapObjects IMS and MapInfo MapXtreme systems.

Major advantages of this model driven by Data Base centralization are:

- Central control

- Easy for data updating

- Keep the latest version

- Generally inexpensive

- Integration possibilities

Disadvantages:

- Not responsive to local needs: users have different invokes

- No local accountability: accountability requires application on the client side

- Large data volume

- Slow response time: users use a browser and take a long time to download new HTML frame

- Less interactive: on client side there is limited application and browser abilities

- Vector data does not appear on the client side: browsers without additional plugin can not read vector files 


\subsubsection{Thick Client Architecture (Client Side Applications)}

In general, a Web browser can handle HTML documents and embed raster images in the standard formats. To deal with other data formats such as vector data, video clips or music files, the browser's functionality has to be extended. When it comes to using exactly the same client sever communication in a thin client architecture, vector files format can not be currently used. To overcome this problem most browser applications offer a mechanism that allows third tier programs to work together with the browser as a plug-in.

The user interface functionality has progressed from simple document fetching to more interactive applications. This progress is as follows: HTML and CGI use HTML forms, CGI, and Java script to increase user interface capabilities. On the other hand, Java applets provide client-side functionality. Currently, user interface capabilities are combined with remote invocations (Figure 2.4) (Byong-Lyol, 1998).

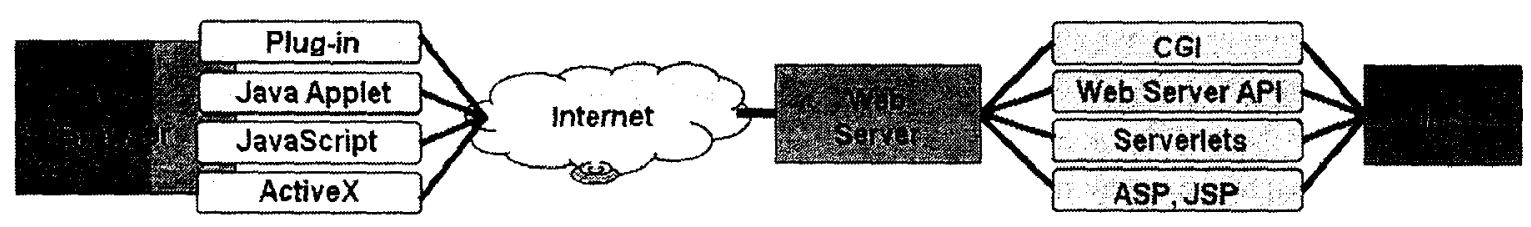

Figure 2.4 Client Side Applications

The major advantages of this model are:

- Document/graphics standards are not required

- Vector data can be used 
- Image quality is not restricted to GIF and JPEG

- Modern interface is possible; it is not restricted to single-click Operations

The drawbacks to Client Side of this model are:

- User-based

- Users are required to obtain additional software

- Browsers are incompatible

\subsubsection{Distributed Architecture}

Recent developments in information technology have resulted in a number of distributed object architectures that provide the framework required for building distributed applications. The framework also supports a large number of servers and applications running concurrently. Many of such frameworks provide natural mechanism for interoperability (Kafatos, 1999). For example, Distributed Component Object Model architecture in windows platform and Java Remote Method Invocation (RMI) in a Java Virtual Machine (JVM) are the most popular protocols that are used in different cases. These architectures may be applied to GIS to improve the traditional client/server GIS model and develop scalable distributed GIS model. Some attempts have been made in academic environments (Zhang, 1998).

The general idea of the distributed GIS service model is that a client program, in either an Internet browser or an independent application, should be able to access the resources 
distributed over the entire network. The resources here refer to both geodata and geoprocessing components available in the network. The client and the server in this context do not refer to any specific machine. Any machine, that requests the remote resources during the processing is a client, and any machine that provides such resources is a server. In a specific program, a client may connect to several servers if needed and a specific machine may be the client at one time and the server at another time. An ideal distributed GIS service model should be a "geodata anywhere, geoprocessing anywhere" model, which means that the geodata and geoprocessing tools could be distributed with the largest flexibility virtually anywhere in the network. The geodata and geoprocessing components do not have to be in the same site, but they should be able to cooperate or integrate whenever they are needed to finish a specific task (Yuan, 2000).

\subsection{WebGIS: Tools and Products}

Depending on the users' access to the source code, Internet GIS tools and products can be classified into two categories: open source and proprietary products. The former is also known as "free software", and the latter can be used to denote all commercial software (Working group on Libra Software, 2000).

\subsubsection{Non-commercial Open Source Tools}

Open source requires software to be free for redistribution, technology-neutral, provided with source code, and pose no restriction on other software (Open Source Initiative, 
2004). Most non-commercial open source tools are Java-based. Advanced and popular tools include: Web-Mapper (http://www.web-mapper.com), MapServer (http://mapserver.gis.umn.edu), OpenGL (http://www.opengl.org), and GeoTools (http://www.geotools.org).

These open source tools are normally supported on a wider range of hardware platforms and software environments. They offer more functionality, flexibility and are more scalable than current proprietary software. However, they normally need much more technical skill to implement. Developers need to be able to identify other required software components, configure the desired features and compile the application. A thorough understanding of core Web technologies and spatial information management expertise are also quite necessary for developers (Anderson, 2003).

\subsubsection{Commercial Non-Open Source Products}

All major GIS vendors provide their own WebGIS products: Intergraph Corp's GeoMedia, MapInfo Corp.'s Map Xtreme, AutoDesk Inc.'s MapGudie, and ESRI's ArcIMS, etc. Although appearing to be similar, these systems are based on "different underlying views of geographic data and technologies". Some of the differences include: "using map prepublishing vs. direct data access; client-level requirements; geographic analysis accessible from the web; and data and platform restrictions" (Limp, 1997). These products are normally easier to customize and implement and do not require as much experience as open source tools. They are general-purpose WebGIS tools, and the 
scalability and extension for modification is relatively limited. Last but not least, the licensing fee for the proprietary products has to be taken into consideration by any organizations that are interested in developing their own WebGIS projects.

\subsection{Sample Sites of WebGIS Applications}

Several sample WebGIS sites powered by ArcIMS were reviewed below. These web sites were devoted to different subjects in environmental area with different degrees of customization.

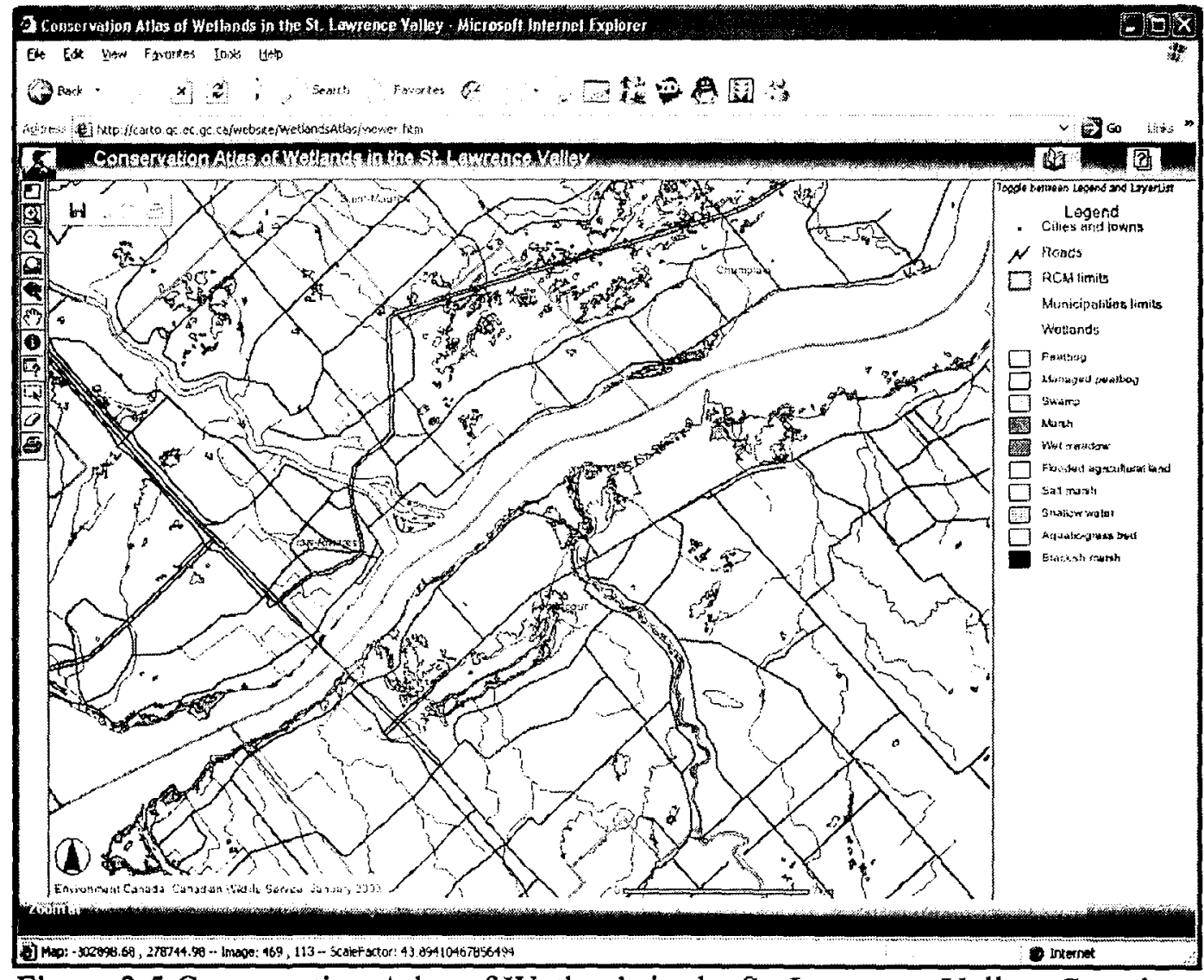

Figure 2.5 Conservation Atlas of Wetlands in the St. Lawrence Valley, Canada 


\subsubsection{Conservation Atlas of Wetlands in the St. Lawrence Valley, Canada}

The ArcIMS HTML map viewer is created by Canadian Wild Life Service (http://carto.qc.ec.gc.ca/website/WetlandsAtlas/viewer.htm). The Conservation Atlas of

Wetlands in the St. Lawrence Valley is intended for a broad public. It brings together general information such as definitions of these environments, the roles of wetlands and their classification, which will be of interest to people who have an interest in this type of habitat for the first time. Those better informed might want to go directly to the more technical sections (Project description and Image classification and processing), which are more intended for computer-assisted mapping enthusiasts. Statistical and descriptive data (maps and statistical tables) as well as the possibility to map the sector of their choice are available for those users to look for specific information. "The main purpose of the Conservation Atlas of Wetlands is to develop a portrait of the wetlands of the St. Lawrence Valley using innovative mapping methods in order to favor bird conservation by helping land managers to make decisions about land use and bird habitat conservation" (Canadian Wild Life Service, 2003).

This viewer is very similar to the standard HTML viewer. Little customization is performed. It is simple and clear, suitable for general public use (Figure 2.5). 


\subsubsection{OakMapper WebGIS Application}

OakMapper (http://kellylab.berkeley.edu/OakMapper/viewer.htm) is used for assessing and monitoring Sudden Oak Death (SOD) in California. The site uses map server of ArcIMS, and the map layers are from ArcSDE.

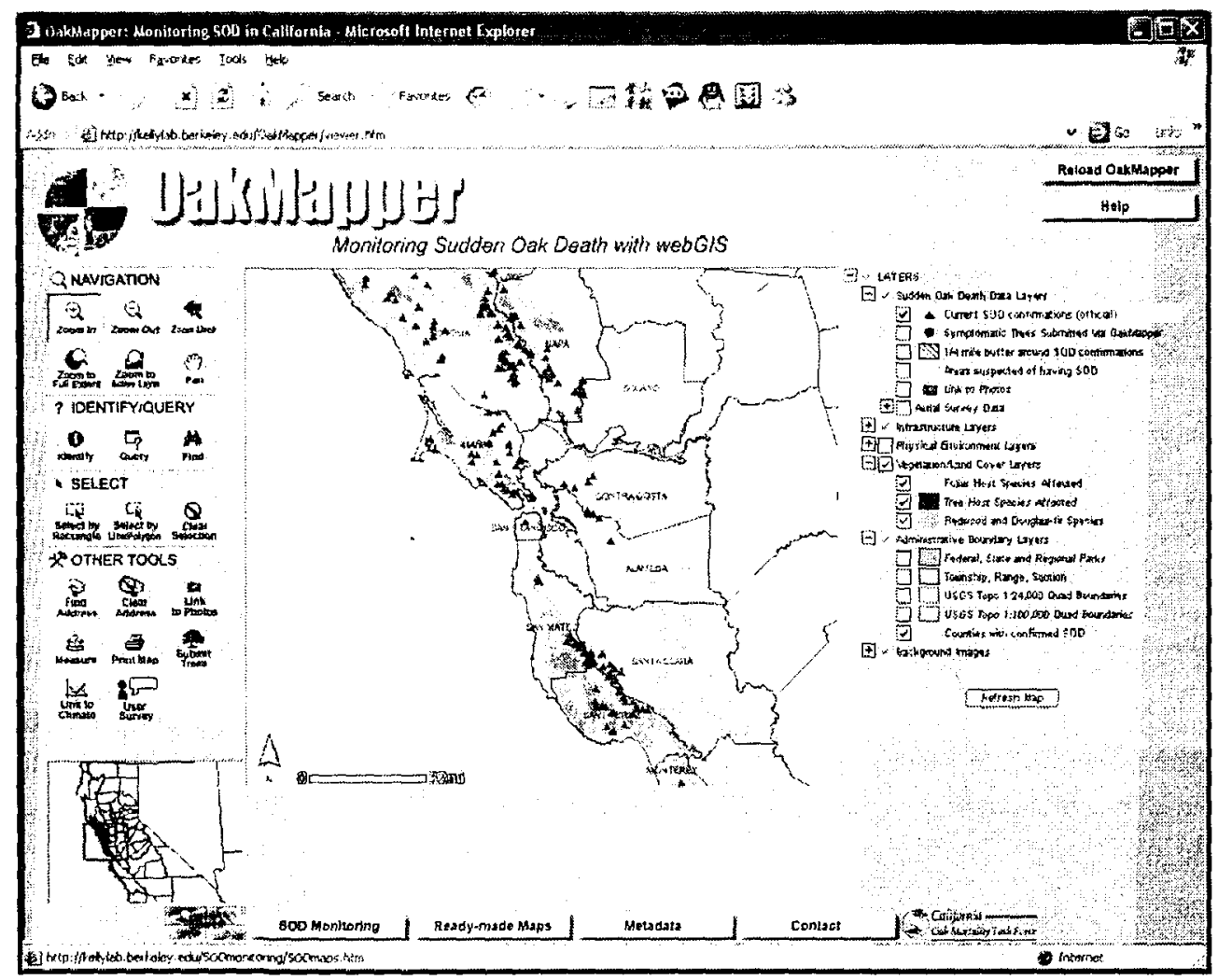

Figure 2.6 OakMapper WebGIS Application

With the OakMapper, the audience will be able to (CAMFER, 2004):

- View current distribution of Sudden Oak Death (SOD) throughout California.

- Zoom, view, and search monitoring data for SOD in California.

- Perform geographic queries. Data can be viewed and spatially queried by address, county, zip code and congressional district.

- Create a custom map. Selected layers can be exported or printed by the user. 
- Log, report, and record occurrences of trees with possible Sudden Oak Death (SOD): This website allows submission of the location and condition of trees with symptoms of SOD directly to the database.

- Find education material on SOD. Information sheets, pest alerts, and other educational material about SOD are provided at the web page.

This map viewer has been moderately customized. Tools bars have been added with names and enhanced with new functionality; buttons with links to other related web pages are also added to the viewer (see Figure 2.6). It provides much more information and functionality compared with the standard viewer.

\subsection{Rapid GIS Application Development Method}

Conventional software development methodologies often fail to address the GIS application development needs due to the complex and dynamic nature of GIS projects. Rapid application development (RAD) method for Web-GIS application development usually is designed to quickly set up the GIS software development with small project startup cost, and allows high flexibility and continuous refinement and enhancement to the design during the software development process. In order to quickly deliver quality GIS software products to customers on a tight schedule, GIS developers offer continuous improvement as the customers gradually adapt to the new GIS system and become ready to take advantage of more advanced GIS and information technologies. 
Web-GIS applications are often called to solve much more complex problems compared to applications in other web applications. Developing applications is often one of the most time-consuming and expensive elements of implementing a GIS. A Web-GIS application often contains a high volume of user interactions, multi-step processes, and multiple ways of performing the same task. The GIS users often desire to have higher level of involvement during the software development. Yet, the detailed functional requirements, scope of works are often hard to define at the beginning of a WebGIS application development project. Sometimes, both the GIS users and GIS developers leave the software requirements and functional specifications purposely vague to allow the inevitable changes along the way of software development process. But this kind of practice often causes confusions and contract conflicts later in the project.

GIS application development often heavily relies on existing GIS software platforms or functional libraries, such as ESRI's ArcIMS JavaScript library. Working within these GIS platforms is often one of the major constraints in a GIS application development. However, these GIS platforms and readily available object codes in the functional libraries also provide unique opportunities for GIS developers to be able to develop more robust GIS application rapidly. An example is the choice of designing user interfaces of a WebGIS application that will be developed within ArcIMS environment using the HTML Viewer. This HTML Viewer is created from ArcIMS Designer, but the developer can quickly assembly a very robust application utilizing the powerful ArcIMS functions. 
Rapid Application Development (RAD) method came to the software development community in the early 1990s (Martin, 1991). There are many different rapid development approaches. In fact, many development service providers have defined their own RAD (Hoffer, et al. 2002). The general common characteristics of a RAD have always included a high level of user involvement in the development process.

Many people have pointed out that RAD only works for systems that have to be developed quickly, and other aspects of application development efforts such as interface consistency and programming standards are often overlooked. However, the success of RAD in the new business environment of increased costs and competitions is undeniable. Some studies have reported some RAD successes ranging from saving 50 percent of costs to nearly cutting more than 60 percent of development time (Hoffer et al. 2002).

The RAD approaches naturally fit the needs of GIS application development, especially in the small to medium size projects that often require accelerated development schedule. There are many success stories of utilizing RAD tools and techniques in GIS projects documented in ESRI user conference proceedings and other publications (Cone, 1999; Dennerlein, 1997; Kroot et al. 2000).

In this study, the rapid GIS application development approach will be used in the planning, design, build, and release phases of the fish species at risk web applications. 


\subsection{GeoDatabase and Metadata}

\subsubsection{Geodatabase}

A geodatabase is a storage mechanism for spatial and attribute data that makes it easier and more intuitive to use geographic information systems (GIS) software across many applications. The geodatabase supports multiple formats of spatial data including map information (raster or vector), attribute data, text, images, and metadata. This makes it ideal for storing, editing, analyzing, serving and archiving natural resource inventory information that contains multiple data formats (e.g. maps, images and texts).

Geographic data, supporting documents, spreadsheets and reports have been stored in operating system files along with other forms of computer data and have not been integrated into a related dataset. Because these data files were in different formats (text vs. image vs. map data), direct linkage of these files is difficult for a number of technical reasons. The following section describes how these geographic data can be linked and used.

\subsubsection{Geodatabase and RDBMS}

To overcome the disadvantages of a file-based storage configuration, modern data processing projects store data in Relational Database Management Systems (RDBMS). A RDBMS stores data in row and column arrays called tables. When geographic data are stored in the tables of an RDBMS the collection of tables is called a geodatabase. 
Using the geodatabase, the study can move away from the static archive of geospatial data and start to address the integration of multiple types of resource information to compose a true geodatabase inventory. This means that map data, report information, species photos, and soils data that the environmental scientists and geoscientists have collected over the past years can be linked and easily accessed through the WebGIS application.

\subsubsection{Metadata}

Metadata is described as "data about data." Besides the spatial and tabular data, metadata is additional information that is required to make the data useful. It is what information developers need to know in order to use the data. Metadata represents a set of characteristics about the data that are normally not contained within the data itself. Metadata usually includes the date, source, map projection, scale, resolution, accuracy, and reliability of the information, as well as data about the format and structure of the data set.

Spatial data supports software-based and organization-wide standards. The benefit of having software-based data standards is that the program is easier to use. By creating metadata, users are creating a standard in naming, defining, cataloguing, and operating for all departments. This in turn is a vital foundation for understanding, collaborating, and sharing resources with others. 
Spatial metadata is important because it supports easier spatial data access and management. Metadata provides a guide to the casual and novice user's questions, such as "How do I know what to ask for?" Metadata can provide information on what is available in an area of interest, where the information is, how current it is, what format it is in, and what use constraints apply. For spatial data professionals, metadata provides item-level metadata management for both features and attributes. This way, updates are easily accommodated and integrated into daily use of the data. Metadata is not an end in itself; it is a tool that will greatly improve work with spatial data and increase overall GIS benefits. 


\section{Chapter 3}

\section{User Requirements and Information Needs Analysis}

Developing a WebGIS is more than simply purchasing and installing the appropriate software and hardware. The implementation strategies have been scientifically assessed and modified so that the requirement can be met within specific (minimum) cost and time.

Although the WebGIS development is using a rapid application development method which is mentioned in Chapter 2, careful planning in the startup phase of the project is still an essential factor to the success of the project (see Figure 3.1).
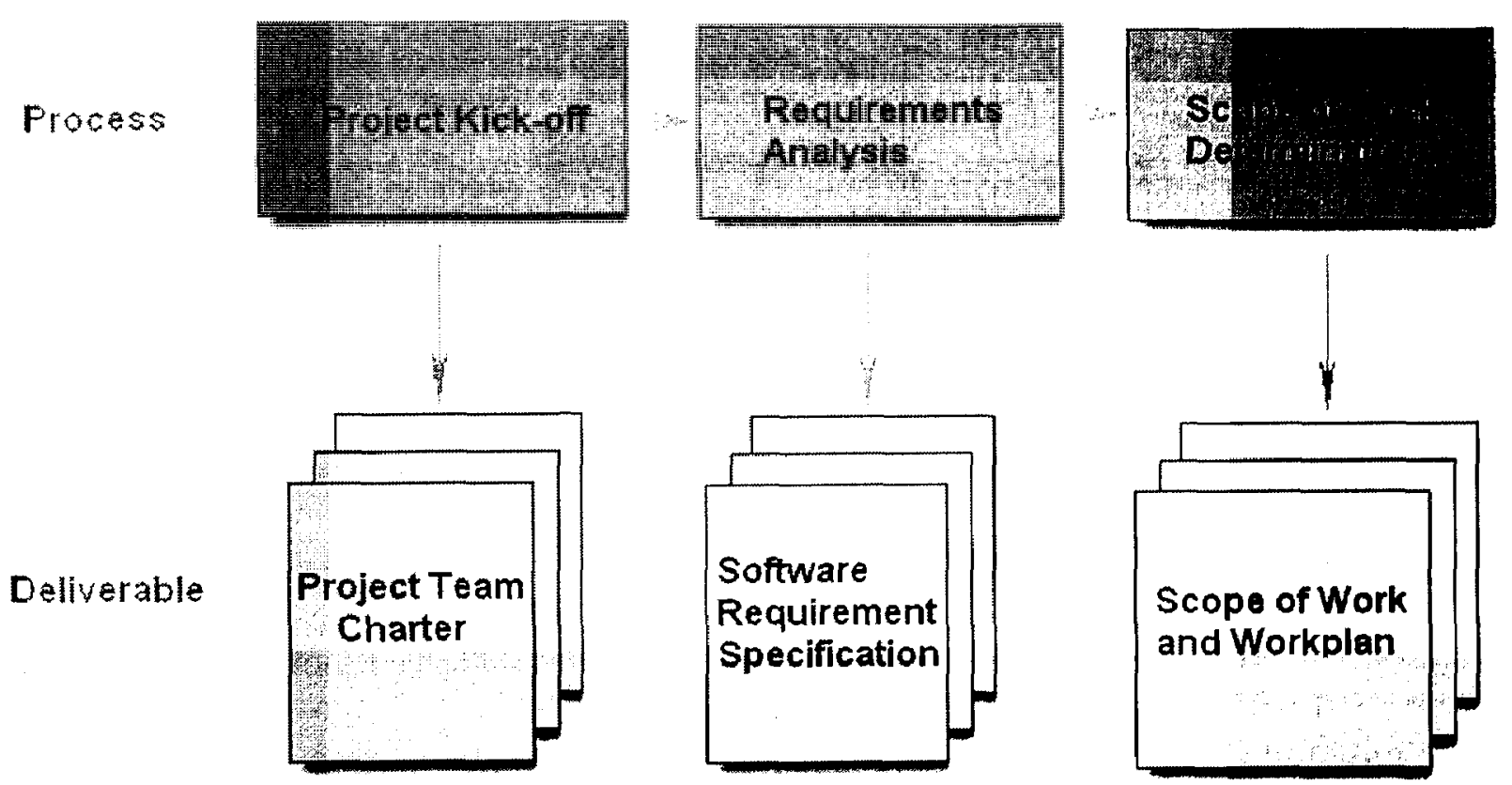

Figure 3.1 Project Start Up and Planning 


\subsection{Development Planning}

A project kick-off meeting was called to define the rules and responsibilities of the FSAR team members. In the study, I, as a WebGIS developer/analyst, conducted most of the user requirement analysis and all of the development research. The FSAR user requirement analysis team includes WebGIS system analyst/developer, the client and some GIS users. A draft work plan and preliminary schedule was determined at this time. In gathering FSAR requirements, the system analyst asked the GIS users and clients three questions:

(1) What must you have in FSAR?

(2) What do you wish to have in FSAR?

(3) What do you NOT want to have in FSAR?

The WebGIS software requirement specification documents the needs in the first category as the basic requirements in great detail, lists the needs in the second category as optional requirements, and notes the third category as being excluded.

In the case of limited funding and development time, developers may also choose to delay the development of more complex GIS functions that support certain advanced GIS analyses. Sometimes, with the ever improving GIS technology, functions that provide better solutions to those needs may come directly from the next release of the underlining GIS platform or software upgrades, such as ArcGIS Server. In the meantime, the WebGIS users may take the time to become more familiar with the basic WebGIS 
applications before they can take advantage of more advanced GIS technologies. The third question may seem odd, but determining what do not need to be in the development can help further bound the scope of work. For example, DFO does not want web users to change fish distribution database, but some WebGIS platforms provide web users the ability to upload data to database. The system analyst must exclude those kinds of WebGIS functions.

\subsection{Survey of User Needs and Requirements}

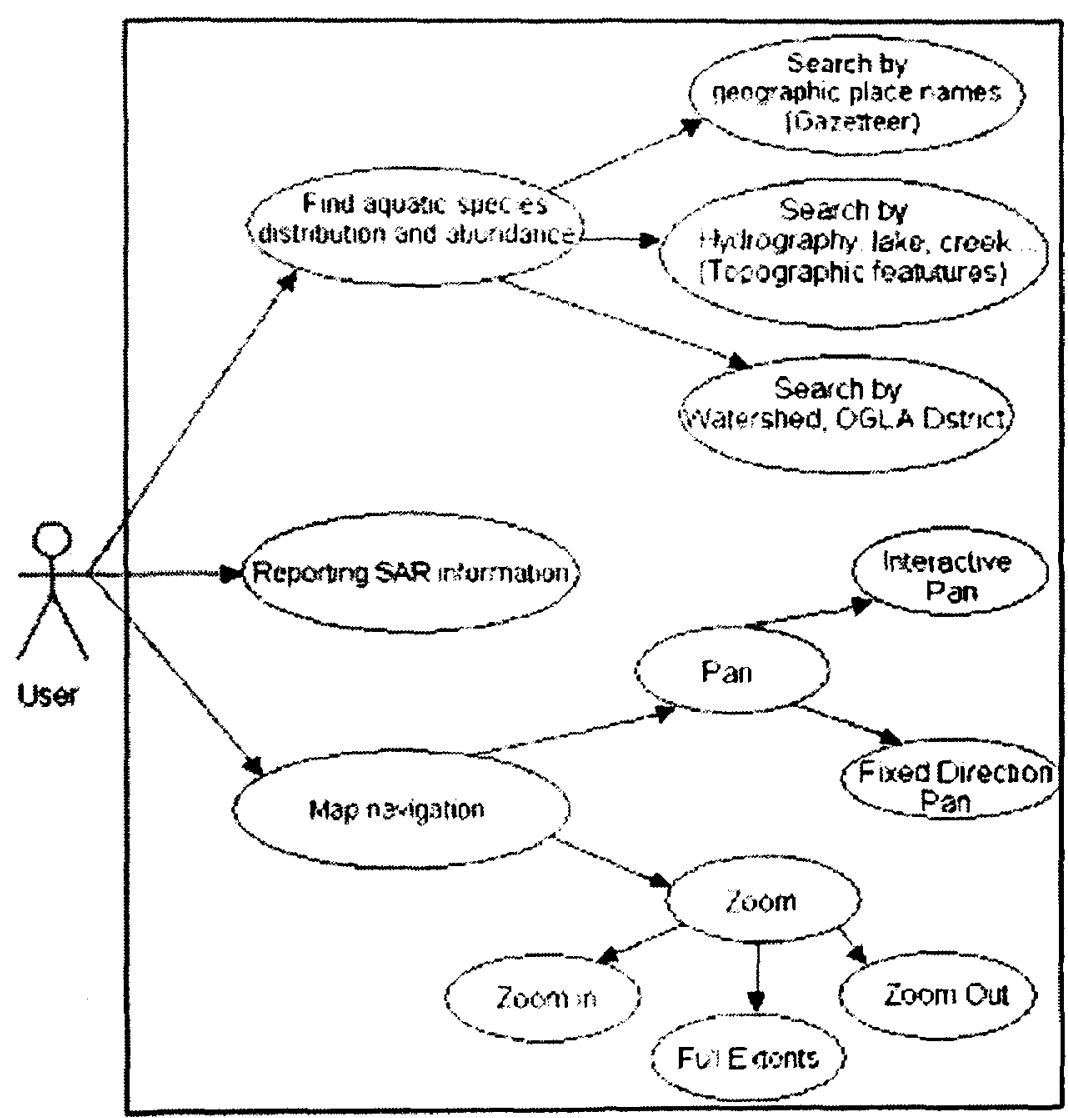

Figure 3.2 An Use Case Diagram

It took a considerable amount of preparation to develop a comprehensive web-based fish species management system. The goal was to identify all the different potential uses of 
WebGIS throughout the different divisions and agencies within DFO. A typical example of one of the use cases diagrams is shown below in Figure 3.2.

As mentioned in Chapter 1, DFO is one of the three federal departments responsible for implementing the Species at Risk Act (SARA). The other two federal departments are Environment Canada and Parks Canada. SARA has placed demands on Fish Habitat Management of DFO, and its partners related to assessment, recovery, monitoring, compliance and protection of aquatic species at risk.

A GIS fish species at risk in Ontario management web interface framework, titled Ontario Aquatic Maps Explorer, is needed for sharing geospatial data, maps, aquatic species and SAR information within and between agencies, such as Environment Canada, Canadian National Parks, and Ontario Ministry of Natural Resources. There will be approximately 100 users who will use the WebGIS tools when Ontario Aquatic Maps Explorer is finished.

In this phase, a survey of user requirements and information needs was performed. Before progressing to the detailed analysis, it is helpful to get an overview of the issues that the FSAR framework faces. The major issues to be resolved are listed as following:

- Aquatic species distribution and abundance mapping;

- Reporting SAR information;

- Map navigation: Identifying, Panning, Zoom-in and Zoom-out of mapping base data, such as hydrologic networks, drains, and water bodies; 
- Data management of fragmented geospatial and aquatic databases;

- External Access to web based mapping applications;

The Ontario Aquatic Maps Explorer is a mapping application for use by DFO and its partners to expedite review of referrals for impacts and threats to fish SAR. The GIS mapping application can be divided into three major components:

1. Common mapping tools,

2. Ontario Search Engine tools,

3. Reporting tools.

These components are shown in Figure 3.3.

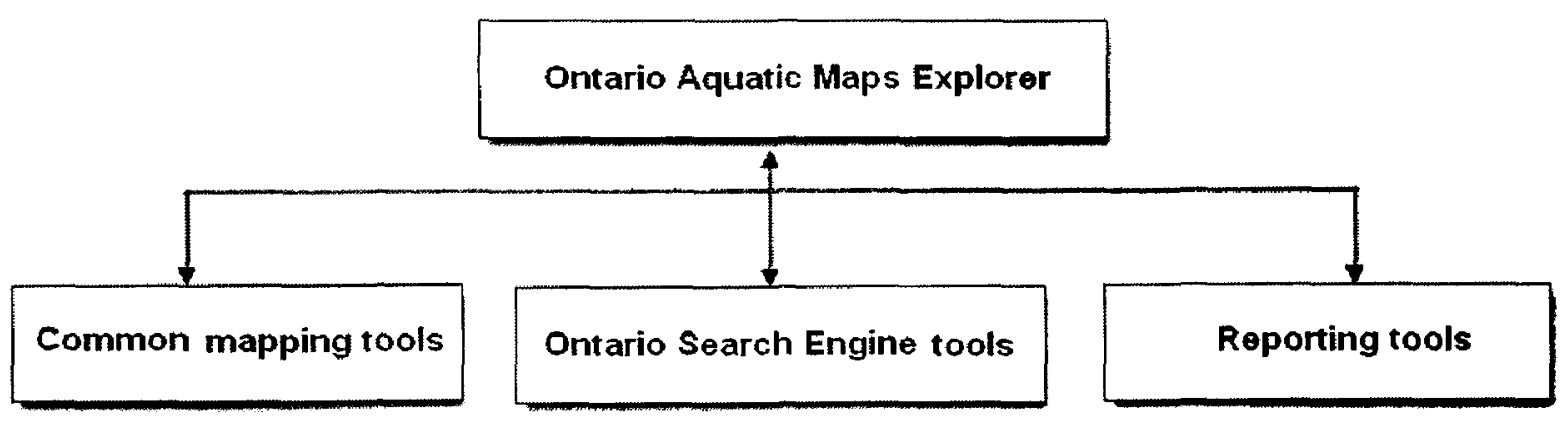

Figure 3.3 Major Functions of FSAR WebGIS Application

\subsection{Major Functions Analysis}

In the following sections, the analysis results of Ontario Aquatic Maps Explorer will be given in detail. 


\subsubsection{Common GIS Mapping Tools}

The Ontario Aquatic Maps Explorer provides a selection of Common GIS mapping tools,

e.g. Zoom in, Zoom out, and Panning. The complete list of common GIS mapping tools is in Table 3.1.

Table 3.1 Common GIS Mapping Tools

\begin{tabular}{|l|l|}
\hline \multicolumn{1}{|c|}{ Common GIS mapping tool Name } & Need Customized in HTML Viewer? \\
\hline Zoom in & Yes \\
\hline Zoom Out & No \\
\hline Zoom to Last & No \\
\hline Full Extents & No \\
\hline Pan & No \\
\hline Select By rectangle & No \\
\hline Clear selection & No \\
\hline Measure Distance & Yes \\
\hline Add text to map & Yes \\
\hline Add Symbol to Map & Yes \\
\hline Add Coordinate to Map & Yes \\
\hline Printing & Yes \\
\hline
\end{tabular}

(See section 5.2 Customising the HTML Viewer Parameters for more information about customisation.) 


\subsubsection{Ontario Search Engine}

Ontario regional search approach provides three types of searching features within Ontario. The three searching tools are Gazetteer Search, Topographic Search and Quick Zoom Search (see Figure 3.4).

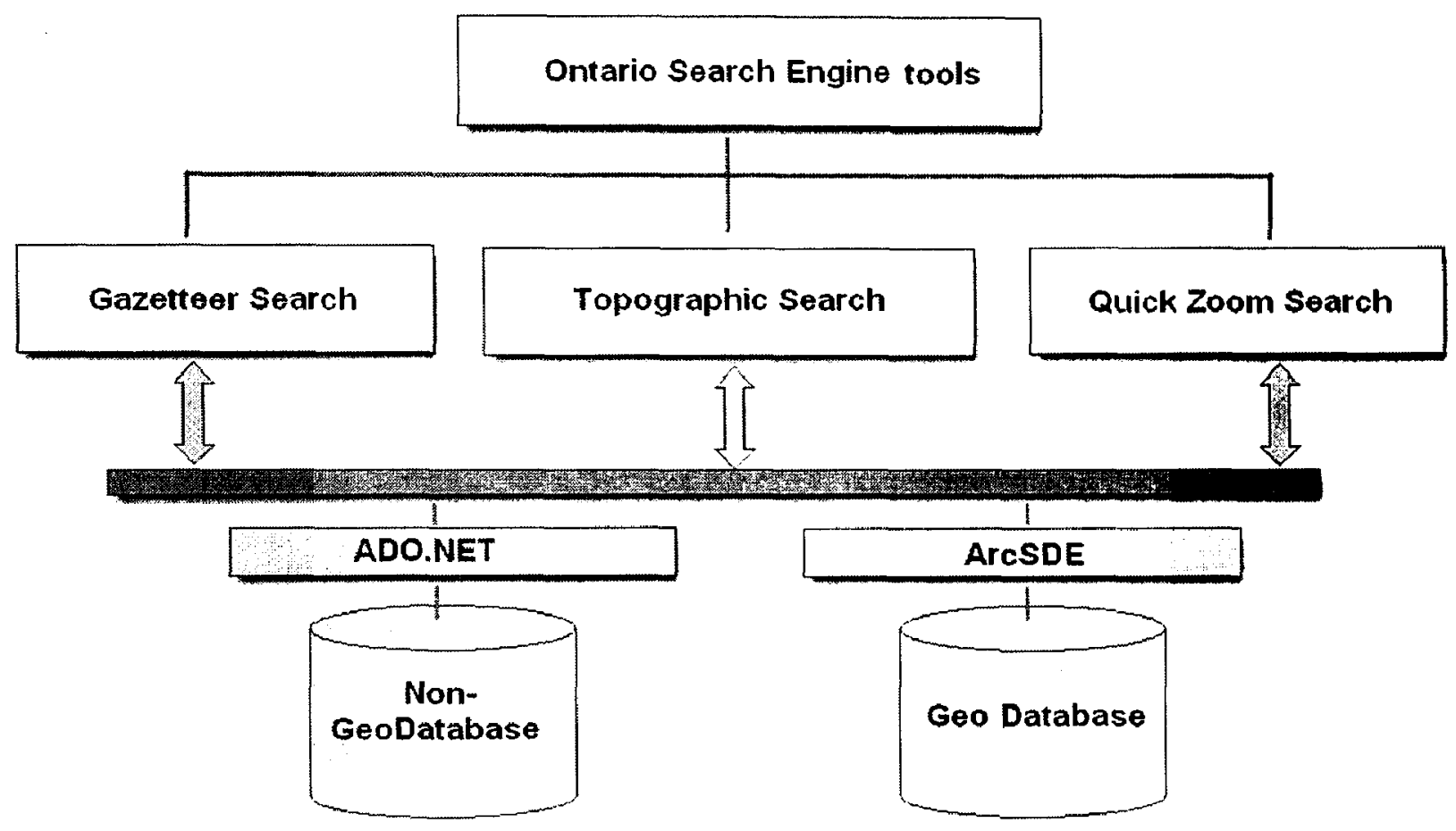

Figure 3.4 Ontario Search Engine Tools

For Gazetteer Search, the user first chooses a gazetteer category, e.g. City category (see Table A.1 in the appendix A for the entire list of Gazetteer Categories list in Ontario). Gazetteer Search engine will look up the (City) category and returns the entire list of the cities in Ontario. Then the map can zoom to the city that the user chooses from the city list. 
The use of the Topographic Search tool is similar to the Gazetteer Search. But the Topographic Search category is completely different. (See Table B.1 Topographic Category list in Appendix B)

If the user wants to quick zoom to CA Watersheds, OGLA districts or OMNR districts, the Quick Zoom Search is the best tool to use.

\subsubsection{Reporting Tools for Access to SAR Information}

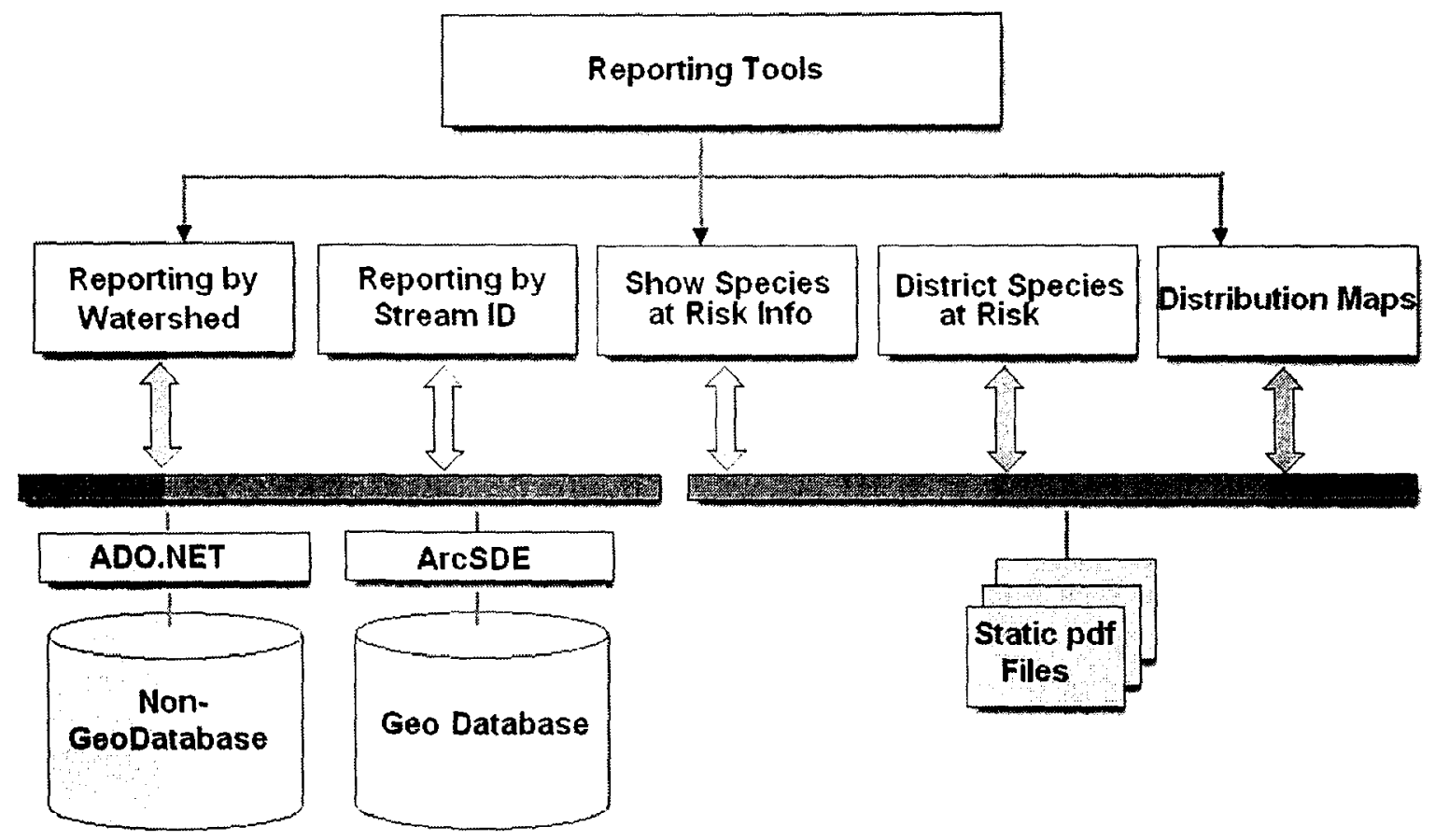

Figure 3.5 Reporting Tools

Reporting tools can display the species list including SAR by tertiary watershed or by stream segment (see Figure 3.5). 
The user navigates to the area of interest on the map, and selects the reporting tool. If the user clicks on the watershed polygon or stream segment, Ontario Aquatic Maps Explorer is ready to give the user a report of fish species and species at risk found in that watershed or stream segment.

Reporting tools also show Species at Risk information for the specific species and provide distribution maps by species and species list at the stream segment level.

\subsection{Data and Database Analysis}

Two major types of data are needed for this ArcIMS website publishing fish species data for Ontario including SAR: base geographic data and aquatic species distribution data for Ontario.

\subsubsection{Geospatial Data}

A geodatabase is an instance of an object-relational database that has been enhanced by adding geographic data storage, referential integrity constraints, map display, feature editing and analysis functions (Zeiler, 1999). It is a collection of feature datasets, feature classes, object classes and relationship classes. A key purpose of the geodatabase is to handle Ontario geographic data with a uniform data model independent of the relational database underneath. The FSAR geodatabase is organized into broad categories of data such as land use, road information, watershed and etc. 
Most of the base geospatial data layers for Ontario area are from Natural Resources Values Information System (NRVIS), National Topographic Database (NTDB), Environment Canada, DFO and Ontario Ministry of Natural Resources (OMNR). The data for aquatic species, including SAR, is from DFO and OMNR (see Table 3.2).

Table 3.2 Map File Layers

\begin{tabular}{|l|l|}
\hline \multicolumn{1}{|c|}{ Data Layer Name } & \\
\hline RAILWAY_SEGMENT & NRVIS \\
\hline ROAD_SEGMENT & NRVIS \\
\hline GEONAMED_PLACE & NRVIS \\
\hline TRANSPORTATION_600K & NRVIS \\
\hline ROAD_600K & NRVIS \\
\hline PROVINCIAL_PARK_REG & NRVIS \\
\hline BUILDING_TO_SCALE & NRVIS \\
\hline COUNTIES_1MILLION & NRVIS \\
\hline GEOGRAPHIC_TOWNSHIP & NRVIS \\
\hline LOT & NRVIS \\
\hline CA_WATERSHED_1MILLION & NTDB \\
\hline MNR_DISTRICT & NRVIS \\
\hline NWP_DISRTICT_1MILLION & NRVIS \\
\hline OGLA_DISTRICTNEW_1MILLIO & DFO \\
N & \\
\hline WATSHD_TERTIARY3 & NRVIS \\
\hline WATER_LINE_PERMANENT_GL & NRVIS \\
\hline WOODED_AREA & NRVIS \\
\hline WATERBODY_SEGMENT & NTDB \\
\hline
\end{tabular}

The above spatial data can provide GIS mapping ability for aquatic species distribution across the province of Ontario. 


\subsubsection{Fish Distribution Data}

FSAR provides Ontario with fish species distribution data and fish species at risk data based on Watershed or stream segment (see Table 3.3).

Table 3.3 Fish Distribution Data Tables

\begin{tabular}{|l|l|}
\hline \multicolumn{1}{|c|}{ Data table name } & \multicolumn{1}{|c|}{ Source } \\
\hline Species Lookup Table (SAR_lookup) & DFO \\
\hline Species Summary Table by Watershed & DFO \\
\hline $\begin{array}{l}\text { Species Summary Table by Stream } \\
\text { segment }\end{array}$ & DFO \\
\hline
\end{tabular}

\subsection{Summary}

The FSAR website can be successful when the WebGIS comprehensively and consistently meet the needs of users. Development of a successful WebGIS depends on well-defined user requirements. Throughout the user requirement analysis (URA) process, FSAR system analyst/developer performed a detailed study of the needs of DFO biologists and environmental scientists. The URA results in a clear specification for the FSAR functionality components as well as for the geospatial data presently being 
required by users. The specification report provides all the details required for an understanding of the functions and spatial data that users require. 


\section{Chapter 4}

\section{Design of the FRAS System Architecture}

As discussed in Section 2.3, there are basically two types of architectures for developing the WebGIS applications: client-side and server-side. In the client-side WebGIS application, the client (Web browser) is enhanced to support GIS functionality. In the server-side GIS application, a Web browser is used only to generate server requests and display the results (see Figure 4.1).

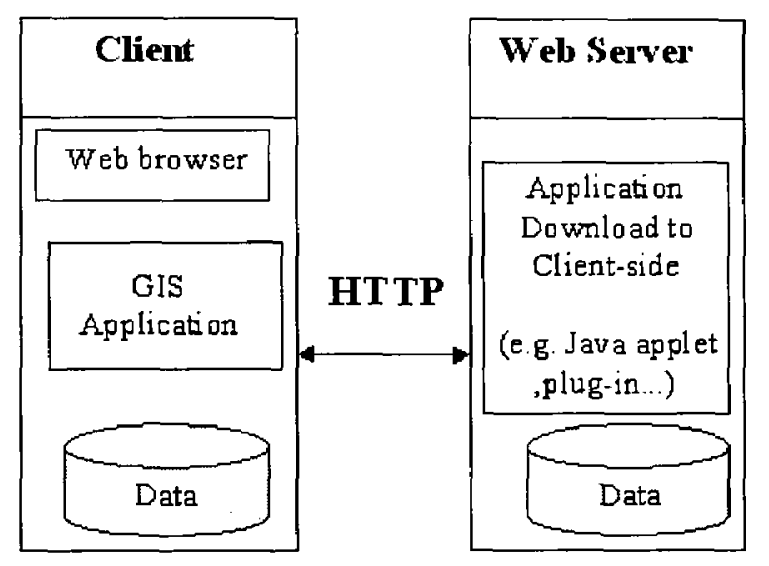

(a) Client-Side Architecture

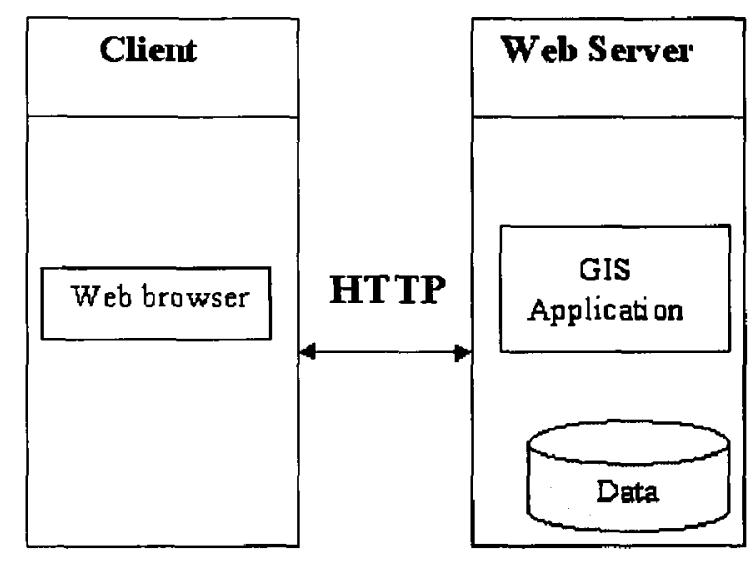

(b) Server-Side Architecture

Figure 4.1 Client-Side vs. Server-Side Architecture

\subsection{Architecture for the FASR System}

The client-side GIS applications are implemented typically by enhancing the Web browser with a Java applet, ActiveX, or plug-ins. Some client-side applications even require users to install a complete client application. In either case, client-side applications require some kind of software (other than a browser) to be transferred to the client-side. An example of a client-side WebGIS application is one that runs as a Java 
applet. The Java code for the applet is transferred to the Web browser as binary instructions that provide a graphical user interface (GUI) for the GIS application. Vectorbased data are then transferred to the client enabling the complex GIS functions on the client.

In the typical server-side WebGIS applications, users send a request to a server (i.e., an address), and the server processes the request and sends the results back as an image embedded in an HTML page via standard HTTP. The response is a standard Web page that a generic browser can view. In the server-side WebGIS applications, all the complex and proprietary software, in addition to the spatial and tabular data, remain on the server (see Figure 4.1(b)). This architecture has several advantages including simplified development, deployment, and maintenance because the application and data are centralized on the server.

Table 4.1 Comparison of Server-Side and Client-Side WebGIS Architectures

\begin{tabular}{|c|c|c|}
\hline & Server-Side WebGIS & Client-Side WebGIS \\
\hline Advantages & $\begin{array}{l}\text { - } \text { Simpler to develop } \\
\text { - } \text { Easier to deploy } \\
\text { - } \text { Easier to maintain } \\
\text { - } \text { Adheres to Internet standards } \\
\text { - } \text { Requires standard Web browser } \\
\text { - Low bandwidth required }\end{array}$ & $\begin{array}{l}\text { - Vector data can be used } \\
\text { - Better image quality } \\
\text { Enhanced GUI }\end{array}$ \\
\hline Disadvantages & $\begin{array}{l}\text { - Primitive Graphical User } \\
\text { Interface } \\
\text { - Low graphics quality } \\
\text { - One-click functionality from a } \\
\text { browser }\end{array}$ & $\begin{array}{l}\text { - } \\
\text { - Rifficult to develop } \\
\text { - } \quad \text { Longer download times } \\
\text { - No adherence to standards } \\
\text { - Platform/browser } \\
\text { incompatibility }\end{array}$ \\
\hline
\end{tabular}


A comparison of the advantages and disadvantages of the server-side and client-side WebGIS applications is listed in Table 4.1.

The optimal architecture depends on the system requirements. One of the goals for the fish species at risk management FSAR system is to develop a Web-base application that could easily be developed, modified and ported to various DFO offices in Ontario regardless of the platforms or network capacities of the DFO offices. The application has to be developed on a tight deadline and budget. After comparing the two types of architectures listed in Table 4.1, the server-side architecture was selected in this study as it is easier to develop.

ESRI ArcIMS 9.0 was selected as the Web map server of the FSAR system. ArcIMS 9.0 is an off-the-shelf Arc Internet Map Server software product on the market. It can be used for "delivering dynamic maps and GIS data and services via the Web" (ESRI, 2005a). Due to availability, ArcIMS version 9.0 is used in this study. The following discussion of the architecture and major components will be based on ArcIMS 9.0.

\subsection{ArcIMS Architecture}

After early Internet solutions of MapObject IMS and ArcIMS 4.0, ESRI developed its newest web-mapping package ArcIMS 9.0 with improved performance and stability. A three-tier architecture is implemented in ArcIMS which includes presentation, business logic and data storage tiers (see Figure 4.2). 


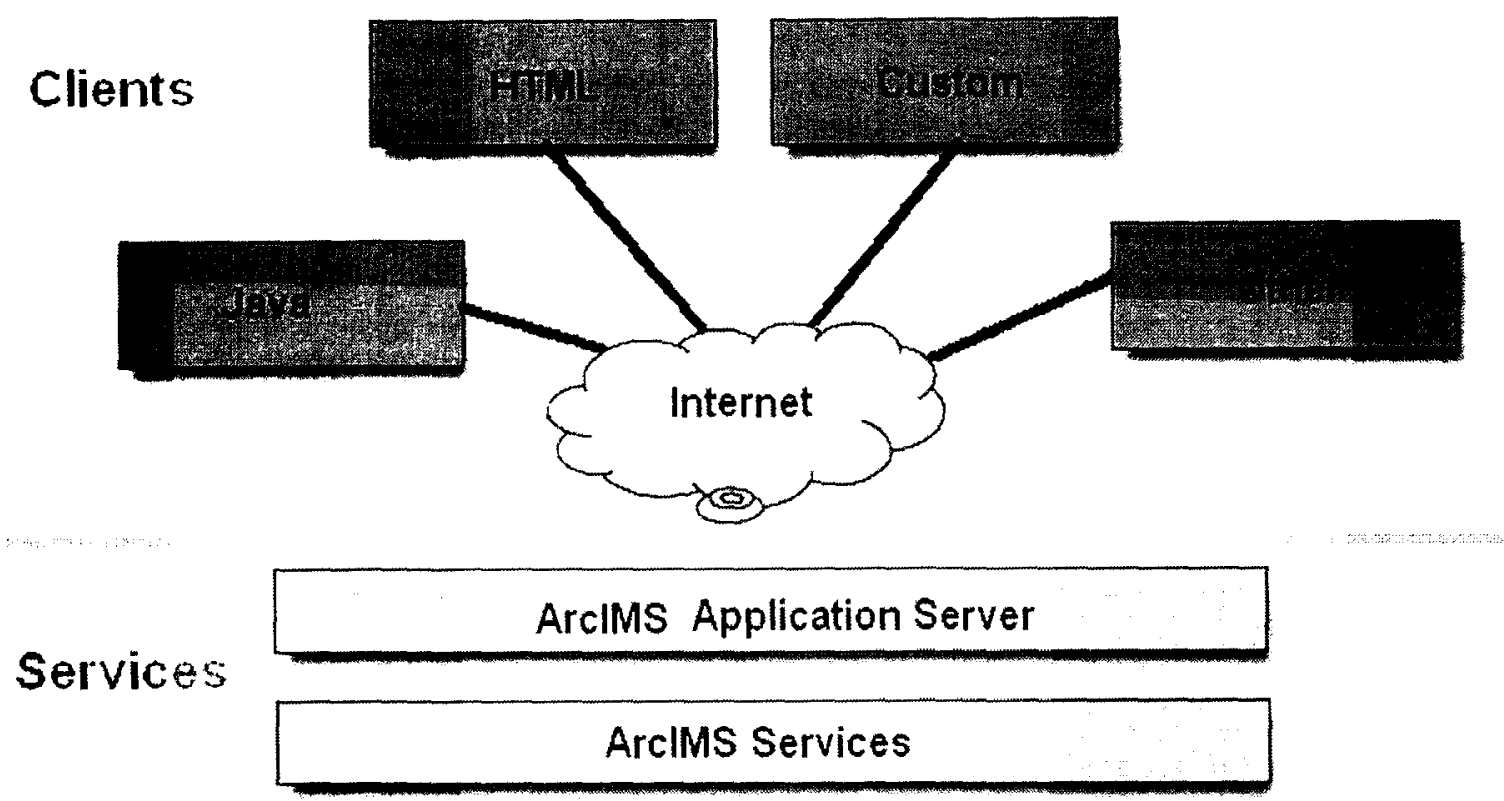

\section{Data Management}

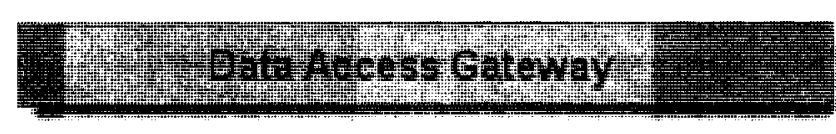

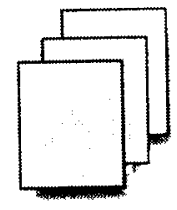

Local

files

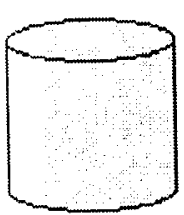

Enterprise

Figure 4.2 ArcIMS Three-Tier Architecture (Source: ESRI, 2003)

The presentation tier is the interface that users can access, analyze and interact with the maps and data. ArcIMS provides three standard viewers: one HTML viewer and two Java viewers. The business logic tier is used for handling requests and administering the ArcIMS site. The server-side components included the ArcIMS Web server, application server, application server connectors, and the ArcIMS manager. The ArcIMS site management applications provide access to components in the business logic tier for 
authoring maps, administering ArcIMS services, Spatial Servers, and designing Web sites. The data tier includes data sources available for use with ArcIMS (ESRI, 2005).

ArcIMS consists of three major applications: Author, Administrator and Designer. Author is used to define the content and appearance for a map that the user wants to publish on the Internet. The outcome from Author is a map configuration file (.AXL file) containing all the definitions of the map layers and symbology. The AXL file is written in ArcXML, an extensible markup language (XML) used specifically for creating Webbased products in ArcIMS (ESRI, 2005; ESRI Virtual Campus, 2005a).

After authoring the map, a map service can be created and started in Administrator. Administrator also manages the website, folders and servers and monitors the performance of the website. The Designer can create websites that allow users to access map services. Either a HTML or a Java viewer can be chosen, and tools and functionality provided through the viewer can be defined at Designer (ESRI Virtual Campus, 2004a).

\section{HTML Viewer vs. Java Viewer}

The viewer is the interface that audience will see and use to interact with the map. A major decision to make while creating an ArcIMS application is the choice of a proper client viewer. ArcIMS provided three standard viewers that can be generated using ArcIMS Designer: HTML Viewer, Java Standard Viewer and Java Custom Viewer. The choice is largely dependent on who is the audience, how much processing will be allowed 
at the client side, how much time and effort the audience would make to view the map and data. Generally speaking, HTML Viewer has lower requirements at the client side, less functionality and is easier to use. Java Viewer has more functionality and more processing at the client side, but normally requires downloading a plug-in or applet before viewing or interacting with the map (ESRI, 2003; ESRI Virtual Campus, 2004a). The differences between these viewers are listed in Table 4.2.

Table 4.2: A Comparision of ArcIMS Standard Viewers

\begin{tabular}{|c|c|c|}
\hline & HTML Viewer & Java Viewers \\
\hline Browser support & $\begin{array}{l}\text { Internet Explorer or } \\
\text { Netscape version } 4 . x \text { or } \\
\text { higher; can be } \\
\text { embedded into any } \\
\text { HTML website }\end{array}$ & $\begin{array}{l}\text { The Java Custom Viewer is supported } \\
\text { only on Internet Explorer version 4.x or } \\
\text { higher; The Java Standard Viewer is } \\
\text { supported on Netscape and Internet } \\
\text { Explorer versions } 4 . x \text { and higher }\end{array}$ \\
\hline Client side & $\begin{array}{l}\text { Little processing, } \\
\text { Thin/Light client }\end{array}$ & $\begin{array}{l}\text { Needs JRE, Java } 2 \text { plug-in or applet } \\
\text { support; Thick/heavy client; More } \\
\text { processing is supported }\end{array}$ \\
\hline Server side & Almost all & Processing Server data \\
\hline $\begin{array}{l}\text { Map service } \\
\text { support }\end{array}$ & $\begin{array}{l}\text { Only one main image } \\
\text { service and an } \\
\text { overview map service }\end{array}$ & Image and/or feature service \\
\hline Functionality & $\begin{array}{l}\text { Less: (i.e. editing } \\
\text { functions) }\end{array}$ & $\begin{array}{l}\text { More, including adding EditNotes, } \\
\text { Maptips and MapNotes }\end{array}$ \\
\hline Customizable & $\begin{array}{l}\text { Highly customizable; } \\
\text { code is completely } \\
\text { open for developers to } \\
\text { edit and customize }\end{array}$ & $\begin{array}{l}\text { Java Standard Viewer: No; } \\
\text { Java Custom Viewer: Yes }\end{array}$ \\
\hline $\begin{array}{l}\text { Able to use local } \\
\text { data? }\end{array}$ & No & Yes \\
\hline Comments & Efficient and easy to & More functionality and complicated; \\
\hline
\end{tabular}




\begin{tabular}{|l|l|l|}
\hline & $\begin{array}{l}\text { use; Good for general } \\
\text { public use }\end{array}$ & Good for intranet use \\
\hline
\end{tabular}

(Source: ESRI, 2003; 2004; 2005a)

Other options provided by ArcIMS include building viewers with one of the ArcIMS application server connectors: the ActiveX connector, ColdFusion connector or Java connector. In addition, a free map viewer ArcExplorer can be downloaded from the ESRI website. It can be used on its own with local data sets or as a client to the Internet data and map servers (ESRI, 2004).

\section{HTML Viewer}

The HTML Viewer, consisting of HTML and JavaScript, must be downloaded to the client. While this client is thinner than the Java Viewer, thin or thick describes the amount of data downloaded to the browser.

The HTML Viewer's robust functionality is one of the most compelling reasons to select it as the viewer of the FSAR system. This functionality can be extended using a combination of Dynamic HTML (DHTML), JavaScript, XML, and other techniques. On the server side, ASP.NET is used with the HTML Viewer without using the connectors. The HTML Viewer supports Image MapServices. Image MapServices send a snapshot of the data in JPEG, TIFF, or PNG format to the client. The data are not streamed as with Feature MapServices. 


\subsection{Design of WebGIS Major Functions}

According to the requirement analysis described in Section 3.2, the server-side WebGIS application is composed of three distinct components: Common GIS Mapping Tools, Ontario Search Engine Tools, and Reporting Tools. This section will address the conceptual design of the three functions for the FRAS system.

\subsubsection{Common GIS Mapping Tools}

Common GIS Mapping Tools are customized from the standard HTML viewer. The customization is implemented by HTML and JavaScript programming. After customization of the HTML viewer, the functions of the developed Common GIS Mapping Tools are summarized in Table 4.3.

Table 4.3 Common GIS Mapping Tools Description

\begin{tabular}{|c|c|}
\hline Tool name & \multicolumn{1}{c|}{ Description after customization } \\
\hline Zoom in & $\begin{array}{l}\text { An icon of the magnifying glass with the plus sign is used to } \\
\text { zoom in on a point or zoom into a selected area. The map } \\
\text { contents will change based on the level of zoom. As user zooms } \\
\text { in, the map panel will display more details. } \\
\text { To zoom in on a point, select the zoom in tool on the toolbar. } \\
\text { Click on a point on the map, which will be centered on the } \\
\text { magnification. Each click increases the map scale, centering the } \\
\text { new map around the point clicked. A scale bar is shown at the }\end{array}$ \\
\hline
\end{tabular}




\begin{tabular}{|c|c|}
\hline & $\begin{array}{l}\text { bottom right of the map panel. } \\
\text { To zoom in on a selected area click/hold/drag the mouse. Once } \\
\text { the mouse button is released the rectangle will disappear and the } \\
\text { map will zoom to the specific area. }\end{array}$ \\
\hline Zoom Out & $\begin{array}{l}\text { An icon of the magnifying glass with the minus sign is used to Zoom } \\
\text { out. As user zooms out the map contents will change to display } \\
\text { more or less information within the map window. } \\
\text { To zoom out on a point. select the zoom out tool from the toolbar. } \\
\text { Click on a point on the map, which will be centered on the } \\
\text { magnification. Each click decreases the map scale, centering the } \\
\text { new map around the point clicked. At the maximum extents of the } \\
\text { map window the map will not zoom out any more. }\end{array}$ \\
\hline Zoom to Last & $\begin{array}{l}\text { An icon of the magnifying glass with the arrow is the zoom to last } \\
\text { extent. Clicking this icon will revert the map window to the } \\
\text { previous map extents. }\end{array}$ \\
\hline Full Extents & $\begin{array}{l}\text { The Full Extents tool is equivalent to zooming out to the maximum } \\
\text { extent. It displays the full map area in the map panel. The new map } \\
\text { scale of the map is indicated in the bottom left corner of the map } \\
\text { window. }\end{array}$ \\
\hline Pan & $\begin{array}{l}\text { The pan tool should show as a hand icon. The pan tool is used to } \\
\text { display adjacent map information on all panning directions. Select } \\
\text { the pan tool on the toolbar. Move the mouse onto the map panel } \\
\text { with the user's finger down, and drag in the direction in which you }\end{array}$ \\
\hline
\end{tabular}




\begin{tabular}{|c|l|}
\hline Identify & $\begin{array}{l}\text { want to move the map. } \\
\text { displays textual information about map features; all map features } \\
\text { have associated information that is stored in a database. Information } \\
\text { from the database can be displayed by clicking on the map feature } \\
\text { with the information tool. }\end{array}$ \\
\hline Select By & $\begin{array}{l}\text { The tool allows the user to select a feature from the layer that is } \\
\text { currently active. }\end{array}$ \\
\hline Zoom to active & This tool sets the map window extents, the maximum extents of the \\
lactive layer in the layer control.
\end{tabular}




\subsubsection{Ontario Search Engine Tools:}

Based on the user requirement analysis, a lot of efforts have been made in this study to make the developed WebGIS system easy for users to search locations with the user interface. The user can just select the categories and quick zoom-in to the location without knowing the lakes or creeks to be searched (see Table 4.4).

Table 4.4 Description of the Ontario Search Engine Tools

\begin{tabular}{|l|l|}
\hline \multicolumn{1}{|c|}{ Search Tools } & \multicolumn{1}{|c|}{ Sub-Features for the Search Tools } \\
\hline Gazetteer Search & $\bullet$ Gazetteer Category List \\
& $\bullet$ Name List \\
& $\bullet$ Button: 'Zoom To' \\
\hline Topographic Search & $\bullet$ Topographic Category List \\
& $\bullet$ Name List \\
& - Button: 'Zoom To' \\
\hline Quick Zoom Search & $\bullet$ Agency List \\
& $\bullet$ District List \\
& $\bullet$ Button: 'Zoom To' \\
\hline
\end{tabular}

\subsubsection{Reporting Tools}

The Reporting Tools (see Table 4.5) are developed to display fish species listed by watershed ID, or by stream ID. By navigating to the area of interest with the navigation tools, the Web user can select the reporting tool, click on the watershed polygon or the 
stream segment and displays a report of fish species and species at risk found in that watershed or stream.

Table 4.5 Descriptions of Reporting Tools

\begin{tabular}{|c|c|}
\hline Reporting Tool & Report Output \\
\hline Reporting by Watershed & $\begin{array}{l}\text { - } \quad \text { Species at Risk Report } \\
\text { - } \quad \text { Species Listing Report }\end{array}$ \\
\hline Reporting by Stream Id & $\begin{array}{l}\text { - Species at Risk Report } \\
\text { - Species Listing Report }\end{array}$ \\
\hline $\begin{array}{l}\text { Show Species at Risk Info } \\
\text { for: the Species' }\end{array}$ & $\begin{array}{ll}\text { - } & \text { Fact Sheet } \\
\text { - } & \text { Species Drawing (image) } \\
\text { - } & \text { COSEWIC Report }\end{array}$ \\
\hline $\begin{array}{l}\text { District Species at Risk } \\
\text { Distribution Maps for: }\end{array}$ & $\begin{array}{l}\text { - } \text { Burlington } \\
\text { - Thunder Bay \&amp; Kenora } \\
\text { - Peterborough } \\
\text { - Prescott } \\
\text { - Parry Sound } \\
\text { - Sarnia } \\
\text { - Sault Ste Marie } \\
\text { - Sudbury } \\
\text { - } \quad \text { Whole Ontario } \\
\end{array}$ \\
\hline
\end{tabular}

\subsection{System Hardware and Software Design}

Selecting suitable software and hardware is an important step in a successful implementation of a WebGIS system. Software was evaluated on functionality and performance, as well as independency of the hardware and operating system. WebGIS requires specific hardware configuration, as well as software. Since the volume of transferred data is enormous, the speed of the Internet connection is vitally important. 
Based on a pilot project which was done separately in DFO, and the experience gained through similar projects, a powerful computer with the hardware and system software configurations (see Table 4.6) are recommended requirement for this thesis study.

Table 4.6 Configuration of the FARS Server System

\begin{tabular}{|l|l|l|}
\hline \multirow{4}{*}{ Hardware } & \multicolumn{1}{|c|}{ Configuration Item } & \multicolumn{1}{c|}{ FSAR System Configuration } \\
\hline \multirow{5}{*}{ Software } & Server & Dell PowerEdge 2850 \\
\cline { 2 - 3 } & CPU & Intel P4 Dual Processor \\
\cline { 2 - 3 } & Memory & 1000 Mega Bytes \\
\cline { 2 - 3 } & Hard drive & 120 GB \\
\cline { 2 - 3 } & Internet connection & T1 (or better) \\
\hline & Operating system (OS) & Microsoft Windows 2003 Server \\
\cline { 2 - 3 } & Web sever & Microsoft Information Server 5.0 \\
\cline { 2 - 3 } & Servlet engine & Tomcat Servlet 5.0 \\
\cline { 2 - 3 } & Map server & ESRI ArcIMS 9.0 \\
\hline
\end{tabular}

Based on the functional capabilities, vendor support, cost, maintenance fee, a survey was conducted over the available hardware and software on the market. After the survey, all the hardware and software were purchased, and all necessary renovation of space and wiring were carried out (see Table 4.7).

Table 4.7 Configurations of Geodatabase (ArcSDE) Server

\begin{tabular}{|l|l|l|}
\hline \multirow{4}{*}{ Hardware } & \multicolumn{1}{|c|}{ Configuration Item } & \multicolumn{1}{c|}{ FSAR System Configuration } \\
\cline { 2 - 3 } & Server & Dell PowerEdge 2850 \\
\cline { 2 - 3 } & Memory & Intel P4 Dual Processor \\
\cline { 2 - 3 } & Hard drive & 1000 Mega Bytes \\
\cline { 2 - 3 } & Internet connection & 240 GB \\
\hline
\end{tabular}




\begin{tabular}{|l|l|l|}
\hline \multirow{3}{*}{ Software } & Operating system (OS) & Microsoft Windows 2000 Server \\
\cline { 2 - 3 } & Database sever & Oracle 8.1.2 \\
\cline { 2 - 3 } & Geospatial database engine & ESRI ArcSDE 8.3 \\
\hline
\end{tabular}




\section{Chapter 5}

\section{Development of the FASR System}

Based on the user requirement analysis described in Chapter 3 and the conceptual design presented in Chapter 4, the WebGIS application is implemented in this Chapter. Section 5.1 describes the selection of suitable developing tools. Then, this chapter will give how to implement the common GIS mapping tools by customizing ArcIMS HTML viewer. The complex developments of the Ontario Search Engine Tools and the Reporting Tools are described in Sections 5.4 and 5.5 respectively.

\subsection{Software Development Tools}

\section{Client-side Techniques: HTML, DHTML, JavaScript}

On the client side, ArcIMS HTML viewer includes HTML files and JavaScript files, which form the foundation of the HTML Viewer. HTML files are used to generate Web page content, and the JavaScript functions can also be modified to include custom functionality such as the use of JavaScript to create the map requests and to interpret the results.

For the above reasons, HTML, DHTML and JavaScript are selected as the client-side programming language. 


\section{Server-side Techniques: IIS, ArcIMS, .NET}

On the server side, before performing geospatial query, the application has to connect to non-geospatial database to get the web page configurations. To select rapid application development tools, Microsoft ASP.NET and C\# are selected as the programming languages, and Visual Studio.NET as the programming environment.

\subsection{Customizing the HTML Viewer Parameters}

In order to satisfy FSAR viewer needs, customization is needed for the standard HTML viewer created from ArcIMS Designer. ArcIMS website is composed of a series of HTML and JavaScript files recording and managing the layout and functions of the website. These files can be classified into the following categories:

- HTML files that define the layout of HTML pages;

- Image files used in the WebPages display elements;

- A special JavaScript parameter file - ArcIMSparam.js. The file stores preferences selected in Designer as well as many other variables that affect the Web site's look and functionality;

- The JavaScript folder contains the HTML viewer JavaScript Library, a series of JavaScript files used to create ArcXML requests and process ArcXML responses from the ArcIMS spatial server (ESRI 2002c). 
When creating FSAR WebGIS site, the ArcIMSparam.js file is the first file to modify. ArcIMSparam.js can be found in the Web site directory and is well documented. It contains global variables defining both the look and behavior of the Web site, and GIS developer can do a significant amount of customization by modifying these variables. Descriptions of the variables are found in ESRI's JavaScript Library documentation.

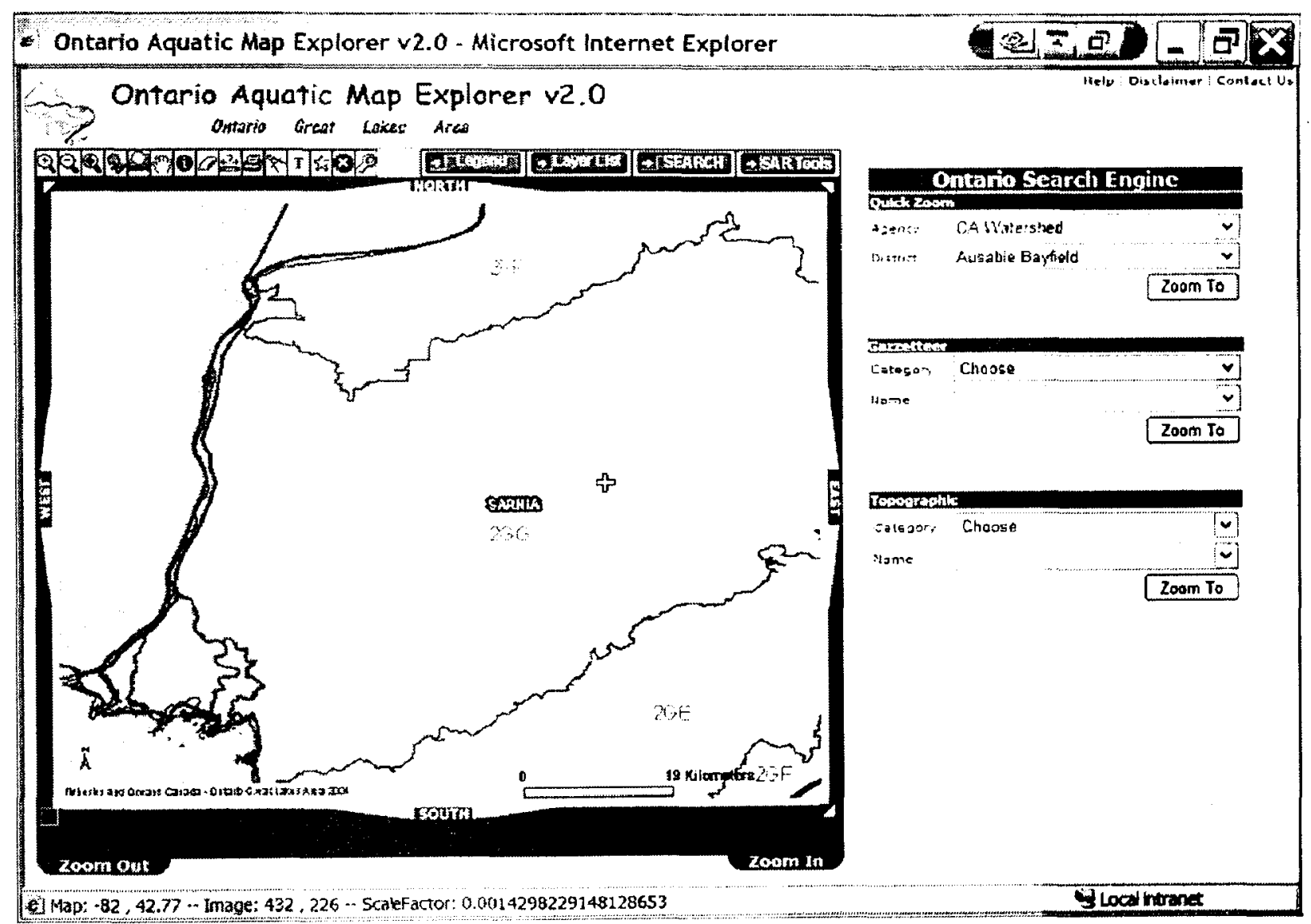

Figure 5.1 Customized Viewer of the FSAR system

All variables can be altered either directly or through DHTML to produce a custom look. ArcIMSparam.js includes variables for

- Changing services and map-extents;

- Setting the initial display of the legend; 
- Defining North arrows and copyright text on an acetate layer;

- Defining fields for attribute display;

- Changing tools and the toolbar;

- Inserting FSAR logo;

- Returning unique values only;

- Allowing queries;

- Displaying a second scale-bar;

After JavaScript and HTML are programmed and setup, the parameters of the standard HTML viewer, a customized FSAR viewer, can be seen in Figure 5.1. Most of the common GIS mapping tools, such as zoom-in, zoom-out and pan, have been customized and implemented.

\subsection{Implementation of Query Functions}

\subsubsection{Gazetteer Search}

Users can select a gazetteer item from category drop-down list (see Table A.1), i.e. City. The list of 'Name' will be updated with the category (i.e. City). See Gazetteer Search interface in Figure 5.2. 


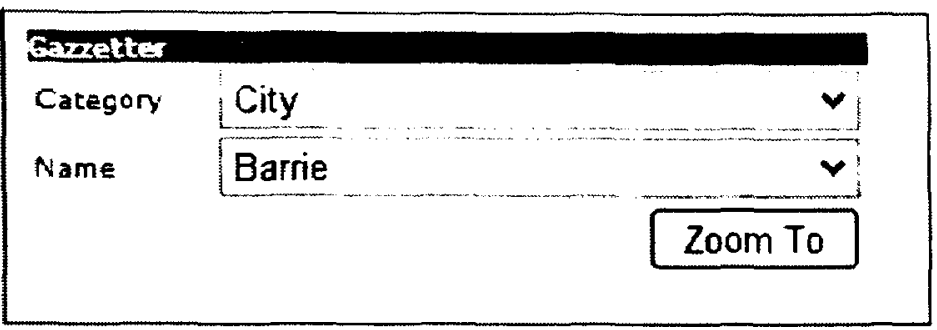

Figure 5.2 Gazetteer Search

The above function was implemented in C\# of Microsoft Visual Studio.NET. When Gazetteer search page is loaded from web site, the function of Page_load (see the code Table A.2) is called. After the web browser receives the Gazetteer search page and the user selects a gazetteer category (e.g. 'City'), the function of RefreshName (also in Table A.2) is called. The control of Name is filled with all city names of Ontario.

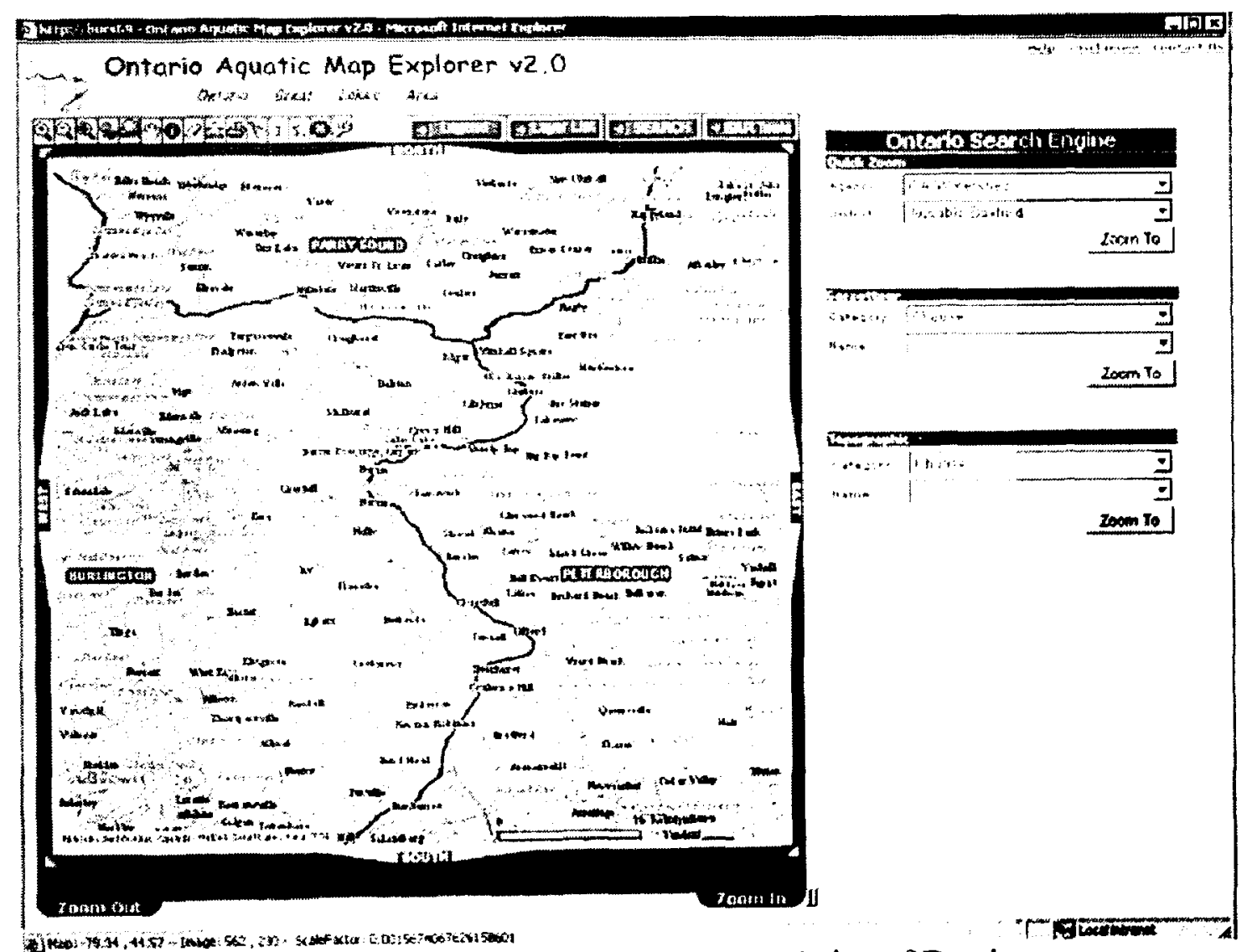

Figure 5.3 Gazetteer Search: 'ZoomTo' city of Barrie 
When user clicks 'Zoom to', the map will zoom to wherever the user selected, i.e. the city of Barrie (see Figure 5.3). Since the viewer is an HTML viewer, the function of button 'Zoom To' is implemented in JavaScript, and the JavaScript code can be found in "see the code" Table A.3.

\subsubsection{Topographic Search Tool}

With the Topographic Search tools (see Figure 5.4), a topographic item (e.g., Hydrography) can be selected from the category drop-down list (see Table B.1). The list of Name will be updated with the entire Hydrography items from category lookup table (see Figure A.2). After selecting a topographic feature, i.e. Dace Lake, the map will zoom to Dace Lake. See Topographic Search interface in Figure 5.5.

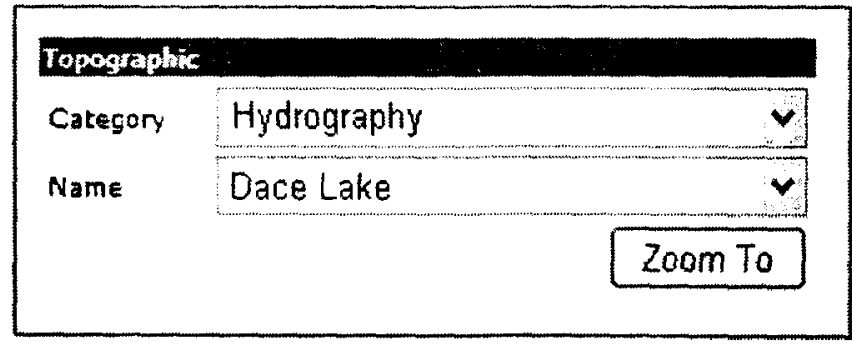

Figure 5.4 Topographic Search 


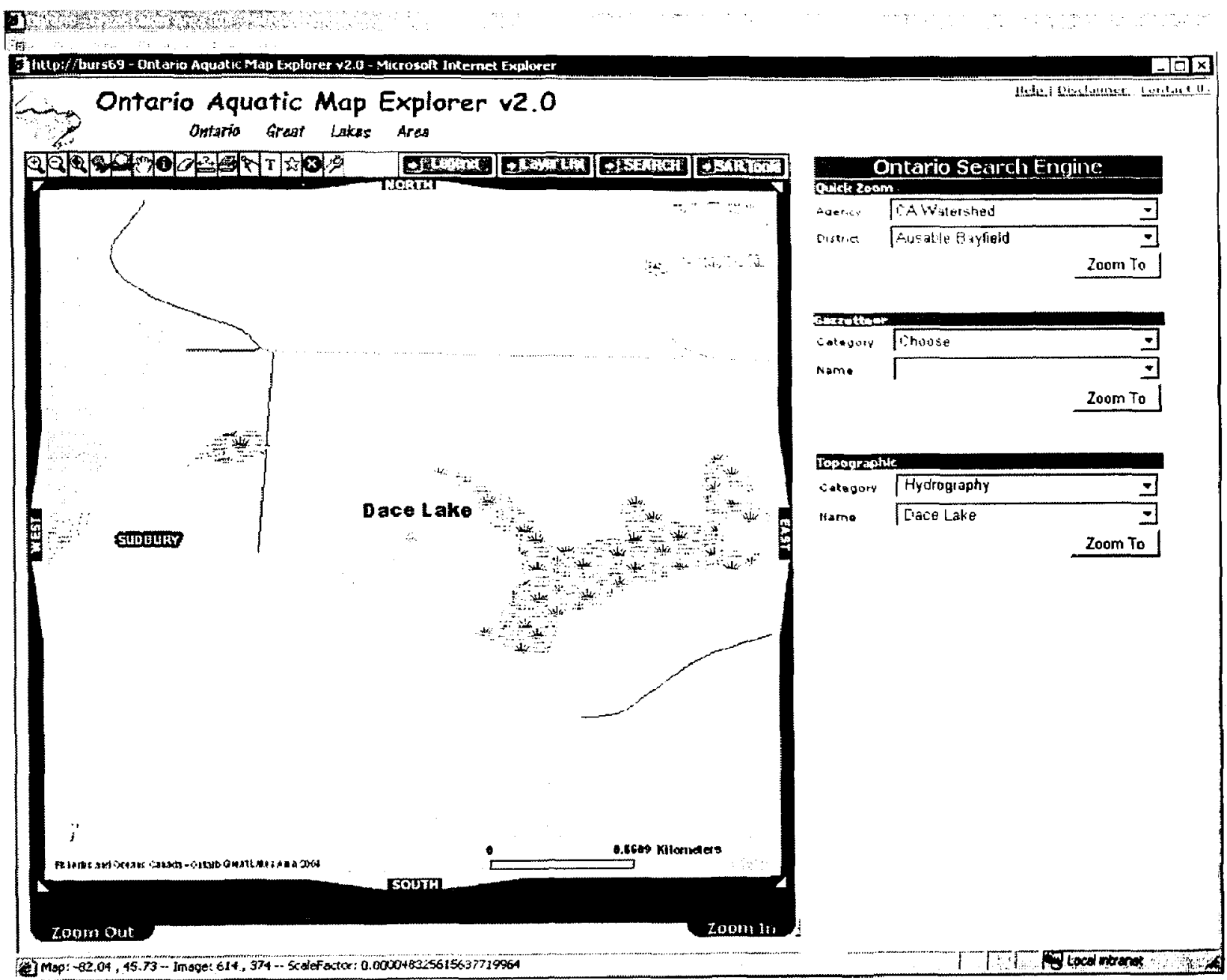

Figure 5.5 Topographic Search: 'ZoomTo' Dace Lake

\subsubsection{Quick Zoom Search}

The user can quickly choose categories from the three agencies: (1) CA Watershed, (2) OGLA District, and (3) OMNR District.

After selecting the agency of OGLA District (see Figure 5.6) $->$ Sarnia $->$ Zoom To, the map of Sarnia will show up (see Figure 5.7). 


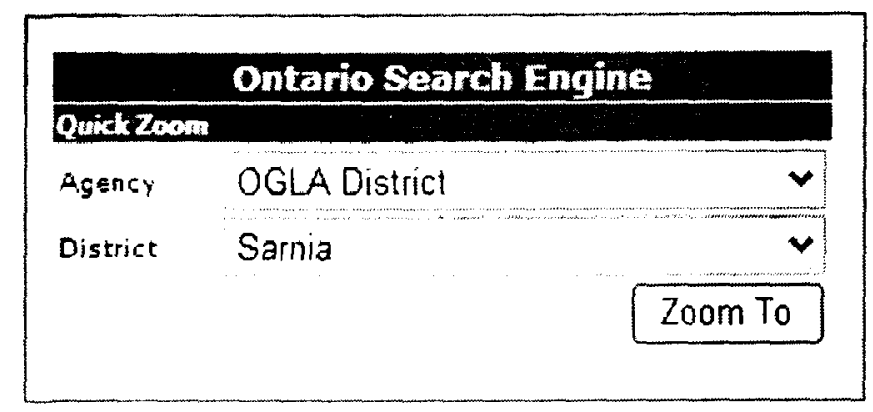

Figure 5.6 Quick Zoom Search

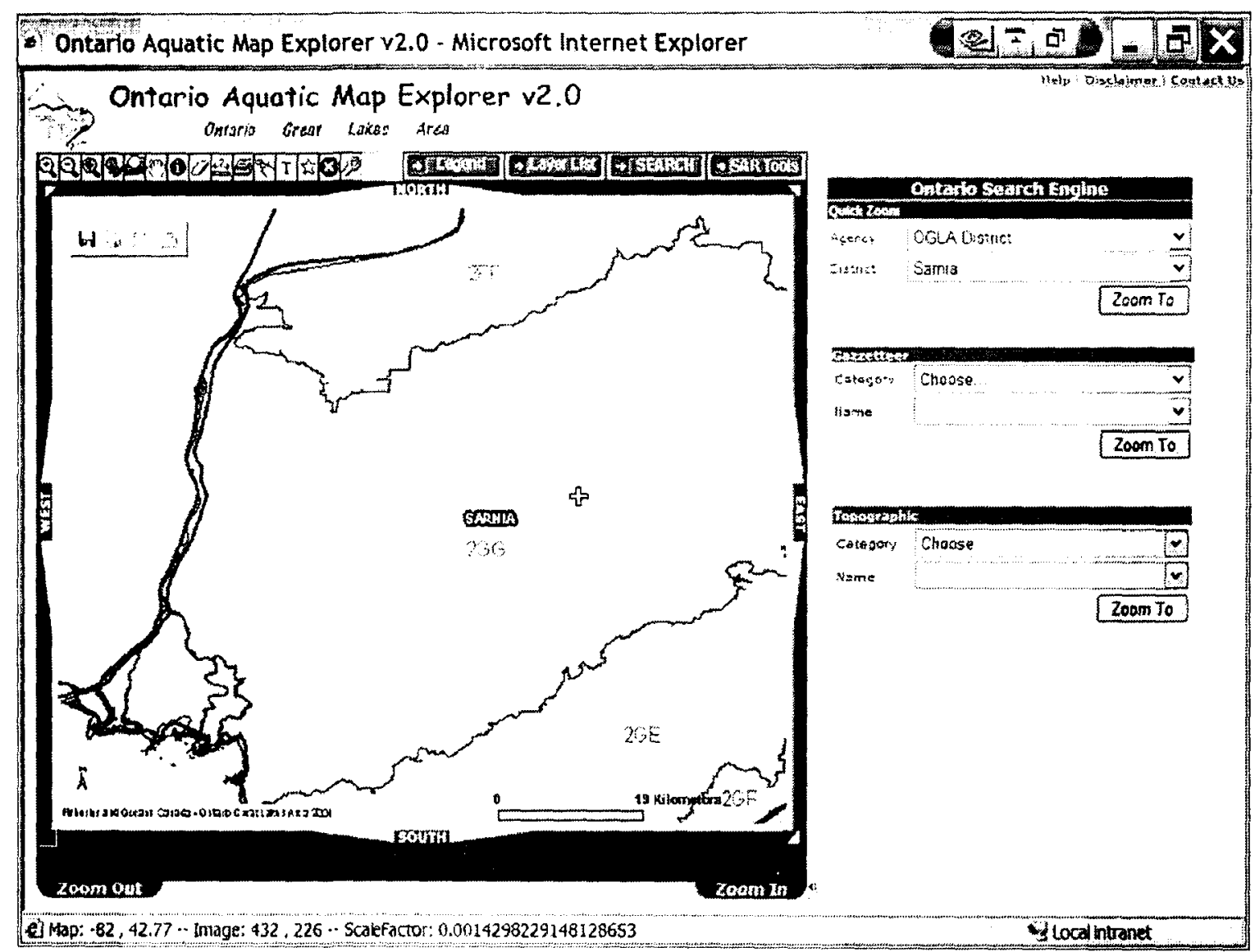

Figure 5.7 Quick ZoomTo the Map of "Sarnia"

The implementations of both the Topographic Search Tools and the Quick Zoom Search tools are similar to that of the Gazetteer Search Tools. Since this study does not focus on the algorithm development or programming, the code for both the Search Tools is listed in the Appendix. 


\subsection{Reporting Tools Implementation}

From the standpoint of implementation, the reporting tools can be divided into two types:

- Dynamic reporting: pulling the report data from database on the fly; and

- Static reporting: download the .pdf or fish image files to the users

\subsubsection{Dynamic Reporting}

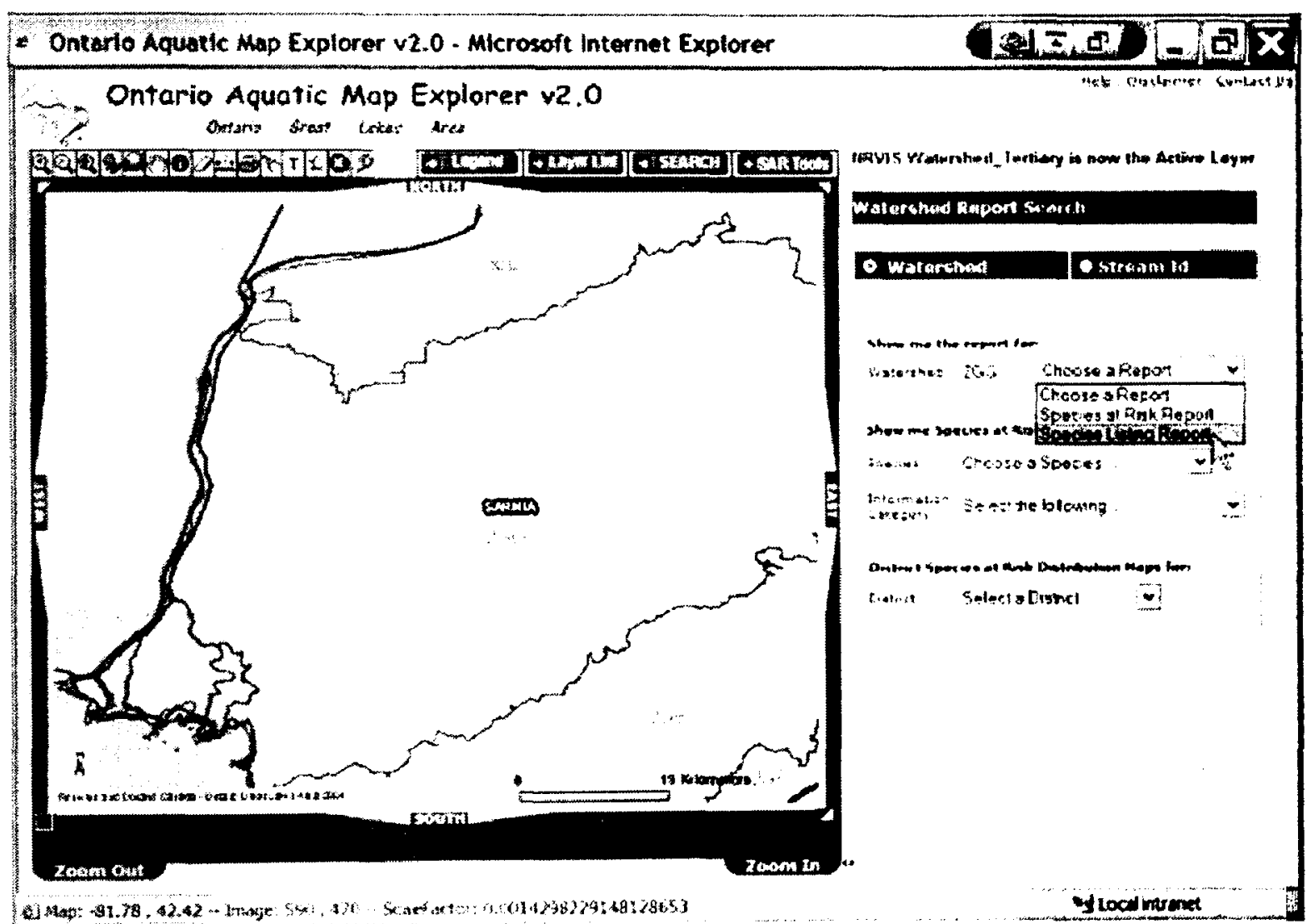

Figure 5.8 Reporting by Watershed

In the FSAR system, dynamic reporting tools include Reporting by Watershed and Reporting by Stream Id. To publish dynamic reports, both reporting tools use the same programming methods. The report itself is developed with Crystal Reports 9.0. To 
publish the report on the web, ASP.NET and C\# are used as developing tools and programming languages, respectively.

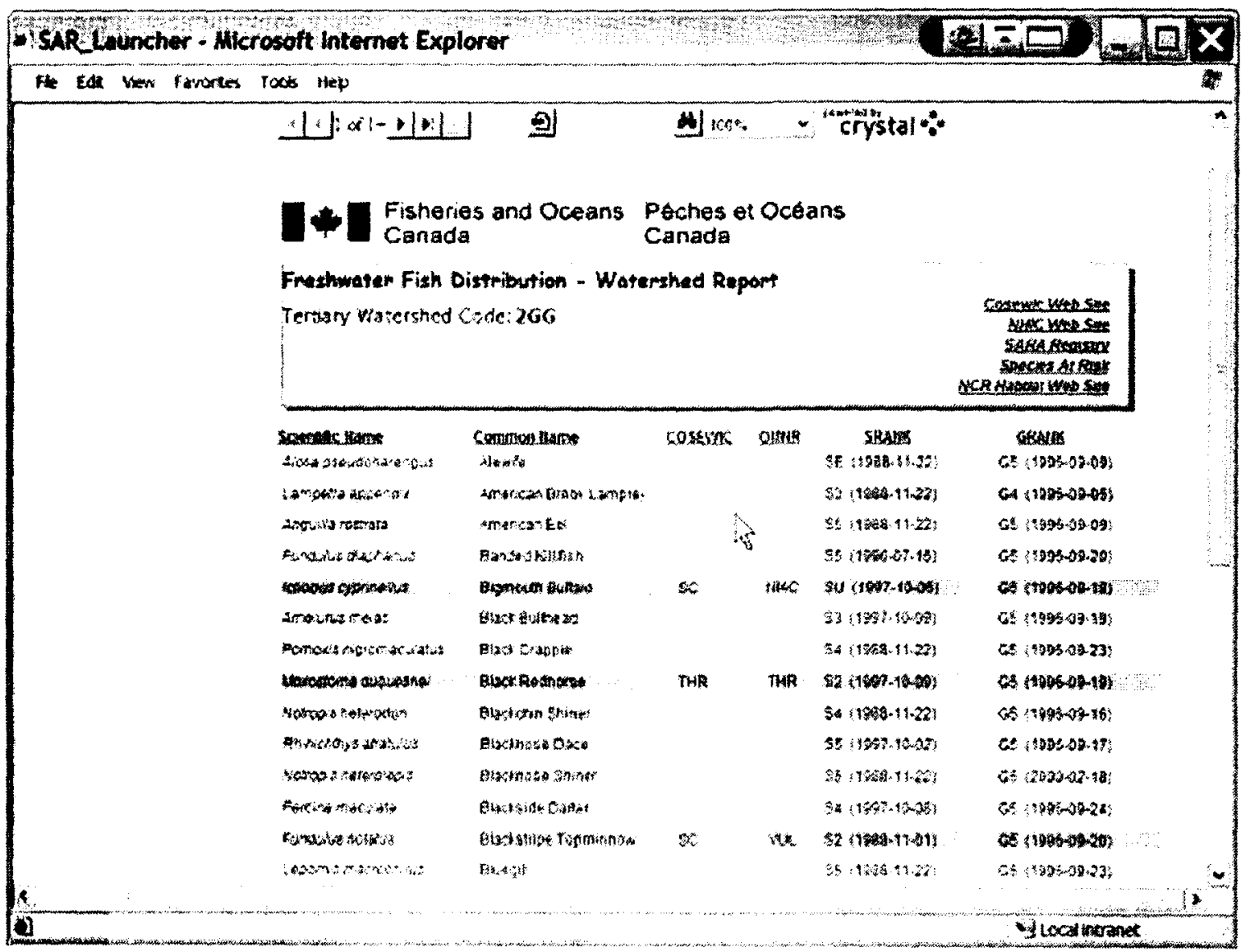

Figure 5.9 Report of fish distribution in watershed $2 \mathrm{GG}$

As shown in Figure 5.8, the user navigates to the area (e.g. Sarnia) of interest, selects the reporting tool (SAR Tools), clicks on the watershed polygon ( $2 \mathrm{GG}$ ) and displays a report of fish species and species at risk found in that watershed (see Figure 5.9).

In Figure 5.8, all fish species in the watershed $2 \mathrm{GG}$ are listed in the report. In the list, three species, Bigmouth Buffalo, Black RedHorse and Blackstripe Topminnow, are highlighted in yellow. This means the three fish species are at risk in the watershed $2 \mathrm{GG}$. 
From Chapter 5 on Global Rank (GRANK) and Provincial Rank (SRANK), users can see how serious the risk is.

\subsubsection{Static Reporting}

Species at Risk Info, Species Drawings (images), and Species at Risk Distribution Maps are static reporting tools (see Figure 5.10). The reports are published in pdf or image format. When the user selects the species static reports, the pdf file will download to user's browser.

- SAR_Luncher - Mkcrosort Internet Explorer

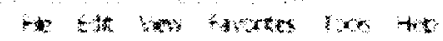

Fisheries and Oceans Péches et Océans

Canada

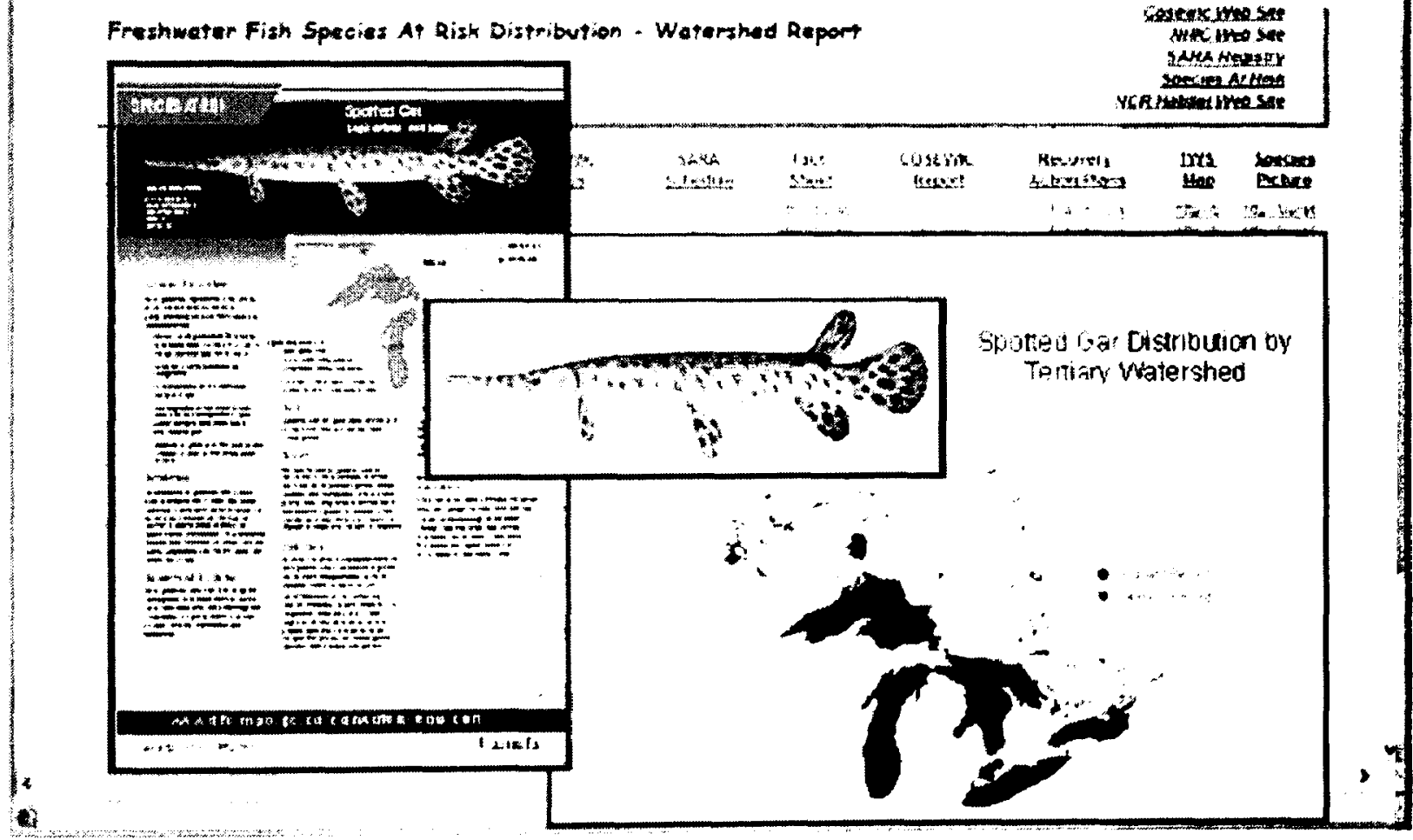

Figure 5.10 Static Reporting 
The final step in WebGIS implementation was to put the system to use. With system integration and testing completed and all applications available for use, the system was released to users. Two activities were in place:

- User support and service, in which new applications will be determined, and

- System maintenance (database, hardware, software), in which the WebGIS must run smoothly.

\subsection{Data and GeoDatabase}

Based on the database design described in Chapter 4 and data source availability, there are three methods for creating a geodatabase (MacDonald, 1999).

- Creating a new geodatabase from scratch;

- Migrating existing data into the geodatabase;

- Building a geodatabase with CASE tools;

\subsubsection{The FSAR Database Development}

In the study, migrating existing data into geodatabase is a major approach to implement the FSAR geodatabase. As shown in Figure 5.11, an ArcSDE geodatabase (OntMXD_Live) was created, taking into account of user requirements and geospatial data needs. The geospatial and non-geospatial data from OMNR, DFO and NTDB were migrated in the geodatabase. There are 18 feature classes that are defined with the same projection in the geodatabase. Tools used for data processing included ArcCatalog 9.0, ArcMap 9.0, ArcToolbox 9.0 and ArcSED 8.3. Besides feature classes in the 
geodatabase, there are four tables containing different types of fish species distribution data for the FSAR system.

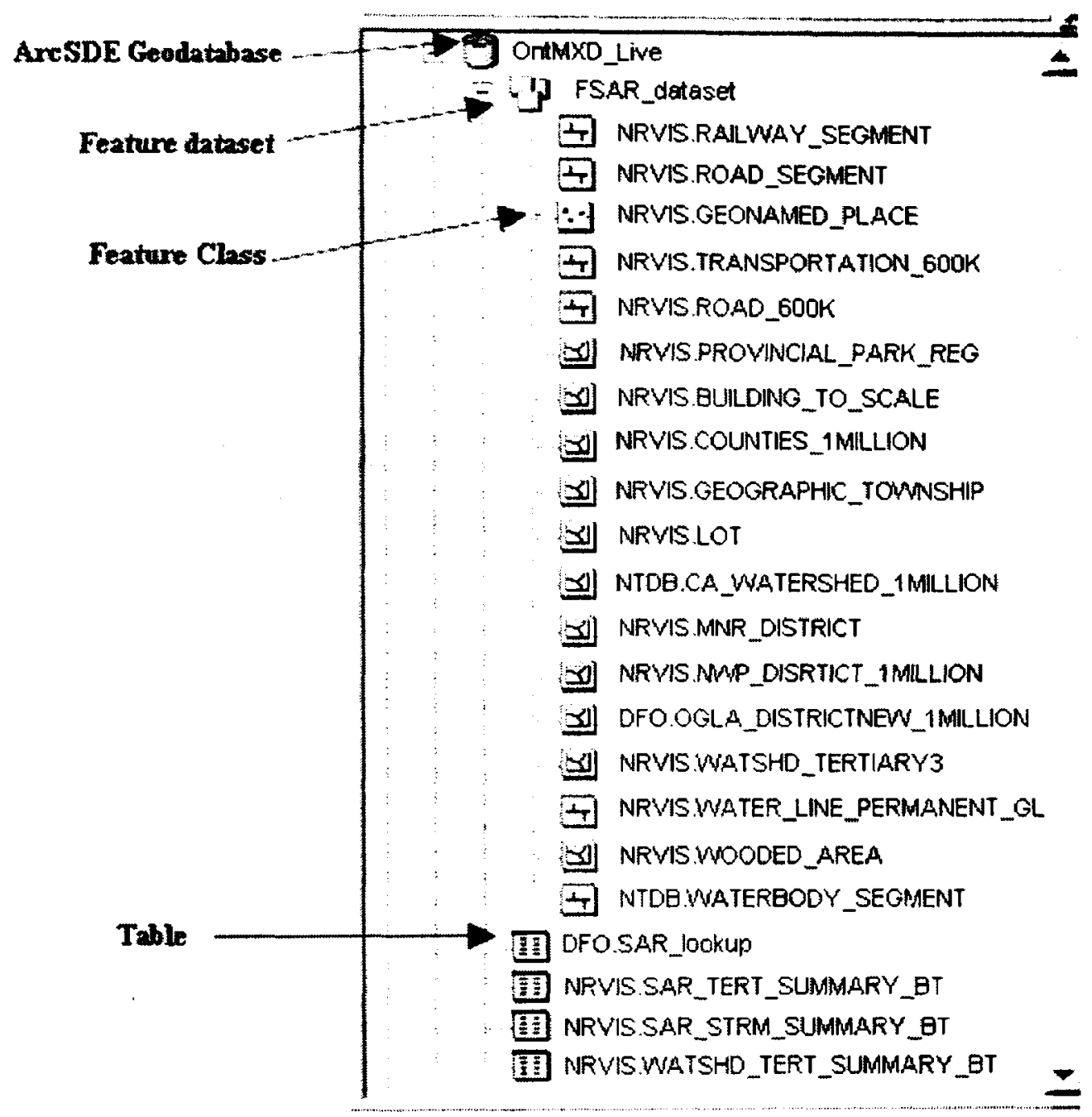

Figure 5.11 FSAR Geodatabase Implementation

Since the FASR system provides fish species data, the tables of 'SAR_lookup', 'SAR_STRM_SUMMARY_BT', and 'SAR_TERT_SUMMARY_BT' are the sources for fish species at risk data based on Global Rank (GRANK) or Provincial Rank (SRANK) as described in the following section. Most SAR data are updated monthly, but some of them are updated either monthly or yearly. History data could be dated back for about 10 
years, and some species could be more than 30 years. The table structure of SAR_lookup, SAR_TERT_SUMMARY_BT and SAR_STRM_SUMMARY_BT can be found in Table C.1, C2 and C3 within Appendix C.

\subsubsection{Global Rank (GRANK) and Provincial Rank (SRANK)}

It is important to understand how species at risk are defined and categorized. In Ontario, "species at risk" are categorized as extinct, extirpated, endangered, threatened, or vulnerable species or a "species of special concern".

\section{Global Rank}

Global ranks (GRANK) are assigned by a consensus of the network of natural heritage programs CDCs (conservation data centres), scientific experts, and The Nature Conservancy (www.tnc.org). This network designates a 'rarity rank' based on the rangewide status of a species, subspecies or variety.

Table 5.1 Global Rank (MNR Ontario, 2005a)

\begin{tabular}{|c|l|}
\hline GRANK & \multicolumn{1}{|c|}{ Definition } \\
\hline G1 & $\begin{array}{l}\text { Extremely rare; usually } 5 \text { or fewer occurrences in the overall range or very } \\
\text { few remaining individuals; or because of some factor(s) making it especially } \\
\text { vulnerable to extinction. }\end{array}$ \\
\hline G2 & $\begin{array}{l}\text { Very rare; usually between } 5 \text { and } 20 \text { occurrences in the overall range or with } \\
\text { many individuals in fewer occurrences; or because of some factor(s) making } \\
\text { it vulnerable to extinction. }\end{array}$ \\
\hline
\end{tabular}




\begin{tabular}{|c|l|}
\hline $\mathbf{G 3}$ & $\begin{array}{l}\text { Rare to uncommon; usually between } 20 \text { and } 100 \text { occurrences; may have fewer } \\
\text { occurrences, but with a large number of individuals in some populations; may } \\
\text { be susceptible to large-scale disturbances. }\end{array}$ \\
\hline G4 & $\begin{array}{l}\text { Common; usually more than } 100 \text { occurrences; usually not susceptible to } \\
\text { immediate threats. }\end{array}$ \\
\hline G5 & Very common; demonstrably secure under present conditions. \\
\hline GH & Historic, no records in the past 20 years. \\
\hline GU & Status uncertain, often because of low search effort or cryptic nature of the \\
& species; more data needed. \\
\hline GX & Globally extinct. No recent records despite specific searches. \\
\hline $\mathbf{P}$ & Denotes inexact numeric rank (i.e. G4?). \\
\hline $\mathbf{G}$ & A "G" (or "T") followed by a blank space means that the NHIC has not yet \\
\hline $\mathbf{G}$ & obtained the Global Rank from The Nature Conservancy. \\
\hline $\mathbf{Q}$ & Unranked, or, if following a ranking, rank tentatively assigned (e.g. G3?). \\
\hline
\end{tabular}

\section{Provincial Rank}

Provincial (or Subnational) ranks (SRANK) are used by the Natural Heritage Information Centre (NHIC) to set provincial protection priorities for rare species and rare natural communities. 
Table 5.2 Provincial Rank (MNR Ontario, 2005b)

\begin{tabular}{|c|c|}
\hline SRANK & Definition \\
\hline S1 & $\begin{array}{l}\text { Extremely rare in Ontario; usually } 5 \text { or fewer occurrences in the province } \\
\text { or very few remaining individuals; often especially vulnerable to } \\
\text { extirpation. }\end{array}$ \\
\hline $\mathbf{S 2}$ & $\begin{array}{l}\text { Very rare in Ontario; usually between } 5 \text { and } 20 \text { occurrences in the } \\
\text { province or with many individuals in fewer occurrences; often } \\
\text { susceptible to extirpation. }\end{array}$ \\
\hline $\mathbf{S 3}$ & $\begin{array}{l}\text { Rare to uncommon in Ontario; usually between } 20 \text { and } 100 \text { occurrences } \\
\text { in the province; may have fewer occurrences, but with a large number of } \\
\text { individuals in some populations; may be susceptible to large-scale } \\
\text { disturbances. Most species with an S3 rank are assigned to the watch list, } \\
\text { unless they have a relatively high global rank. }\end{array}$ \\
\hline S4 & $\begin{array}{l}\text { Common and apparently secure in Ontario; usually with more than } 100 \\
\text { occurrences in the province. }\end{array}$ \\
\hline S5 & Very common and demonstrably secure in Ontario. \\
\hline SH & $\begin{array}{l}\text { Historically known from Ontario, but not verified recently (typically not } \\
\text { recorded in the province in the last } 20 \text { years); however suitable habitat is } \\
\text { thought to be still present in the province and there is reasonable } \\
\text { expectation that the species may be rediscovered. }\end{array}$ \\
\hline $\mathbf{C}$ & $\begin{array}{l}\text { Captive/Cultivated; existing in the province only in a cultivated state; } \\
\text { introduced population not yet fully established and self-sustaining. }\end{array}$ \\
\hline $\mathbf{S ?}$ & $\begin{array}{l}\text { Not Ranked Yet, or if following a ranking, Rank Uncertain (e.g. S3?). S? } \\
\text { species have not had a rank assigned. }\end{array}$ \\
\hline
\end{tabular}




\begin{tabular}{|c|c|}
\hline $\mathbf{S A}$ & $\begin{array}{l}\text { Accidental; of accidental or casual occurrence in the province; far } \\
\text { outside its normal range; some species may occasionally breed in the } \\
\text { province. }\end{array}$ \\
\hline SAB & Breeding accidental. \\
\hline SAN & Non-breeding accidental. \\
\hline SE & Exotic; not believed to be a native component of Ontario's fish. \\
\hline SR & $\begin{array}{l}\text { Reported for Ontario, but without persuasive documentation which } \\
\text { would provide a basis for either accepting or rejecting the report. }\end{array}$ \\
\hline SRF & Reported falsely from Ontario. \\
\hline SU & $\begin{array}{l}\text { Unrankable, often because of low search effort or cryptic nature of the } \\
\text { species, there is insufficient information available to assign a more } \\
\text { accurate rank; more data is needed. }\end{array}$ \\
\hline SX & $\begin{array}{l}\text { Apparently extirpated from Ontario, with little likelihood of rediscovery. } \\
\text { Typically not seen in the province for many decades, despite searches at } \\
\text { known historic sites. }\end{array}$ \\
\hline SZ & $\begin{array}{l}\text { Not of practical conservation concern inasmuch as there are no clearly } \\
\text { definable occurrences; applies to long distance migrants, winter vagrants, } \\
\text { and eruptive species, which are too transitory and/or dispersed in their } \\
\text { occurrence(s) to be reliably mapped; most such species are non-breeders, } \\
\text { however, some may occasionally breed. }\end{array}$ \\
\hline SZB & Breeding migrants/vagrants. \\
\hline SZN & Non-breeding migrants/vagrants. \\
\hline
\end{tabular}




\subsubsection{DFO Schedules}

Fisheries and Ocean Canada uses a schedule list for the protection priorities for species at risk.

Table 5.3 DFO Schedule Rank

\begin{tabular}{|l|l|}
\hline \multicolumn{1}{|c|}{ Schedule rank } & \multicolumn{1}{|c|}{ The color of the stream segment (river) } \\
\hline Schedule 1 Species At Risk & Red: Recovery strategy development underway \\
\hline Schedule 2 Species At Risk & Yellow: Species are awaiting reassessment \\
\hline Schedule 3 Species At Risk & $\begin{array}{l}\text { Green: Same as Schedule 2, but need more } \\
\text { attention }\end{array}$ \\
\hline Non Species At Risk & Blue: Non Species At Risk \\
\hline
\end{tabular}




\section{Chapter 6}

\section{Conclusions and Recommendations}

This chapter outlines the conclusions derived from the results of this study. It also includes recommendations for future research and enhancement of the current system. In addition, recommendations are made in order to extend the use of the WebGIS solutions.

\subsection{Conclusions}

WebGIS and geospatial data are suitable for publishing the information of fish species at risk. In this study, interactive mapping tools are developed for biologists and environmental scientists to interact with GIS data. This thesis approached the reporting and sharing problems of environmental data through current WebGiS technology that would enable the users to navigate the geospatial data and get the aquatic information that are of interest to them. The following are the conclusions drawn from the study.

- This thesis study addressed the issue of searching the fish species data and reporting the fish species information by using the current WebGIS technology. The biologists and environmental scientists can search and report the information of fish species at risk in Ontario by interactive map operation.

- The thesis study result, the FSAR system, provides an easy and inexpensive way for the users to access fish species at risk information among the DFO offices and their 
partners in Ontario. It helps to improve user participation in the fish species management. In the long run, the availability of fish species at risk data is also expected to help planning species recovery process and decision-making for both the DFO and its partners.

- User requirement analysis is crucial to the development of the Web-based system. Since the rapid application (RAD) method was used in the study, the end-users could use some functions before the complete implementation of the FSAR system, and some new requirements could be created. At this time, the user requirement analysis documents should be updated. The development circle should re-start at user requirement analysis. The functionality, conceptual design, and implementation and test of the system are all based on it.

- The commercial ArcIMS software is a powerful tool for supporting the FSAR system development. The ArcIMS's HTML viewer provides a framework to customize. It helps the developers to meet most of the user's common GIS operation requirements.

- Reporting tools help a user to better understand fish species at risk characteristics. In the FSAR system, fish species at risk distribution changes as time changes. It publishes dynamic information.

- The result of the study: Ontario Aquatic Maps Explorer is running on the DFO Intranet and now it has more than one hundred users. The study objective has been reached. 


\subsection{Future Enhancement}

The FSRA system implemented in this study can be enhanced in many ways for publishing fish species management data depending on the availability of data and requirements of the users.

The first enhancement is to increase available data and information. Detailed land cover and land use data can be incorporated as the background information to improve the overall assessment of the fish species. For fish species management and reporting purposes, pollution sources are an important part that has not been discussed much in this thesis. Due to the spatial distribution of pollution sources, point sources, such as industrial and commercial sources can be incorporated into this reporting system. Besides fish species data, reporting of water quality, air quality and other environmental quality data can also be incorporated into this website.

The second enhancement is to change many manual steps into automatic functions. There are nearly 6000 development referrals per year in the region that are ongoing development work in and adjacent to fish habitat of lakes, rivers and streams. Many of the steps in maintaining and updating the website can be turned into standard procedures with proper programming, such as data capture and updating of data.

The third enhancement is to improve interactivity and functionality. Because of the thin client design, HTML Viewer as adopted in this thesis study has relatively fewer 
functionalities and interactivity. To improve these features, a parallel thicker client can be developed for more experienced and professional users. Java viewer can be adopted which requires Java 2 applet to process data at the client side. Users can render map and query data without going through the server, which means waiting for data transfer every time to refresh the map. Users can also combine local data with the streamed feature data from the server and then use desktop GIS tools to further analyze the data. With the same dataset, different users can choose to use different viewers (thin or thick) based on their needs, facility and experience.

The fourth enhancement is to improve help function at the website as required by user feedback. Tutorials/examples can be added to explain the use of tools. Relevant help based on the current context can be displayed for the users so that they do not need to go through the whole help documentation.

\subsection{Recommendations}

Although this study has addressed internal data query and reporting problems among government agencies, another goal is to provide an improved approach for the general public to access species at risk data and related information in an up-to-date and low-cost manner by utilizing WebGIS technology. This approach can serve an environmental education purpose to keep the public informed. Only when overall environmental education is improved, will the public be more actively involved in environmental issues to protect species at risk. People with better environmental consciousness will voluntarily conserve the environment in the long run. 
For individuals and organizations interested in providing WebGIS services, a review and investigation of open source tools is encouraged. These tools are mentioned in Chapter 2, Since no cost is associated with the use of open source software, it is an economical solution for organizations with experienced developers.

Improving the link of ArcIMS to external database is an outstanding issue facing Web GIS providers due to "lack of integration among the geodatabases and WebGIS to enable real-time data processing" (Kolodziej, 2002). Many times the users will need to search and report on the external database, which is not easy from the standard viewer. Solutions include doing proper programming, or choosing appropriate software products that support linking databases to ArcIMS. The Canadian Geospatial Data Infrastructure (CGDI) is an example of such products that "allows end-users to search and report on mapping and enterprise databases from a Web platform" (TDC Group, 2004. Taylor Technologies, 2004) Because HTML Viewer is a thin client design, it has fewer abilities of interactivity and analysis. For example, most functions of the WebGIS are 'pulling' data from database, therefore, the user cannot add content to the website. To improve those features, an ASP.NET application can be developed, so that geoscientists and environmental scientists can directly update a geodatabase for themselves, as opposed to having to mail the geospatial data to the Burlington central office.

There is a need to develop more Web-based tools to share environmental datasets and information. WebGIS has the potential to share data, provide easy access for users with 
limited GIS knowledge, and assemble data and information customized for specific topics, such as wetlands, that support informed decision-making. Therefore, these tools will be especially useful for decision-makers and administrators who often have limited expertise in GIS and complex spatial analyses. 


\section{References}

Alesheikh, A. A. and Helali H., 2001. Distributing National Geospatial Information. Proceedings of Digital Earth 2001, Fredericton, NB, Canada

Anderson G., and Moreno-Sanchez, 2003. Building Web-based spatial information solutions around open specifications and open source software. Transactions in GIS, Vol. 7, pp. 447.

Byong-Lyol L, Young-Chan K, and Jin-I Y, 1998. Web interface for GIS in agriculture. The Asian Federation for Information Technology in Agriculture

Canadian Wild Life Service, 2003. Conservation Atlas of Wetlands in the St. Lawrence Valley, Quebec, Canada. URL:

http://carto.qc.ec.gc.ca/website/WetlandsAtlas/viewer.htm

CAMFER, 2003. Center for the Assessment and Monitoring of Forest and Environmental Resources and the California Oak Mortality Task Force to monitor Sudden Oak Death in California, University of California, Berkeley, California, USA. URL: http://kellylab.berkeley.edu/OakMapper/viewer.htm

Cone, L., D. Moonie, S. Oppmann, N. von Meyer, B. Ader, and J. Steffenson, 1999. USDI BLM and USDA Forest Service - Working toward a national integrated land system. Federal GIS Connections Fall 1999 ESRI, Redlands, California, USA

COSEWIC. 2003. Canadian species at risk, May 2003. Committee on the Status of Endangered Wildlife in Canada. Ottawa, Ontario, Canada.

Crognale G., 1999. Environmental Management Strategies: the 21st century perspective. Chapter 11, Effective Risk Management and Communication: Tips on Working with the Public. New Jersey: Prentice Hall. 
DFO (Fisheries and Oceans Canada), 2005. About the Species at Risk Act. Ottawa, Ontario, Canada. URL:

http://www.dfo-mpo.gc.ca/species-especes/aboutAct/aboutAct_e.asp (18 Aug. 2005)

Environmental Systems Research Institute (ESRI), 2002a. Using ArcIMS (v4.0.1). Redlands, California, USA

Environmental Systems Research Institute (ESRI), 2002b. ArcXML Programmer's Reference Guide. Redlands, California, USA

Environmental Systems Research Institute (ESRI), 2002c. Customizing ArcIMS: HTML viewer. Redlands, California, USA

Environmental Systems Research Institute (ESRI) 2003. ArcIMS architecture and functionality. White paper. Redlands, California, USA

Environmental Systems Research Institute (ESRI), 2005a. ESRI support center URL: http://support.esri.com

Environmental Systems Research Institute (ESRI), 2005b. ArcIMS 9.0 Desktop Help. Redlands, California, USA

Environmental Systems Research Institute (ESRI) Virtual Campus, 2005c. Learning ArcIMS 9.0. Redlands, California, USA.

Environmental Systems Research Institute (ESRI) Virtual Campus, 2004d. Customizing ArcIMS 9.0. Redlands, California, USA 
Fisheries and Ocean Canada, 2005. Fish Habitat \& Fluctuating Water Levels on the Great Lakes (T2), URL: http://www.dfo-mpo.gc.ca/regions/central/pub/fact-fait/t2_e.htm (18 Aug. 2005)

Frye, E. and Denning, R. 1995. Michigan township uses watershed-based decision support system. GeoInfo Systems 5: pp. 55-57

Green, D. and Bossomaier, T., 2002. Online GIS and Spatial Metadata. Taylor \& Francis.

Hansen, P. E., 1991. Introduction to environmental management, Elsevier

Hegle A. K., 1998. What are computer users looking for in a system? Modern Maturity, Nov-Dec Issue, AARP

Hoffer, A., J. George, and J. Valacich, 2002. Modern system analysis and design. Prentice Hall, Upper Saddle River, New Jersey, USA

Jim Szpara, 2005. Air Quality Monitoring Locations Idaho DEQ (Department of Environmental Quality). State of Idaho, USA. URL: http://mapserver.deq.state.id.us/Website/emissions/viewer.htm (19 Aug. 2005)

Kolodziej, K., 2002. A Safety ".NET"-GIS Web Services Aid Homeland Security. GEO World. Aug 2002

Kroot, C. M. Smith, S. Rich, and J. Sardano. 2000. Building and Deploying an Enterprise Geographic Information System Using ArcInfo 8.0, Oracle, and Citrix. Proceedings of the ESRI International User Conference, Redlands, California, USA

Limp W.F., 1997. Weave Maps Across the Web. GIS World. Sep. p46-55

Longley P. A., 2001. Geographic Information Systems and Science. John Wiley \& Sons Macdonald, A. and ESRI, 2001. Building a geodatabase. ESRI, Redlands, CA, USA 
Maguire, D., 1999. GIS Industry Outlook 2002. GeoWorld, Dec. p. $42-43$

Maguire, D. J., 1991. An Overview and Definition of GIS. Geographical Information Systems. 1st edition. John Wiley \& Sons

Martin, J. 1991. Rapid Application Development. New York: Macmillan Publishing Company

MNR Ontario, 2005a. GRANK Definition, Ministry of Natural Resources, Ontario, Canada. URL: http://nhic.mnr.gov.on.ca/MNR/nhic/glossary/grank.cfm (18 Aug. 2005)

MNR Ontario, 2005b. Provincial Rank (SRANK) Definition, Ministry of Natural Resources, Ontario, Canada. URL: http://nhic.mnr.gov.on.ca/MNR/nhic/glossary/srank.cfm (18 Aug. 2005)

Open Source Initiative, 2004. The Open Source Definition. Potsdam, New York, USA. http://www.opensource.org

Peng, Zhong-Ren and Tsou, Ming-Hsiang, 2003. Internet GIS: Distributed Geographic Information Services for the Internet and Wireless Networks. John Wiley \& Sons. Hoboken, New Jersey, USA.

Pickus, J. and M. Hewitt. 1992. Resource at risk: Analyzing sensitivity of groundwater to pesticides. Geo Info Systems 2(10): pp. 50-55.

Plewe, B., 1997. GIS Online: Information, Mapping, and the Internet. Onward Press. Santa Fe, N.M. USA.

RENEW (REcovery of Nationally Endangered Wildlife). 2002. Recovery of nationally endangered wildlife in Canada. Annual report no. 12. Ottawa, Ontario, Canada 
Runyon, T., R. Hammitt, and R. Lindquist. 1994. Buried danger: Integrating GIS and GPS to identify radiologically contaminated sites. Geo Info Systems 4(8): pp. 28-36.

Strand EJ, 1998. What's the Right Way to Web Map Data. Synergetics Inc.Fort Collins, CO, USA. URL: http://www.geoplace.com/gw/1998/1298/1298nab.asp (18 Aug. 2005)

Taylor Technologies, 2004. Rapid Integration Toolkit Available for ArcIMS. URL: www.Geoplace.com/PressRelease (18 Aug. 2005)

TDC Group, 2004. GIS Software Links Databases to ESRI ArcIMS. From http://www.geoplace.com/PressRelease/ (18 Aug. 2005)

Working group on Libra Software, 2000. Open Source: Information Society Opportunities for Europe? URL: http://eu.conecta.it/paper/

COSEWIC. 2003. Canadian species at risk, May 2003. Committee on the Status of Endangered Wildlife in Canada. Ottawa, Ontario, Canada. 


\section{Appendix A}

\section{Gazetteer Search}

Table A.1 Gazetteer Category List Table

\begin{tabular}{|l|}
\hline \multicolumn{1}{|c|}{ CATEGORY } \\
\hline Bay \\
\hline Beach \\
\hline Cape \\
\hline Cave \\
\hline Channel \\
\hline City \\
\hline Cliff \\
\hline Conservation Area \\
\hline Conservation area \\
\hline Crater \\
\hline Falls \\
\hline Forest \\
\hline Geographical area \\
\hline Indian Reserve \\
\hline Island \\
\hline Lake \\
\hline Low vegetation \\
\hline Military area \\
\hline
\end{tabular}




\begin{tabular}{|l|}
\hline Miscellaneous \\
\hline Mountain \\
\hline Other municipal/district area - major agglomeratio \\
\hline Other municipal/district area - miscellaneous \\
\hline Plain \\
\hline Province \\
\hline Rapids \\
\hline River \\
\hline River feature \\
\hline Shoal \\
\hline Spring \\
\hline Town \\
\hline Unincorporated area \\
\hline Valley \\
\hline Village \\
\hline
\end{tabular}




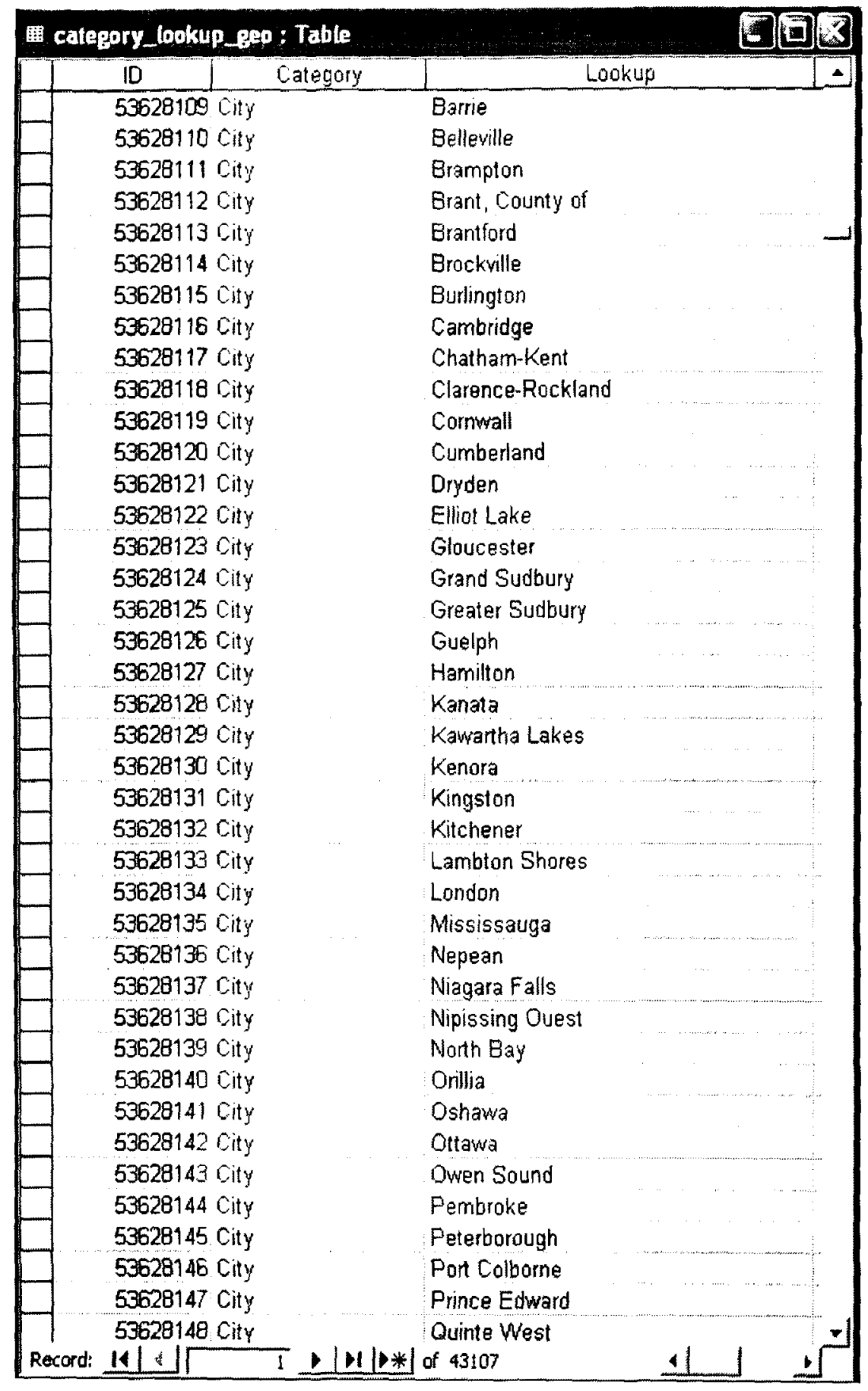

Figure A.1 Gazetteer Category Lookup: City 
面 category_lookup_topo: Table

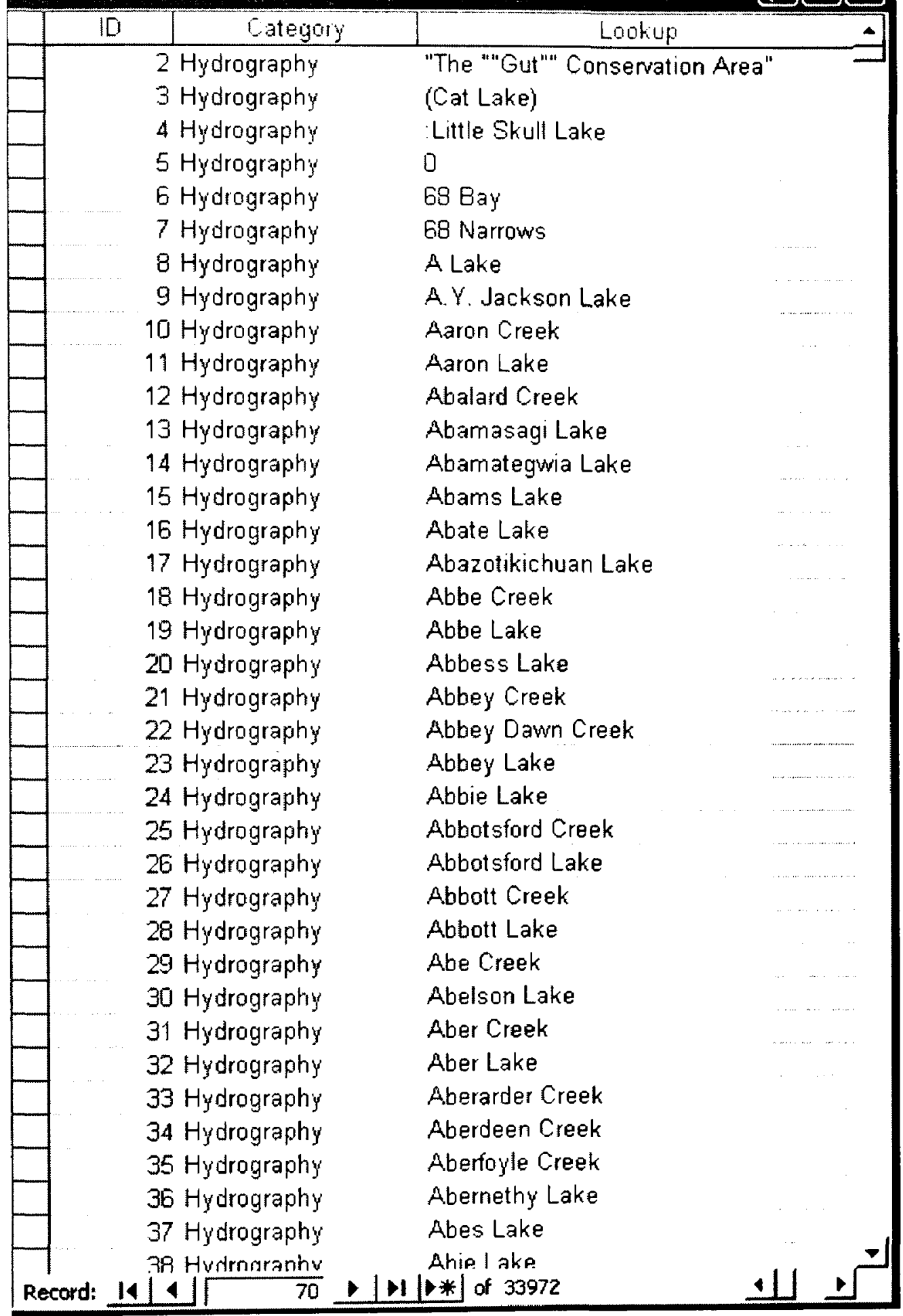

Figure A.2 Topographic Category Lookup: Hydrography 
Table A.2 The C\# Code for Gazetteer Page Load and Refresh Control of 'Name'

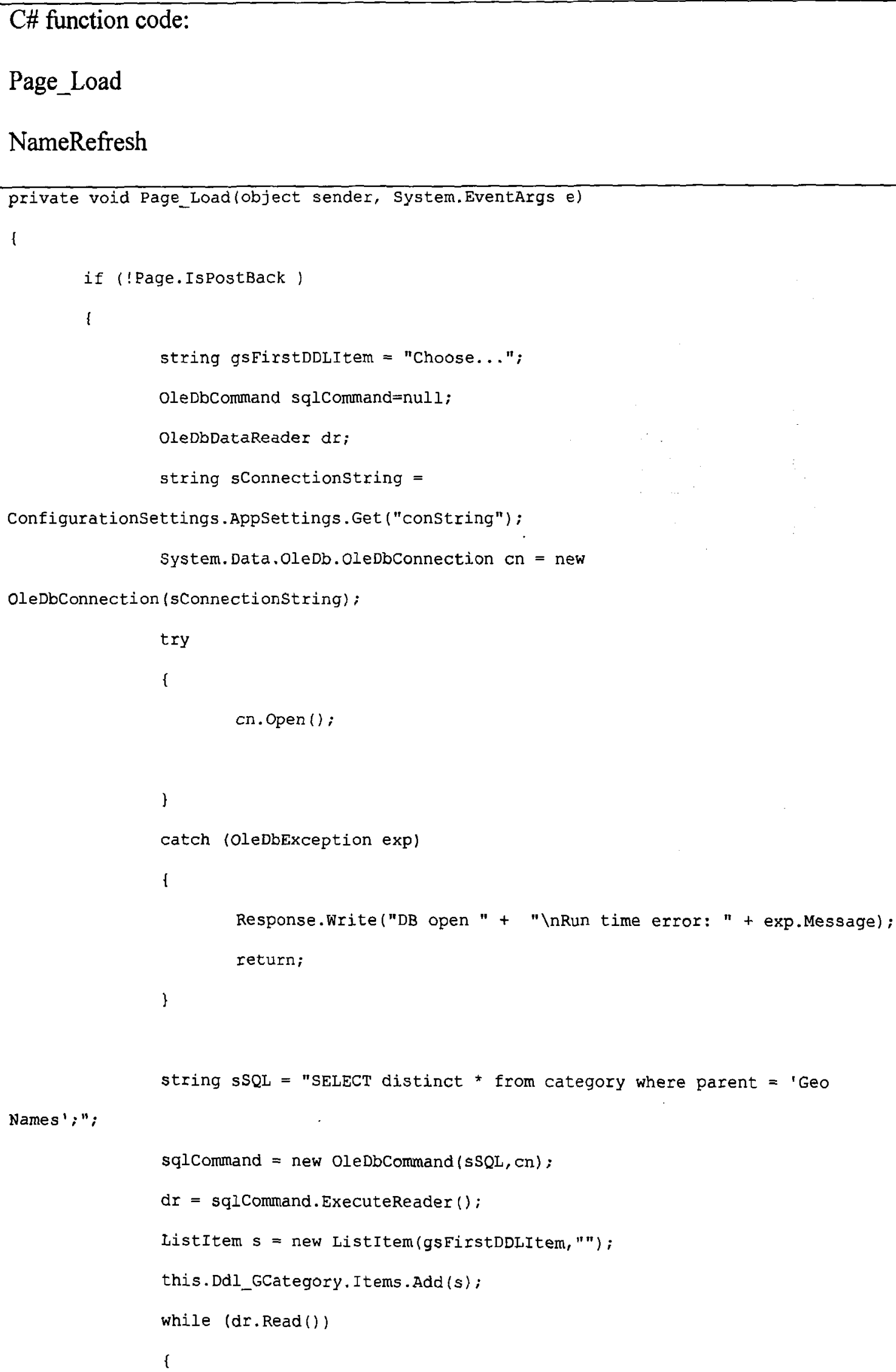




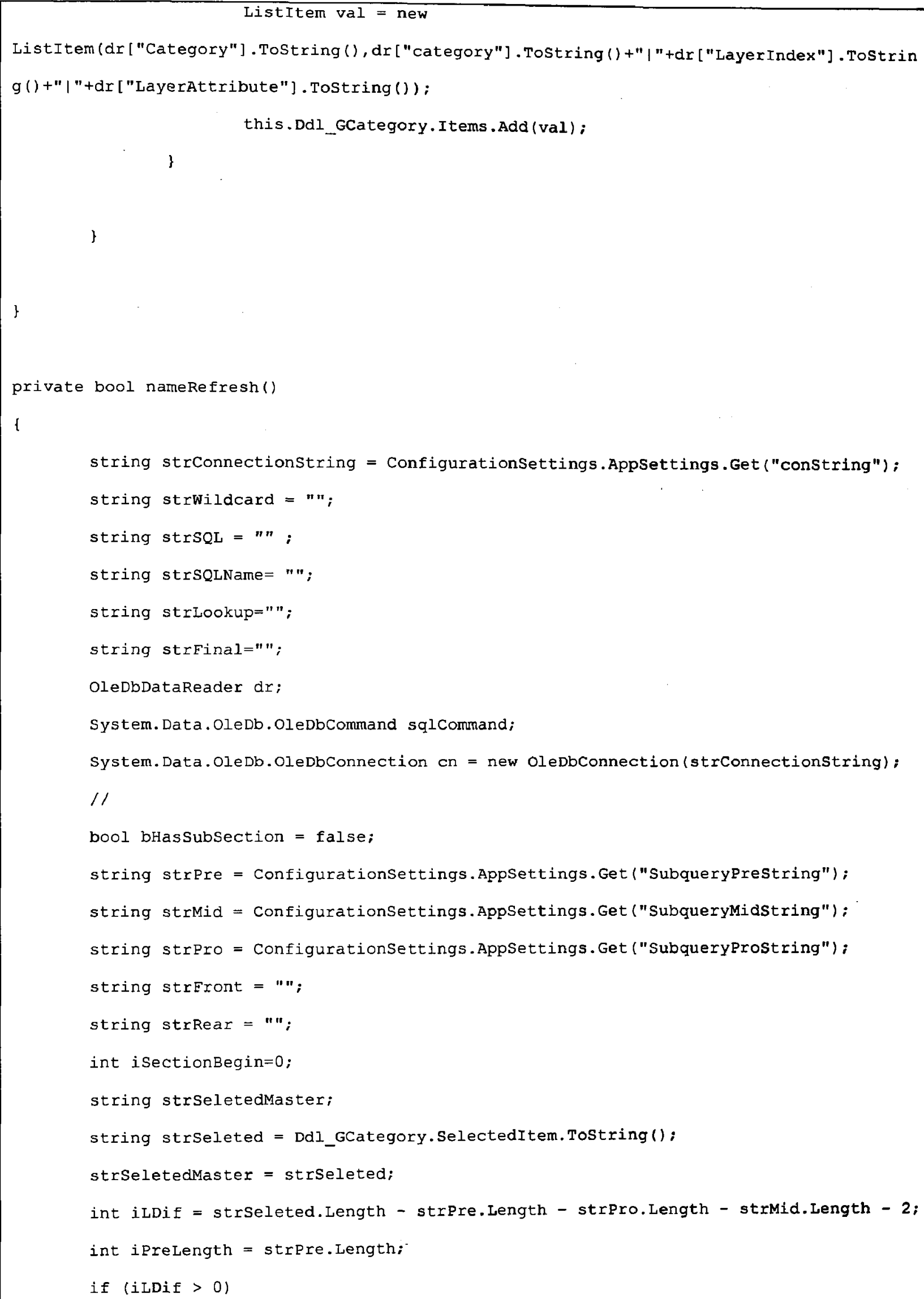




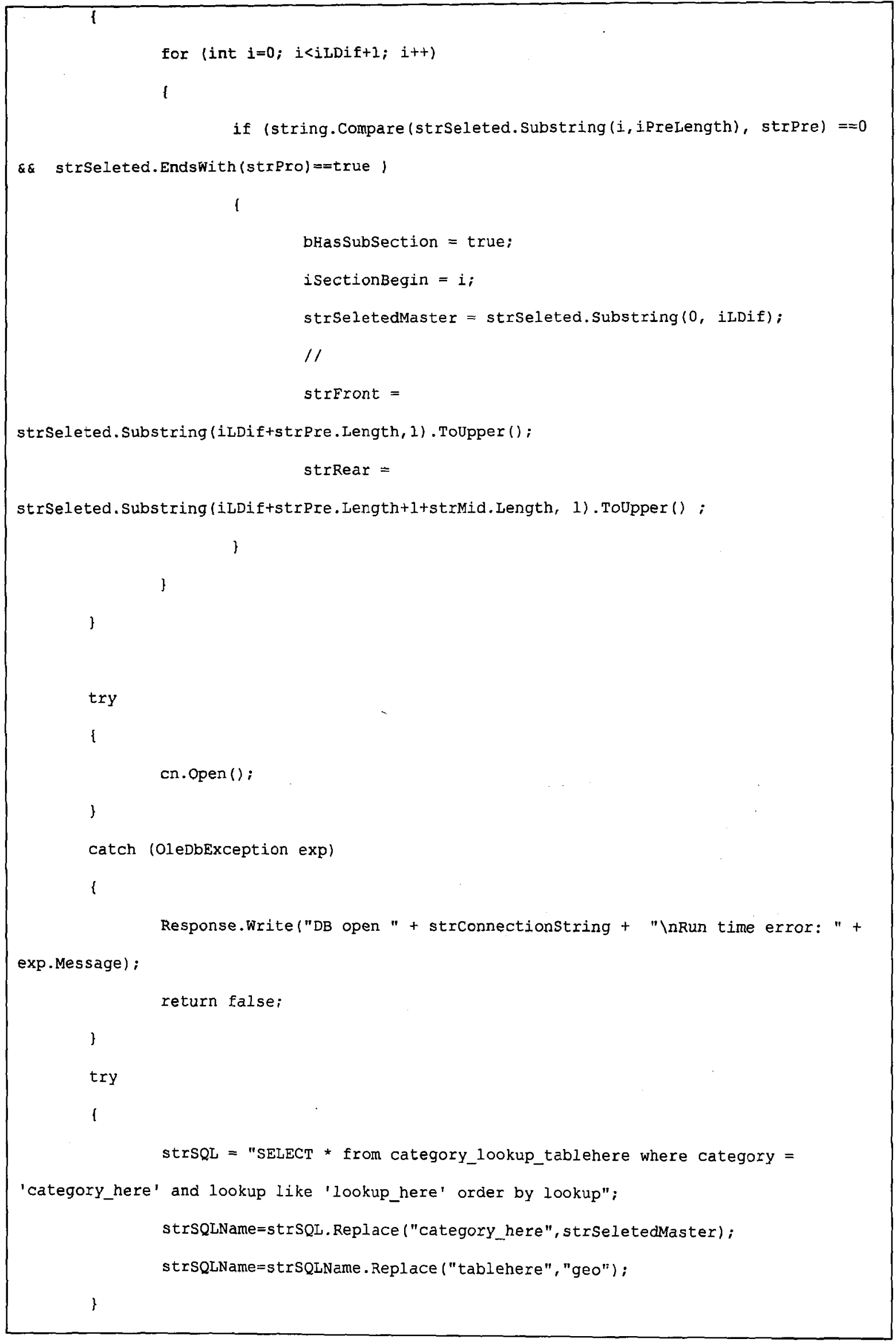




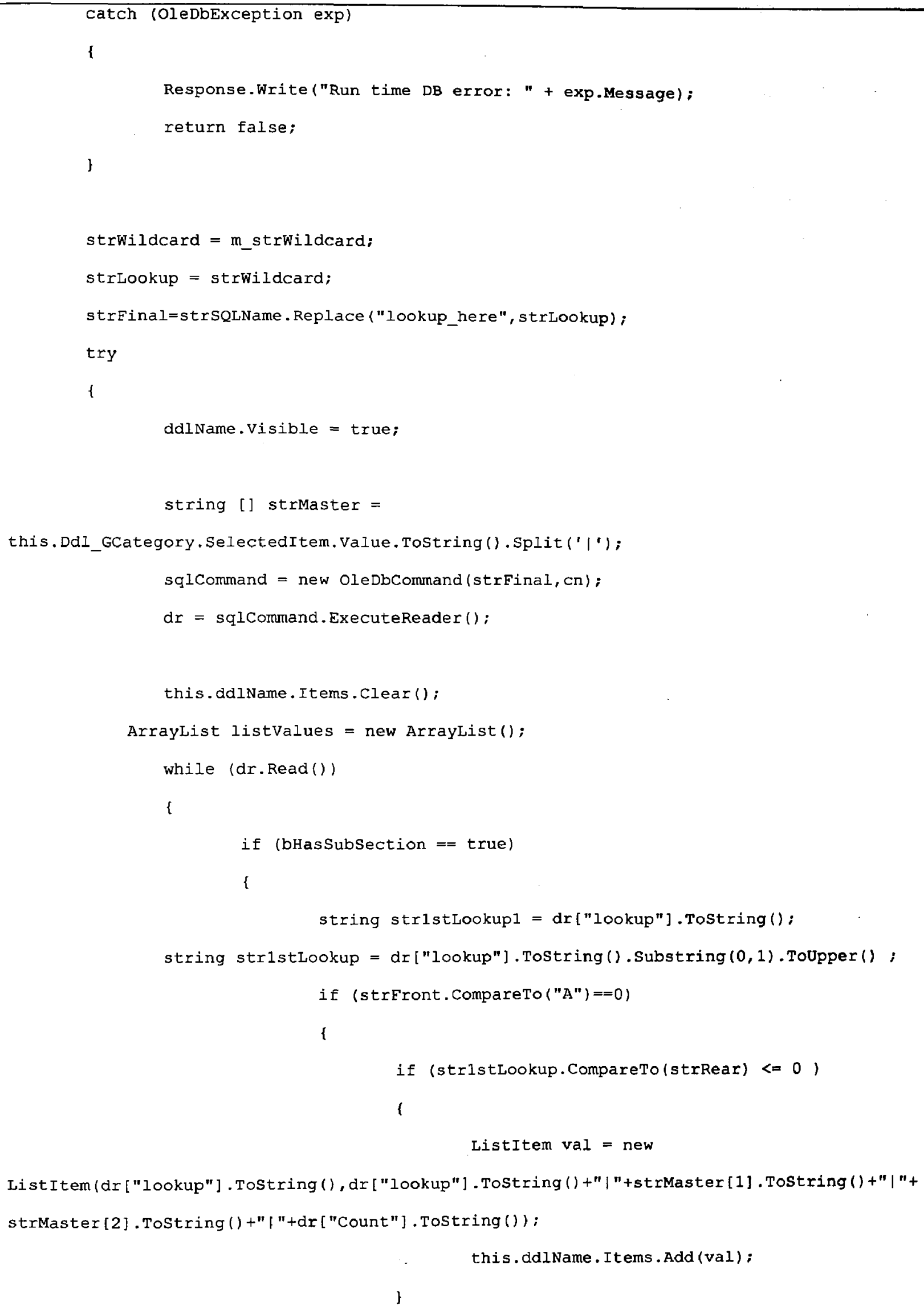




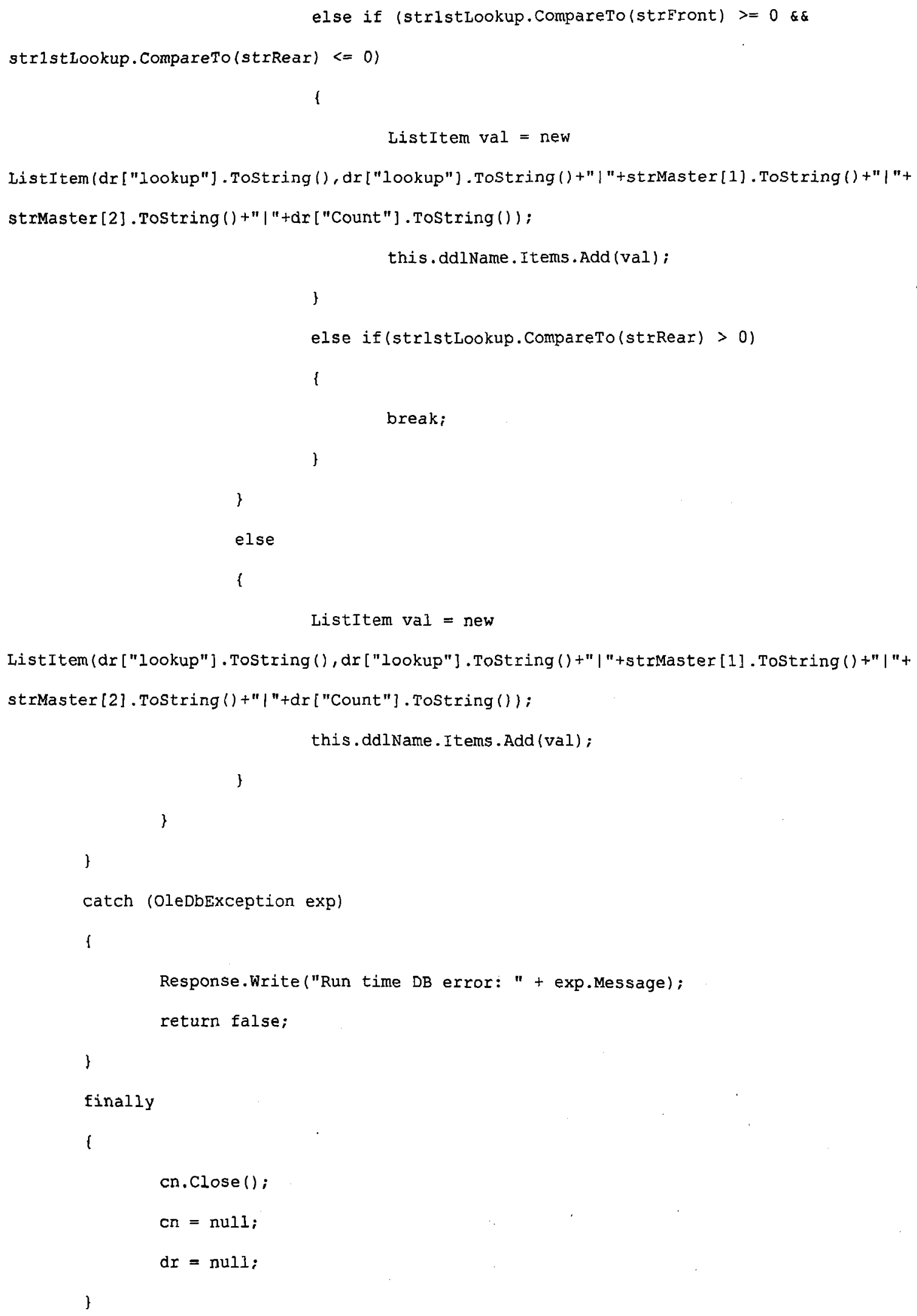




\begin{tabular}{|l|} 
cn.Close (); \\
cn $=$ null; \\
dr $=$ null; \\
return true; \\
r
\end{tabular}

Table A.3 The JavaScript Code for Button Zoom-To JavaScript function:

\section{ZoomTo}

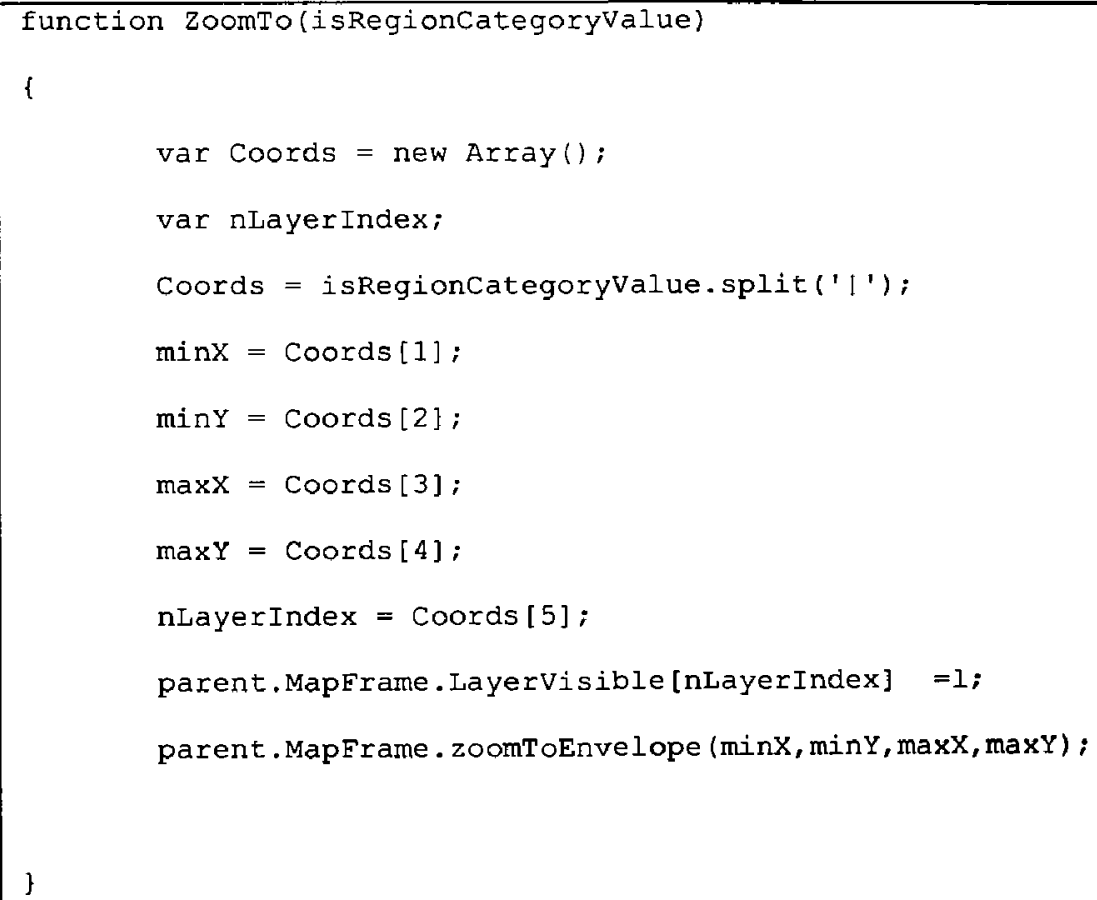




\section{Appendix B}

Topographic Search

Table B.1 Topographic Category List Table:

\begin{tabular}{|l|}
\hline \multicolumn{1}{|c|}{ CATEGORY } \\
\hline Hydrographic \\
\hline Place \\
\hline Relief \\
\hline Shoreline \\
\hline Transport \\
\hline
\end{tabular}




\section{Appendix C}

FSAR Data Structure

Table C.1 Species Lookup Table (DFO.SAR_lookup)

\begin{tabular}{|l|l|l|}
\hline \multicolumn{1}{|c|}{ Field Name } & \multicolumn{1}{|c|}{ Data Type } & \multicolumn{1}{c|}{ Description } \\
\hline COMMON_NAME & Char & Fish Species Name (KEY) \\
\hline FACTSHEET & Char & Path of PDF fact sheet on species \\
\hline COSEWICREPORT & Char & Path of PDF cosewic report on species \\
\hline NHIC_site & Char & Provincial SAR Website \\
\hline COSEWIC_site & Char & Federal SAR Website \\
\hline
\end{tabular}

Table C.2 Species Summary Table by Watershed (NRVIS.SAR_TERT_SUMMARY_BT)

\begin{tabular}{|l|l|l|}
\hline \multicolumn{1}{|c|}{ Field Name } & Data Type & \multicolumn{1}{c|}{ Description } \\
\hline MNRTWS & Char & Tertiary Watershed Code (Key) \\
\hline SCIENTIFIC_NAME & Char & Latin Fish Species Name \\
\hline COMMON_NAME & Char & Common Fish Species Name \\
\hline COUNT & Int & Number of fish observations per watershed \\
\hline GRANK & Char & Nature Serve Ranking \\
\hline SRANK & Char & NHIC Ranking \\
\hline COSEWIC & Char & Federal Ranking \\
\hline MNR & Char & Provincial Ranking \\
\hline TRACK & Char & Species Actively Tracked / Monitored \\
\hline FAMILY & Char & Species Family Name \\
\hline
\end{tabular}

(See Section 5.5.2 Global Rank (GRANK) for more information and attribute definitions.) 
Table C.3 Species Summary Table by Segment

(NRVIS.SAR STRM SUMMARY BT)

\begin{tabular}{|l|l|l|}
\hline \multicolumn{1}{|c|}{ Field Name } & Data Type & \multicolumn{1}{c|}{ Description } \\
\hline MNRSTR & Char & Stream Segment Code (Key) \\
\hline SCIENTIFIC_NAME & Char & Latin Fish Species Name \\
\hline COMMON_NAME & Char & Common Fish Species Name \\
\hline COUNT & Int & $\begin{array}{l}\text { Number of fish observations per stream } \\
\text { segment }\end{array}$ \\
\hline GRANK & Char & Nature Serve Ranking \\
\hline SRANK & Char & NHIC Ranking \\
\hline COSEWIC & Char & Federal Ranking \\
\hline MNR & Char & Provincial Ranking \\
\hline TRACK & Char & Species Actively Tracked / Monitored \\
\hline FAMILY & Char & Species Family Name \\
\hline
\end{tabular}

(See Section 5.5.2 Global Rank (GRANK) for more information and attribute definitions.)

Table C.4 Tertiary Watershed Layer (NRVIS.WATSHD_TERT_SUMMARY_BT)

\begin{tabular}{|l|l|l|}
\hline \multicolumn{1}{|c|}{ Field Name } & \multicolumn{1}{c|}{ Data Type } & \multicolumn{1}{c|}{ Description } \\
\hline AREA & Double & Area (Decimal Degrees) \\
\hline PERIMETER & Double & Perimeter (Decimal Degrees) \\
\hline ONT_TWS_ & Char & Coverage Internal ID \\
\hline ONT_TWS_ID & Char & Coverage User ID \\
\hline TERTIARY & Char & Tertiary Watershed Code (Key) \\
\hline SECONDARY & Char & Secondary Watershed Code \\
\hline PRIMARY & Char & Primary Watershed Code \\
\hline SOURCE & Int & MNR/NRCAN/BOTH \\
\hline MERGE & Int & Not Sure (value of 1) \\
\hline CALC_AREA & Double & Area based on Lambert Conic Projection $(\mathrm{km})$ \\
\hline
\end{tabular}

